

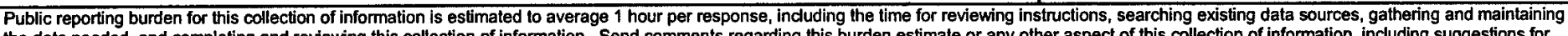

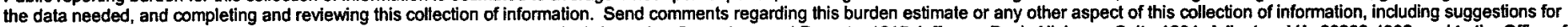

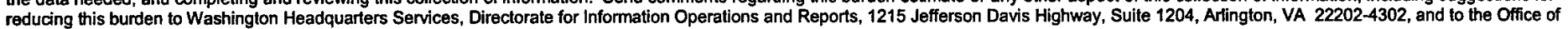
Management and Budget, Paperwork Reduction Project (0704-0188), Washington, DC 20503

\section{TITLE AND SUBTITLE}

Signal Transduction in Prostate Cancer

5. FUNDING NUMBERS

DAMD17-00-1-0077

\section{AUTHOR(S)}

Charles L. Sawyers, M.D.

7. PERFORMING ORGANIZATION NAME(S) AND ADDRESS(ES)

The University of California, Los Angeles

Los Angeles, CA 90095-1406
8. PERFORMING ORGANIZATION REPORT NUMBER

E-Mail: Sawyerslemednet.ucla.edu

\section{SPONSORING / MONITORING} AGENCY NAME(S) AND ADDRESS(ES)

10. SPONSORING / MONITORING AGENCY REPORT NUMBER

I U.S. Army Medical Research and Materiel Command

Fort Detrick, Maryland 21702-5012

\section{SUPPLEMENTARY NOTES}

Original contains color plates; All DTIC reproductions will be in black and white.

\section{2a. DISTRIBUTION / AVAILABILITY STATEMENT}

12b. DISTRIBUTION CODE

Approved for Public Release; Distribution Unlimited

\section{ABSTRACT (Maximum 200 Words)}

The goal of this Prostate Cancer Center Initiation Award was to examine signal

transduction pathways involved in prostate cancer progression, with an eye toward

translational research applications. The program had two Projects and a Core Animal

Facility. The first project (Dr. Carey) focused on crosstalk between receptor tyrosine kinases and the androgen receptor (AR), using the Her2/neu kinase as a model system. During the funding period we completed preclinical studies with an EGFR/Her2-neu kinase inhibitor with new, unexpected insights about the clinical application of these drugs. We have also defined some of the molecular details of AR/Her2 crosstalk. Finally we developed imaging technologies to follow disease progression in mouse models. The second project (Dr. Cohen) examined the role of IGF binding protein 3 (IGFBP-3) in the context of crosstalk with the retinoic acid co-receptor $\mathrm{RXR} \alpha$. We confirmed that IGFBP-3 induces apoptosis in synergistic fashion with RXRa ligands in multiple prostate models, using the Core facility. Both projects led to the conception of clinical translational projects hat are components of the recently funded UCLA Prostate SPORE grant.

\section{SUBJECT TERMS}

Tyrosine kinase; androgen receptor; insulin-like growth factor; IGFBP-3;

\begin{tabular}{|c|c|c|}
\hline $\begin{array}{c}\text { 17. SECURITY CLASSIFICATION } \\
\text { OF REPORT } \\
\text { Unclassified }\end{array}$ & $\begin{array}{c}\text { 18. SECURITY CLASSIFICATION } \\
\text { OF THIS PAGE } \\
\text { Unclassified }\end{array}$ & $\begin{array}{c}\text { 19. SECURITY CLASSIFICATION } \\
\text { OF ABSTRACT } \\
\text { Unclassified }\end{array}$ \\
\hline
\end{tabular}

NSN 7540-01-280-5500 


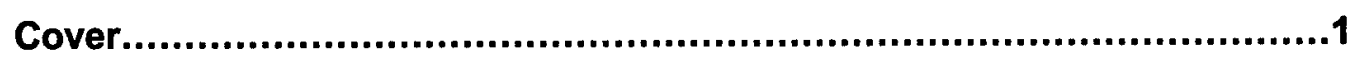

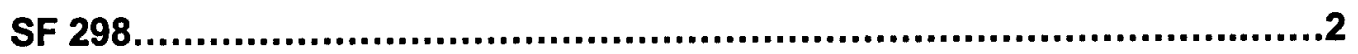

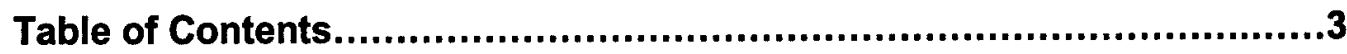

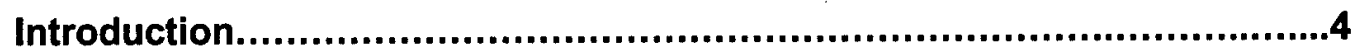

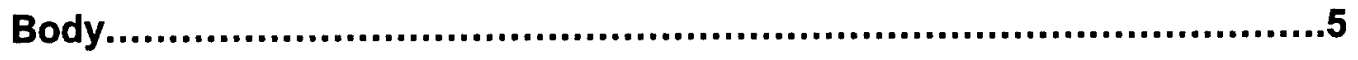

Key Research Accomplishments..................................................13

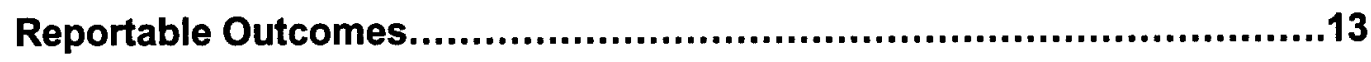

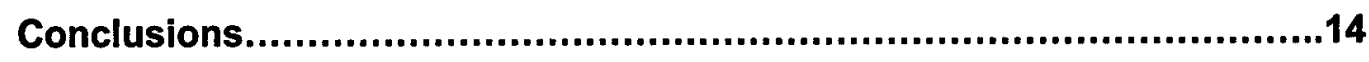

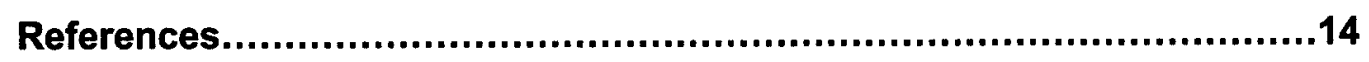

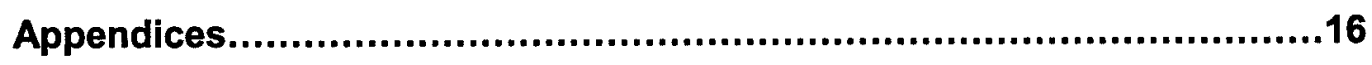


Sawyers, Charles

\section{Introduction}

Although nearly all advanced prostate cancers will respond to hormone ablation therapy using anti-androgen drugs such as leuprolide, flutamide or casodex, these tumors inevitably progress to an androgen-independent (also called hormone refractory) stage. Taxane-based chemotherapy has recently been shown to give high response rates in these patients (Petrylak et al., 1999; Smith et al., 1999), but the duration of these responses is generally short. It is clear that more insight into the molecular basis of androgen independence is needed to have a therapeutic impact. Our group has been studying this problem through the use of human prostate cancer cell lines and xenografts that undergo this transition.

The phase I portion of this proposal was entitled "Identification of genes involved in androgen independent prostate cancer progression through expression cloning." During this initial period of funding we identified two genes - the Her $2 /$ neu tyrosine kinase receptor and the cathepsin $\mathrm{D}$ protease - which confer androgen independent growth when introduced into androgen dependent prostate cancer cell lines (defined as the ability to grow as a subcutaneous tumor in castrate male SCID mice). These findings formed the basis of our competitive renewal (Phase II), entitled "Transgenic Models of Prostate Cancer," with the goal of generating transgenic mouse models based on genes identified through studies of our xenograft models. The original specific aims, based on the genes we had identified at the time of the competing renewal submission, were:

\section{Aim 1 - Creation of Transgenic Mice with Constitutive Activation of the EGFR Pathway in the Prostate}

We previously reported that the EGFR/Her-2 signaling pathway was upregulated in our LAPC-4 xenograft model. We have showed that overexpression of ErbB2/Her-2 is sufficient to convert prostate cells to androgen independence through ligand-independent activation of androgen receptor (AR) signaling (Craft et al., 1999). The goal of this Aim was to create transgenic mice expressing either Her-2/neu in the prostate to test the hypothesis that dysregulation of the EGFR signaling pathway is sufficient to cause prostate cancer.

\section{Aim 2 - Further Characterization of Prostate Cancers in Cathepsin D Transgenic Mice}

We isolated the cathepsin D lysosomal protease gene in a functional expression cloning screen for genes that can confer androgen-independent growth in prostate cancer cells. We have confirmed that overexpression of cathepsin D facilitates progression to androgen independence in our xenograft models and created cathepsin D transgenic mice that develop prostatic hyperplasia and prostate cancer at 1 year. The goal of this Aim was to further characterize this phenotype. 

Aim 3 - Development of the TVA Retrovirus System to Introduce Multiple Transgenes
into the Mouse Prostate

As the number of candidate genes implicated in prostate cancer grows, it will be necessary to create mouse models in which multiple individual mutations can be combined in the same cell. This goal has been successfully achieved in glioblastoma mouse models through the use of the TVA system (Fisher et al., 1999; Holland et al., 1998; Holland and Varmus, 1998). This model uses transgenic expression of the avian retrovirus receptor TVA in the brain to target infection of high titer, replication competent avian retroviruses expressing different oncogenes. The goal of this Aim was to create mice expressing the TVA receptor specifically in the prostate epithelium and optimize the infection of the prostate cells by avian retroviruses. This reagent will allow the introduction of oncogenes singly and in combination to create novel prostate cancer models and avoid the problem of altered transgene expression when androgen levels are manipulated.

Additional Aims developed during the past year - $\underline{\text { Creation of transgenic mice }}$ expressing Akt and c-Myc in the mouse prostate

During the past two years, we have expanded this list of genes to include Akt and c-myc, based on work from our group and others implicating both of these genes in prostate cancer progression. The results from these two additional transgenic strains are included in the final report.

\section{Body}

\section{Generation of mice expressing Her-2/Neu}

Through our studies of human prostate cancer xenografts, we found that expression of the Her-2/neu repector tyrosine kinase was unregulated in some androgen-independent sublines when compared to isogenic controls. We also showed that overexpression of Her-2/neu was sufficient to convert androgen-dependent prostate human prostate cancer cells to androgen independence in vitro and in vivo. Finally, this gain-of-function was associated with the ability of Her-2/neu to enhance the response of the androgen receptor to limiting doses of ligand (Craft et al., 1999).

More recently, we have published our results from performing the reciprocal experiment - inhibition of the EGFR/Her-2 family of receptor tyrosine kinases in prostate cancer cells using a small molecule EGFR/Her-2 kinase inhibitor (Mellinghoff et al., 2002). The results showed that androgen-independent sublines of the LAPC4 and LAPC9 prostate cancer xenografts were more sensitive to EGFR/Her2 inhibition that isogenic androgendependent sublines. When castrate mice bearing androgen-independent tumors were treated with supplemental androgen, we found that the growth inhibitory effects of EGFR/Her2 inhibition were lost. These and other data from our group support a model in which prostate cells use the EGFR/Her2 pathway to send an accessory signal to the androgen receptor pathway to maximize the response to ligand. We believe the 
requirement for EGFR/Her2 pathway signaling is most evident in the setting of low concentrations of androgen (as seen in the castrate state), thereby explaining the antitumor activity of EGFR/Her-2 inhibitors against our xenograft models in castrate animals and the "rescue" of this anti-tumor activity by androgen supplementation.

These data, together with other studies showing increased expression of Her-2/neu protein in advanced state androgen-independent cancers, provide the rationale for creating Her-2/neu transgenic mice. Because of the large size of the Her-2/neu cDNA, the initial cloning and characterization of the transgenic construct took longer than expected. However, we have now been successful in demonstrating androgen-dependent transgene expression of a construct under the control of the modified probasin promoter (ARR2/probasin) provided by Dr. Matusik at Vanderbilt. In addition, we have now generated 2 transgene positive founder mice which have been bred to give F1 males. We have performed histological analysis of two 3 month old male mice from one founder and fail to see any obvious phenotype. We are currently performing immunohistochemical and immunoblot studies to verify expression of the transgene. Assuming that we document Her2 expression, cohorts of mice will be aged and crosses to other relevant strains (Akt, c-myc, see below).

\section{Generation of mice expressing cathepsin D}

We engineered a transgenic expression construct using the basal probasin promoter ($426 /+28$ ) (previously used to generate SV40T expressing TRAMP mice) to express full length, wild-type cathepsin D in the mouse prostate. We generated 4 founder lines, demonstrated low level transgene expression by western blot in prostate lobes, and peformed histological analysis of the prostates from male mice from three different founder lines. One mouse from one founder developed a localized prostate cancer after one year of age. Although no cancers were observed in any wild-type controls, we have failed (to date) to detect any additional cancers in other transgenic lines expressing cathepsin $\mathrm{D}$. Therefore, we cannot confidently ascribe the cancer phenotype in that one mouse to cathepsin $\mathrm{D}$ until we have completed further analysis of more mice. The histologic features we did observe in 14 male transgene-expressing animals ranging in age from 6-18 months are detailed in table 1 in the appendix, and summarized below.

Prostate findings: The changes in the prostate are mainly seen in the anterior and dorsal lobes, which manifest primarily as an increase in glandular crowding with loss of secretions. These areas of glandular crowding likely represent foci of hyperplasia; however, there is no overt nuclear stratification, loss of nuclear polarity, pleomorphism, increased mitotic activity or invasive growth patterns to suggest prostatic adenocarcinoma. With the exception of the one mouse mentioned above who developed cancer (note: this mouse is not listed in the table), these changes are consistent with the notion that cathepsin D overexpression alone is insufficient to convert prostate cells to a neoplastic process. A major caveat is the fact that transgene expression was low.

Liver findings: An unexpected result in the histological analysis of the mice was the presence of steatohepatitis (defined as fatty change in the liver with inflammation) and 
hepatic adenomas in a significant number of the transgenic mice. In addition, these mice often had moderate splenomegaly which we attribute to pulmonary hypertension secondary the liver lesions. Three mice had clear evidence of well differentiated hepatocellular carcinomas (HCC), often appearing in a background steatohepatitis. In consultation with hepatology colleages at UCLA (Dr. Hal Yee and others), our current interpretation of these data cathepsin D is initiating an inflammatory reaction which leads to steatohepatitis. The damaged liver undergoes a process of regenerative nodular hyperplasia, which can lead to the formation of adenomatous nodules. A subset of these have the potential to become neoplastic, which we detect histologically as well differentiated hepatocellular carcinomas. A number of additional studies must be performed to explore this hypothesis further. These include: demonstration of transgene expression in the liver (which would certainly be unexpected, but it is quite possible that probasin may be expressed in a small subset of cells), molecular characterization of the adenomas and hepatocellular carcinomas, and serial analysis of multiple timepoints. Because these studies represent a diversion from the goals of our project, we plan to transfer the mice to Dr. Yee and his hepatology colleagues for further analysis.

Transgenic mice expressing constitutively active Akt develop prostatic intraepithelial neoplasia (PIN) but not prostate cancer

Work from a number of laboratories, including ours, has identified loss of function mutations or transcriptional silencing of the PTEN tumor suppressor gene as a potential mechanism for prostate cancer initiation and progression (Cairns et al., 1997; Vlietstra et al., 1998; Whang et al., 1998). Homozygous deletion of PTEN causes embryonic lethality, but PTEN $+/$ - mice develop a range of cancers, including prostate cancer. The penetrance of prostate cancer varies across genetic backgrounds and is generally low, presumably due to more rapid development of other tumors such as lymphomas and leukemias. When PTEN +/- mice are crossed to $\mathrm{p} 27-/-$ mice, the incidence of prostate lesions is increased but tumors continue to develop in multiple tissues. Additional experiments are underway to define the consequences of prostate-specific deletion of PTEN by crossing mice with germline conditional PTEN knockout alleles with probasinCre transgenic mice (Hong Wu, UCLA, personal communication). The collective evidence from these models supports the notion that PTEN functions as a tumor suppressor gene in the prostate.

PTEN is a lipid phosphatase whose primary substrate is the phosphatidyl inositol lipid PIP3. Cells lacking PTEN have increased levels of PIP3, which functions as a second messenger to activate downstream signaling pathways by recruitment of pleckstrin homology domain ( $\mathrm{PH}$ domain) containing proteins to the inner surface of the cell membrane. The best studied of these is Akt, a serine/threonine kinase activated by PIP3 which has oncogenic potential through regulation of a number of pathways involved in cell growth and survival (reviewed in Vivanco and Sawyers). We have generated transgenic mice expressing an active allele of Akt (Myr-Akt, which is constitutively targeted to the membrane through a myristolation sequence at the $\mathrm{N}$-terminus). Our goals were: (i) to generate a transgenic mouse model caused by dyregulation of this pathway that only gives prostate cancer (in contrast to the existing PTEN knockout models) and 
(ii) to determine if constitutive Akt activation is sufficient to give a prostate cancer phenotype resembling that seen with PTEN loss (or do other PIP3-regulated pathways play a role).

As with the cathepsin $\mathrm{D}$ mice, the transgene was cloned into the minimal probasin promoter construct, expression was validated in cell lines, then multiple founder lines were generated and screened. In addition, we generated mice expressing myr-Akt under the control of the C3(1) promoter, which is expressed in prostate and the female breast, and has been used by Jeff Green and colleagues to develop an SV40 T Ag model of breast and prostate cancer (Maroulakou et al., 1994; Shibata et al., 1996). With both promoters we documented transgene expression in the prostate lobes by immunohistochemistry (figure 1), then examined an aged cohort of mice for pathologic findings.
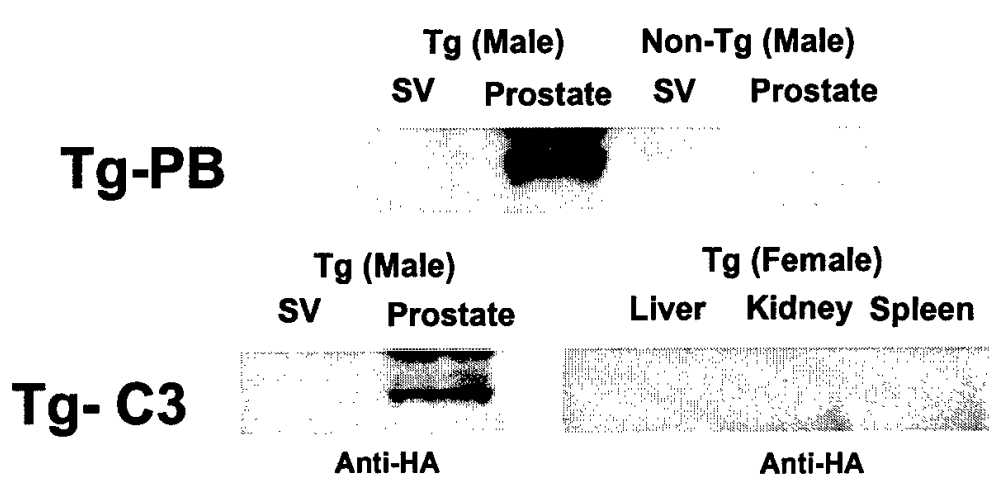

Figure 1. Expression of myr-Akt in prostate lobes of male transgenic mice. Individual lobes of the prostate (ventral, dorsal, lateral) were isolated and pooled to make protein lysates in the lanes marked "prostate." $\mathrm{SV}=$ seminal vesicle. The lysates in the right lanes were from wildtype controls (top panel) or transgene-positive female mice (bottom panel). Western blots were performed using an antibody to the HA epitope, which was engineered into the myr-Akt cDNA.

Prostate phenotype: Male mice from different founders of the probasin/myr-Akt mice and the C3(1)/myr-Akt mice developed preneoplastic lesions consistent with prostatic intraepithelial neoplasia (PIN). Cells in these lesions showed the following features epithelial hyperplasia, cellular stratification, pleomorphism, nuclear and nucleolar hyperchromatism and enlargement (figure 2). Of note, these slides were reviewed as part of a prostate mouse models workshop held in October, 2001 at Jackson Labs, in conjunction with the Mouse Models of Human Cancer Consortium (MMHCC) from the NCI, and were used to help reach a consensus definition of mouse PIN. None of the animals developed prostate cancer with 12-18 months (later timepoints have not been analyzed).

Endometrial phenotype: Remarkably, we noted endometrial abnormalities in 8 of 16 female mice expressing the C3(1)/myr-Akt transgene, and these lesions were detected in mice ranging from age 3-14 months. The histological features (which were read in conjunction with human gynecological pathologists at UCLA) were characteristic of the human lesion called simple hyperplasia with and without atypia, which is characterized by architectural disarray (data not shown). These findings are of interest because the most penetrant phenotype in female PTEN +/- mice is complex atypical hyperplasia of the endometrium, which is a more advanced but related abnormality. Further 
characterization of this phenotype requires measurement of transgene expression in the uterus.

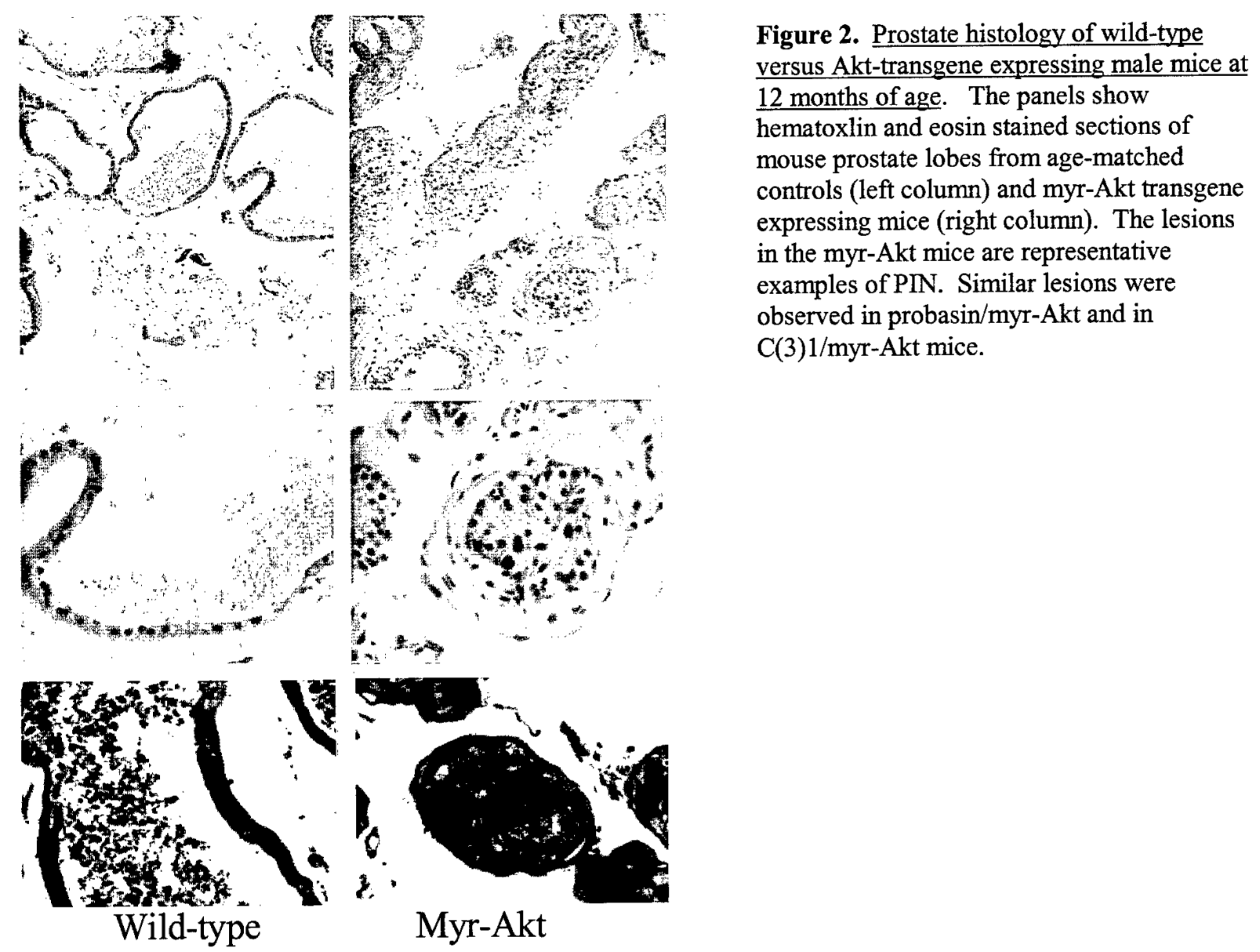

In summary, our major findings from the Akt transgenic mouse studies are the development of preneoplastic changes in the prostates and uteri of transgenic mice, but no overt cancers. These data, taken together with reports of Akt transgene expression in other tissues, suggest that constitutively active Akt may be involved in the early initiation stage of both these cancers but is unlikely to be sufficient to invoke invasive malignant transformation. Since conditional loss of PTEN in the mouse prostate does give prostate cancer, we believe their must be a complementary pathway that is required for full transformation my Akt. In future work we will use these mice as a tool to help identify this pathway through a variety of approaches (such as transcriptional profiling of PTEN KO versus Akt transgenic mice).

\section{Generation of mice expressing c-Myc}

During our cell-based studies of transformation due to PTEN loss, we noted that PTEN null cells had increased expression and activity of the c-Myc transcription factor. In addition, c-Myc is expressed in a significant fraction of human prostate cancers and is 
localized to a region of chromosome 8 (8q24) that is often amplified in human prostate cancer (and even human PIN). To further investigate the potential role of c-Myc in prostate cancer, we constructed transgenic mice expressing wild-type c-Myc under the control of the simple probasin promoter $(-426 /+28)$ as well as the higher expressing ARR2/probasin promoter provided by Dr. Matusik from Vanderbilt. These mice develop PIN then cancer with extremely reproducible kinetics and are likely to be an extremely useful model of prostate cancer. Our findings are described in detail in the appended manuscript which has been submitted for publication.

Briefly, founders were obtained using both constructs and transgene expression was documented by western blot. The phenotype of transgenic Myc expression in these mice is quite striking. We first noted that all of the mice from all the founders of the ARR2/probasin Myc lines had PIN as early as 2 weeks of age. The penetrance of PIN is essentially 100 percent and appears to involve the entire prostate gland, raising the possibility that Myc upregulation is sufficient as a single hit to induce PIN. At six months of age all animals have invasive cancers. In parallel with our analysis of the ARR2/probasin Myc mice, we have analyzed mice expression Myc from the probasin ($426 /+28)$ promoter. Similar to the ARR2/probasin promoter Myc mice, the $(-426 /+28)$ promoter mice all develop PIN that progresses to invasive cancer, but with slower kinetics. Specifically, these mice all display evidence of PIN at 6 months and have invasive cancers at 12 months. Of note, the tumor cells do not express the neuroendocrine marker synaptophysin, thereby distinguishing this model from the SV40 $\mathrm{T}$ Ag models such as TRAMP and LADY.

We also conducted expression profiling experiments using Affymetrix gene chips and identified a signature of Myc expression in the mouse prostate. This gene list was of interest because it contained a number of genes implicated in human prostate cancer, such as NKX3.1 and Pim1. Future experiments will explore the functional role of these candidate genes. The mouse gene list was also used to query human prostate cancer datasets and allowed us to find a smaller cohort of genes whose expression appeared to be highly correlated. This comparison of mouse and human datasets helps validate the relevance of our mouse model to human cancer and may allow us to prioritize certain genes on the mouse list for functional studies.

\section{Generation of mice expressing the avian retrovirus receptor TVA}

Recognizing the increasingly complex interplay of multiple genetic events in prostate cancer, a major goal of the competitive renewal application is to generate a model whereby multiple genes could be introduced simultaneously into the prostate gland by retroviral infection. This would avoid the time consuming process of producing individual transgenic lines for each gene of interest, then crossing multiple strains of mice. In addition, the gene of interest would be expressed under the control of the retroviral LTR promoter rather than the androgen-regulated probasin promoter, thereby allowing the effects of castration on prostate cancer growth to be distinguished from effects on transgene expression. 
Toward this end, we generated transgenic mice expressing the avian retrovirus receptor TVA under the control of the $-426 /+26$ probasin promoter as well as the ARR2/probasin promoter. The constructs were validated by transfecting human prostate cancer cells (LNCaP) with the ARR2/probasin TVAR plasmid, then infecting the cells with a luciferase-expressing avian retrovirus. Next we asked if we could infect the prostate glands of transgenic TVAR mice. Our first experiments were conducted in mice generated using the $-426 /+28$ probasin TVAR construct, but similar experiments are in progress with the mice expressing the ARR2/probasin TVAR construct. Using avian RCAS virus expressing green fluorescent protein (GFP), we have definitive evidence of GFP expression in the prostate lobes that were injected with virus using an orthotopic injection strategy (figure 3 ).
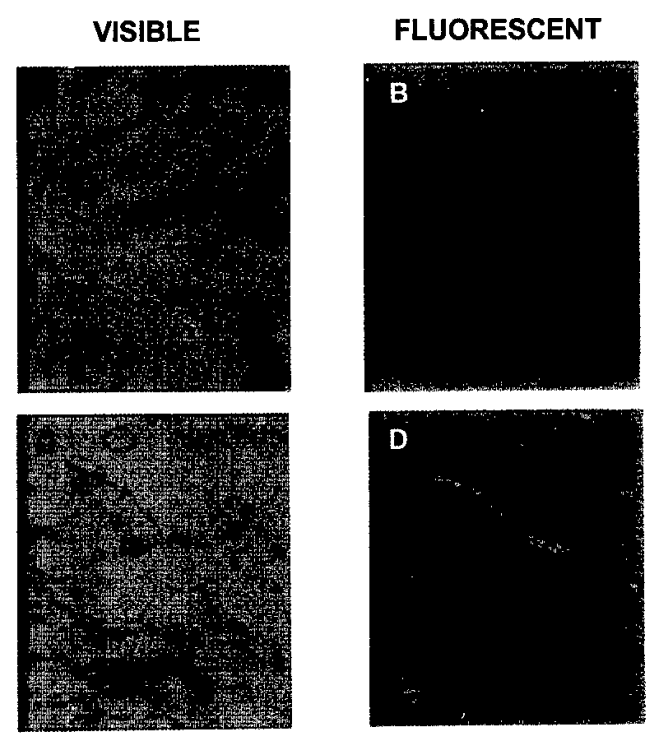

Figure 3. Injection of green fluorescent protein (GFP) expressing avian retrovirus in TVA transgenic mice. Aged matched mice were injected orthotopically with 10uL of RCAS GFP virus producing Df1 GFP cell line. Three weeks post injection, whole mounts were made of the prostates and visualized using a fluorescent microscope. Only cells containing TVA Receptor (TVAR) will be susceptible to infection and as a result glow green under fluorescent microscopy. (A and B) Dorsal-Lateral prostate from wild-type FVB mouse. No infected cells were present as can be seen in field B. (C and D) Dorsal-Lateral prostate from PB-TVAR FVB mouse. Infected cells were present as can be seen by the green cells in field D.

While this result validates the feasibility of the approach, there is much to be done to optimize gene delivery and precisely define the cell types that are infected. These studies will be accomplished using $\beta$-galactosidase expressing RCAS virus so that prostate lobes can be sectioned and stained. In addition, we are evaluating the effects of castration followed by androgen supplementation prior to virus injection in order to increase the fraction of cells in $\mathrm{S}$ phase (which should increase infection frequency). We are also expanding our colony of mice expressing TVAR from the ARR2/probasin promoter, and will compare the relative infection efficiency across the two strains. Finally, we conducting experiments using the renal capsule tissue recombination assay developed by Cunha, with the modification of using prostates from TVA mice. Briefly, prostates from TVA transgenic mice are harvested, infected with marker genes (or avian Myc virus), 
then implanted under the kidney capsule with urogenital mesenchyme to allow prostate regeneration. We expect this approach will give us higher infection frequency and faster readouts.

\section{Generation of luciferase expressing mice}

After constructing transgenic strains with phenotypes that range from PIN (cathepsin D, $\mathrm{Akt}$ ) to cancer (Myc), we recognized the need to develop tools to track disease progression in a single mouse over time. After examining a number of technologies such as mouse microPET, microCT and optical imaging, we have settled on luciferase imaging as the most sensitive and user friendly. Therefore, we have generated transgenic mice expressing firefly luciferase under the control of the ARR2/probasin transgenic construct. Several founder lines have been screened by intraperitoneal injection of luciferin followed by optimal imaging using the Xenogen system. Two different lines show prostate specific, easily detectable expression of luciferase (figure 4). We are crossing these mice to our myc transgenics to determine the utility of this approach for following disease progression.
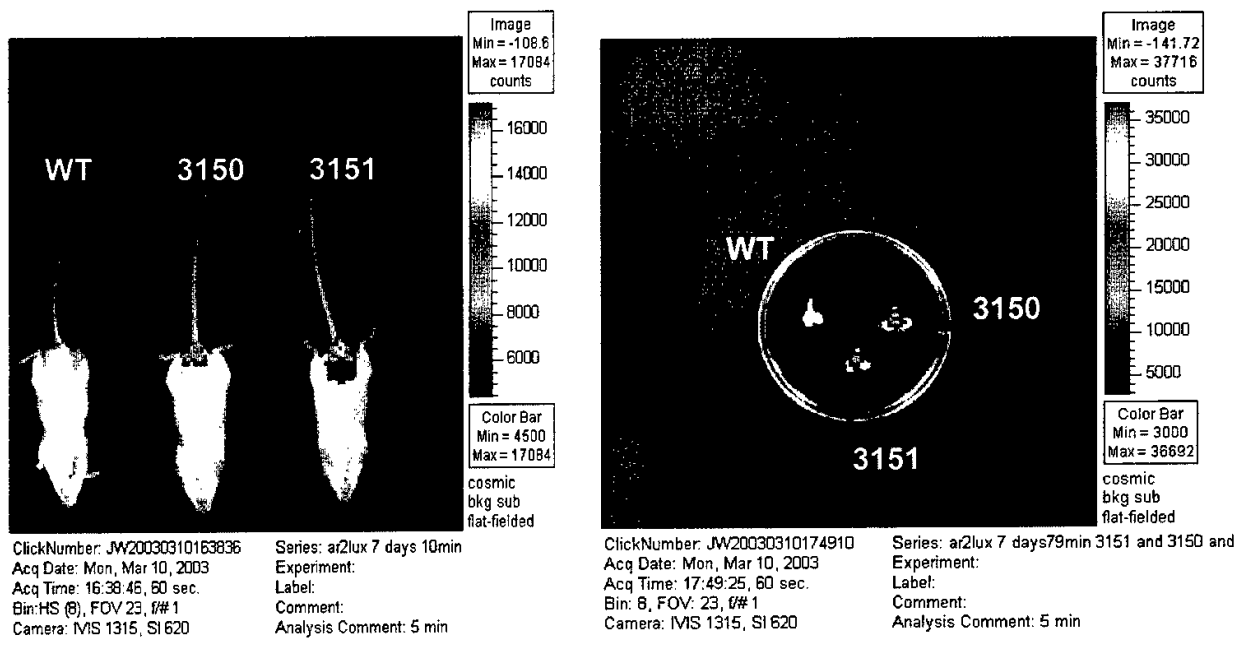

Figure 4. Optical imaging showing prostate-specific luciferase expression in whole animals (left) and isolated prostate glands (right). Animal $\# 3150$ and 3151 are two independent transgenic mice carrying ARR2/Pb-luciferase transgene. 


\section{Key Research Accomplishments}

1. Generation of Her-2/neu transgenic mice - phenotype: to be defined

2. Generation of cathepsin D transgenic mice - phenotype: PIN

3. Generation of myr-Akt transgenic mice - phenotype: PIN

4. Generation of c-myc transgenic mice - phenotype: PIN that progresses to cancer

5. Generation of TVAR transgenic mice - phenotype: susceptible to RCAS infection

6. Generation of luciferase transgenic mice - phenotype: prostate-specific light detection

\section{Reportable Outcomes}

Mellinghoff I.K., Tran T., Sawyers, C.L. (2002) Growth inhibitory effects of the dual ErbB1/ErbB2 tyrosine kinase inhibitor PKI-166 on human prostate cancer xenografts. Cancer Research. 62:5254-5259.

Chen C.D., Sawyers C.L. (2002) NF-kB Activates Prostate-Specific Antigen Expression and Is Upregulated in Androgen-Independent Prostate Cancer. Mol. Cell. Biol. 22(8):2862-2870.

Nickerson T., Chang F, Lorimer D, Smeekens SP, Sawyers CL, Pollak M (2001) In Vivo Progression of LAPC-9 and LNCaP Prostate Cancer Models to Androgen Independence Is Associated with Increased Expression of Insulin-like Growth Factor I (IGF-I) Receptor (IGF-IR) Cancer Research 61.6276-6280.

Ellwood-Yen K, Graeber TG, Wongvipat J, Iruela-Arispe L, Zhang J, Matusik R, Thomas GV, Sawyers CL (2003) Myc-driven murine prostate cancer shares molecular features with human prostate tumors. Submitted.

\section{Personnel Receiving Pay From The Research Effort}

Charles L. Sawyers, M.D. - Professor

Ingo K. Mellinghoff - Clinical Instructor

Katharine Ellwood Yen - Post-Grad

Francis Chang - Grad Student

Karin Deborah Hepner - Grad Student

Igor Vivanco - Grad Student

Derek Welsbie - Grad Student

John Wongvipat - Staff Research Associate IV

Mihal Lillian Emberton - Staff Research Associate I

Chris Tran - Specialist

Minna D. Balbas - Lab Helper 


\section{Conclusions}

We made considerable progress in the generation of transgenic mice that may serve as prostate cancer models. Our most significant accomplishment is the phenotype of the cMyc transgenic mice, which display highly penetrant PIN and invasive adenocarcinoma, without any of the features of neuroendocrine differentiation that can be an issue with the SV40 T Ag models. In addition to optimizing the TVAR and luciferase models as tools, we will embark on crosses of mice that are indicated based on oncogene cooperativity observed in vitro and genetic lesions observed in human tumors. Finally, the tumor progression in the myc mice provides an opportunity to discover complementary secondary genetic lesions using modern genomics tools such as expression microarray chips and array-based comparative genomic hybridization (CGH).

\section{References}

Cairns, P., Okami, K., Halachmi, S., Halachmi, N., Esteller, M., Herman, J. G., Jen, J., Isaacs, W. B., Bova, G. S., and Sidransky, D. (1997). Frequent inactivation of PTEN/MMAC1 in primary prostate cancer. Cancer Res 57, 4997-5000.

Craft, N., Shostak, Y., Carey, M., and Sawyers, C. L. (1999). A mechanism for hormoneindependent prostate cancer through modulation of androgen receptor signaling by the HER-2/neu tyrosine kinase. Nat Med 5, 280-285.

Fisher, G. H., Orsulic, S., Holland, E., Hively, W. P., Li, Y., Lewis, B. C., Williams, B. O., and Varmus, H. E. (1999). Development of a flexible and specific gene delivery system for production of murine tumor models. Oncogene 18, 5253-5260.

Holland, E. C., Hively, W. P., DePinho, R. A., and Varmus, H. E. (1998). A constitutively active epidermal growth factor receptor cooperates with disruption of G1 cell-cycle arrest pathways to induce glioma-like lesions in mice. Genes Dev 12, 36753685 .

Holland, E. C., and Varmus, H. E. (1998). Basic fibroblast growth factor induces cell migration and proliferation after glia-specific gene transfer in mice. Proc Natl Acad Sci U S A 95, 1218-1223.

Maroulakou, I. G., Anver, M., Garrett, L., and Green, J. E. (1994). Prostate and mammary adenocarcinoma in transgenic mice carrying a rat C3(1) simian virus 40 large tumor antigen fusion gene. Proc Natl Acad Sci U S A 91, 11236-11240.

Mellinghoff, I. K., Tran, C., and Sawyers, C. L. (2002). Growth Inhibitory Effects of the Dual ErbB1/ErbB2 Tyrosine Kinase Inhibitor PKI-166 on Human Prostate Cancer Xenografts. Cancer Res 62, 5254-5259. 
Petrylak, D. P., Macarthur, R. B., O'Connor, J., Shelton, G., Judge, T., Balog, J., Pfaff, C., Bagiella, E., Heitjan, D., Fine, R., et al. (1999). Phase I trial of docetaxel with estramustine in androgen-independent prostate cancer. J Clin Oncol 17, 958-967.

Shibata, M. A., Ward, J. M., Devor, D. E., Liu, M. L., and Green, J. E. (1996). Progression of prostatic intraepithelial neoplasia to invasive carcinoma in C3(1)/SV40 large $\mathrm{T}$ antigen transgenic mice: histopathological and molecular biological alterations. Cancer Res 56, 4894-4903.

Smith, D. C., Esper, P., Strawderman, M., Redman, B., and Pienta, K. J. (1999). Phase II trial of oral estramustine, oral etoposide, and intravenous paclitaxel in hormonerefractory prostate cancer. J Clin Oncol 17, 1664-1671.

Vlietstra, R. J., van Alewijk, D. C., Hermans, K. G., van Steenbrugge, G. J., and Trapman, J. (1998). Frequent inactivation of PTEN in prostate cancer cell lines and xenografts. Cancer Res 58, 2720-2723.

Whang, Y. E., Wu, X., Suzuki, H., Reiter, R. E., Tran, C., Vessella, R. L., Said, J. W., Isaacs, W. B., and Sawyers, C. L. (1998). Inactivation of the tumor suppressor PTEN/MMAC1 in advanced human prostate cancer through loss of expression. Proc Natl Acad Sci U S A 95, 5246-5250. 
- Growth Inhibitory Effects of the Dual ErbB1/ErbB2 Tyrosine Kinase Inhibitor - PKI-166 on Human Prostate Cancer Xenografts ${ }^{1}$

\author{
Ingo K. Mellinghoff, Chris Tran, and Charles L. Sawyers ${ }^{2}$ \\ Departments of Medicine [I. K. M., C. T., C. L. S.] and Molecular Biology Institute [C. L. S.], University of California Los Angeles, School of Medicine, Los Angeles, California, \\ 90095
}

\section{ABSTRACT}

Experiments with human prostate cancer cell lines have shown that forced overexpression of the ErbB2-receptor tyrosine kinase (RTK) promotes androgen-independent growth and increases androgen receptortranscriptional activity in a ligand-independent fashion. To investigate the relationship between ErbB-RTK signaling and androgen in genetically unmanipulated human prostate cancer, we performed biochemical and biological studies with the dual ErbB1/ErbB2 RTK inhibitor PKI-166 using human prostate cancer xenograft models with isogenic sublines reflecting the transition from androgen-dependent to androgen-independent growth. In the presence of low androgen concentrations, PKI-166 showed profound growth-inhibitory effects on tumor growth, which could be partially reversed by androgen add-back. At physiological androgen concentrations, androgen withdrawal greatly enhanced the ability of PKI166 to retard tumor growth. The level of extracellular signal-regulated kinase activation correlated with the response to PKI-166 treatment, whereas the expression levels of ErbB1 and ErbB2 did not. These results suggest that ErbB1/ErbB2 RTKs play an important role in the biology of androgen-independent prostate cancer and provide a rationale for clinical evaluation of inhibitors targeted to this pathway.

\section{INTRODUCTION}

Carcinoma of the prostate is the most common malignancy affecting males and causes enormous morbidity and mortality in the United States and Western Europe. About one-third of men relapse after radical prostatectomy surgery because of previously undetected metastatic disease. Metastatic prostate cancer responds for a variable period of time to androgen-deprivation therapy but eventually resumes growth despite castrate levels of androgen. This state of disease, termed "androgen-independent" prostate cancer, is characterized by expression of the $A R^{3}$ and AR-regulated genes, suggesting that the AR pathway is reactivated in a "ligand-independent" fashion. Several mechanisms have been proposed to explain the phenomenon of AR reactivation in the setting of castrate levels of ligand. These include mutations in $A R$ that alter its ligand-binding affinity, overexpression of AR because of gene amplification, and/or increased recruitment of intracellular signal transduction pathways, which activate AR through ligand-independent mechanisms (1).

ErbB RTKs have been implicated as one such pathway that may play a role in androgen-independent prostate cancer progression. Experimental support for this concept comes from the observation that: (a) activation of ErbB1 and/or ErbB2 RTKs by EGF or forced

Received 5/16/02; accepted 7/12/02.

The costs of publication of this article were defrayed in part by the payment of page charges. This article must therefore be hereby marked advertisement in accordance with 18 U.S.C. Section 1734 solely to indicate this fact.

${ }^{1}$ Supported by grants from the National Cancer Institute, Department of Defense, and CaPCure. C. L. S. is a Doris Duke Distinguished Clinical Scientist.

${ }^{2}$ To whom requests for reprints should be addressed, at 11-934 Factor Building, University of Califomia Los Angeles-Hematology-Oncology; 10833 Le Conte Avenue, Los Angeles, CA 90095-1678. Phone: (310) 206-5585; Fax: (310) 206-8502; E-mail: csawyers@mednet.ucla.edu.

${ }^{3}$ The abbreviations used are: AR, androgen receptor; RTK, receptor tyrosine kinase; EGF, epidermal growth factor; ERK, extracellular signal-regulated kinase; UCLA, University of Califomia Los Angeles; TGF, transforming growth factor; SCID, severe combined immunodeficient; AW, androgen withdrawal; MAPK, mitogen-activated protein kinase. overexpression of ErbB2, respectively, results in androgen-independent activation of AR transcriptional activity in prostate cancer cell lines (2-4); $(b)$ forced overexpression of ErbB2 promotes androgenindependent growth of prostate cancer cells $(2,3)$; and $(c)$ androgenindependent prostate cancers express increased levels of ErbB2 receptor protein $(2,5-7)$. However, it is still uncertain whether ErbB1and ErbB2-mediated signals contribute to the progression of human prostate cancer, which, unlike breast cancer (8), rarely shows amplification of $E r b B$-gene loci. Using xenograft models of human prostate cancer, we show here a striking interplay of $A R$ and ErbB signaling pathways. Growth inhibition by the ATP site-specific ErbB1/ErbB2 RTK inhibitor PKI-166 was greatest in androgen-independent tumors, significantly augmented by simultaneous $\mathrm{AW}$, and partially rescued by androgen supplementation. Growth inhibition by PKI-166 was positively correlated with the basal activation state of the ERKs ERK1/2. Our findings suggest that ErbB1/ErbB2 RTKs play an important role in the biology of human prostate cancer and may be a viable therapeutic target for novel kinase inhibitors (9).

\section{MATERIALS AND METHODS}

Reagents. The LAPC4 cell line was established from the LAPC4 human prostate cancer xenograft (10), A431 cells were kindly provided by Dr. Harvey Hershman (UCLA), and LNCaP cells were purchased from American Type Culture Collection. PKI-166 was obtained from Novartis Pharma AG, Basel, Switzerland. EGF and standard chemical reagents were obtained from Sigma. Antibodies against ErbB1 (sc-101 and sc-03), ERK1/2 (sc-94), TGF- $\alpha$ (sc9043), and prostate-specific antigen ( $s c-7638$ ) were obtained from Santa Cruz Biotechnology, against ErbB2 from Oncogene Sciences (OP-15), against phosphotyrosine from Upstate ( $4 G 10$ ), against activated ErbB1 from Chemicon ( $M A b 3052$ ), against phospho-ERK (Thr183/Tyr185) from Promega (V803I), and against phospho-Akt (Ser473) from Cell Signaling Technology ( $A$ b927I)

Pulse-Chase Experiments and Immunoblotting. A431 cells were labeled for $12 \mathrm{~h}$ in methionine-free DMEM with $0.2 \mathrm{mCi}\left[{ }^{35} \mathrm{~S}\right]$ methionine/cysteine (Translabel; ICN Biomedicals) per $10-\mathrm{cm}$ plate. Cells were subsequently washed three times in serum-free DMEM. Serum-free DMEM with $15 \mathrm{mg} /$ liter unlabeled methionine ("chase-medium") was added to each plate in the presence or absence of $5 \mu \mathrm{M}$ PKI-166. Ten min later $100 \mathrm{ng} / \mathrm{ml}$ EGF was added where indicated in Fig. $1 B$. Cells were lysed immediately after the third wash in serum-free DMEM (baseline sample) and at various intervals after the addition of chase-medium. Cell lysis, immunoprecipitation, SDS-PAGE-electrophoresis, autoradiography, and immunoblotting was performed following standard protocols (11). Protein concentration was determined in all of the lysates by Bio-Rad, and equal amounts of protein were loaded per lane. Quantification of immunoblot bands was performed using ImageQuant software.

Animal Experiments. SCID (C.B.-17 Scid/Scid) mice were bred and maintained in a laminar flow tower in a defined flora colony as described previously (12). All of the manipulations with the animals were performed in a laminar flow hood with sterile techniques following the guidelines of the UCLA Animal Research Committee. For preparation of single cell suspensions, LAPC4 (10) and LAPC9 (13) tumors continuously passaged in SCID mice were minced in serum-free Iscove's medium (Life Technologies, Inc. Grand Island, NY), washed, digested with $0.1 \%$ Pronase E (EM Science, Gibbstown, NJ), washed again, and filtered through a $200 \mu \mathrm{m}$ nylon mesh (BioDesign Inc. of New York, Carmel, NY). The cells were plated overnight, resuspended in PrEGM, and injected with Matrigel into the right flank of SCID mice. Tumor size was determined with calipers, and mice were randomized to 


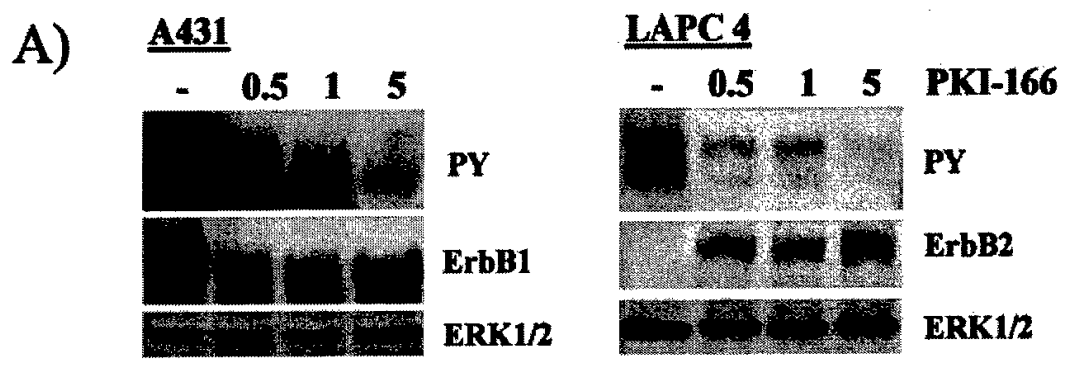

Fig. 1. PKJ-166 inhibits ErbBl and ErbB2 receptor signaling and degradation. $A$, immunoblots of A431 (left panel) and LAPC4 (right panel) cells treated for $12 \mathrm{~h}$ with various concentrations of PKI-166 (in $\mu \mathrm{M}$ ) before stimulation with EGF (100 $\mathrm{ng} / \mathrm{ml}$ ) for $10 \mathrm{~min} . B$, left panel, autoradiograph of immunoprecipitated ErbB1 (top row) and immunoblots (middle and bottom row) of lysates from A431 cells metabolically labeled for $12 \mathrm{~h}$ with $\left[{ }^{35}\right.$ S]methionine and chased in the presence of PKI$166(5 \mu \mathrm{M})$ and/or EGF $(100 \mathrm{ng} / \mathrm{ml})$. PKI-166 was added $10 \mathrm{~min}$ before EGF where indicated. Right panel, immunoblot of A431 cells treated with PKI-166 for $12 \mathrm{~h}$ using a ErbBl antibodies directed against $\mathrm{NH}_{2}$-terminal and $\mathrm{COOH}$-terminal epitopes. $C$, immunoblots of lysates from LAPC9 (left top panel and right panel) or A431 (left bottom panel) xenograft tumors harvested $1 \mathrm{~h}$ after the fifth daily dose of PKI-166 (2 tumors per condition). The right panel shows lysates of LAPC9 tumors from mice injected i.p. with PBS, $0.1 \mathrm{mg} E G F$, or $0.01 \mathrm{mg}$ EGF $1 \mathrm{~h}$ after the fifth daily dose of PKI-166. Tumors were harvested $5 \mathrm{~min}$ after EGF injection.
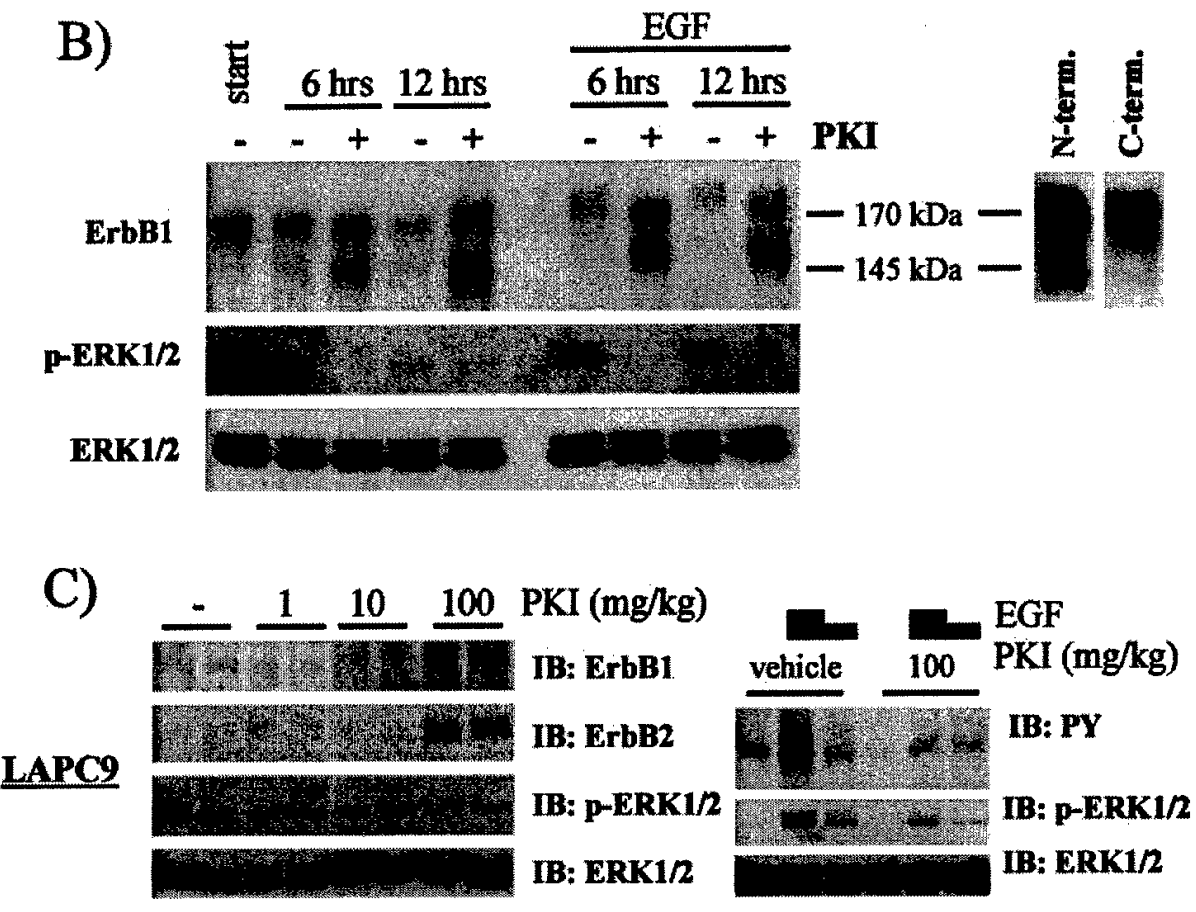

$\mathbf{A 4 3 1}$

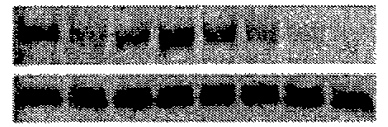

IB: PY

IB: ERK1/2 treatment groups when tumor size reached $\sim 100 \mathrm{~mm}^{3}$. Mean tumor volumes (in $\mathrm{mm}^{3}$ ) at treatment begin was equal between groups. PKI-166 was administered daily by gavage with an 18-gauge animal feeding needle (VWR, San Dimas, CA). Testosterone pellets (Innovative Research of America) were implanted s.c. Tumor growth data are expressed as fold tumor volume compared with day 1 (Fig. 2, $A$ and $C$ ) or as ratio between the fold increases in tumor volume for PKI-166 and vehicle treated mice ("T/C"; Figs. $2 B$ and $3 B$ ). Statistical analyses comparing fold increases between groups were performed on the natural logarithms of the tumor volumes corrected for baseline volumes. Student's $t$ test was used for comparison of two groups. ANOVA using the Tukey Studentized range method was used for multigroup comparisons.

\section{RESULTS}

PKI-166 Blocks ErbB1/ErbB2 Activity in Prostate Cancer Cells. We first examined the effects of PKI-166 on EGF-induced signal transduction through ErbB1 and ErbB2 RTKs in the human prostate cancer cell lines LAPC4 and LNCaP, both of which express the AR. The human vulvar carcinoma cell line A431, which expresses high levels of $E r b B I$ because of amplification of the erbB1 locus, was used as a positive control. In A431 cells treated with EGF, immuno- blotting with a phosphotyrosine antibody showed a dominant band of $M_{\mathrm{r}} \sim 170,000$ representing the phosphorylated ErbB1 receptor (Fig. $1 A$ ). In EGF-treated LAPC-4 cells, which express considerably less ErbB1 than A431 cells but more ErbB2 (data not shown), tyrosine phosphorylation of a $M_{\mathrm{r}} 170,000$ and a $M_{\mathrm{r}} 185,000$ band was observed representing phosphorylated ErbB1 and ErbB2, respectively. Dosedependent inhibition of receptor autophosphorylation was noted after pretreatment with PKI-166, with estimated $\mathrm{IC}_{50}$ values of $0.5 \mu \mathrm{M}$ for ErbB1 and $5 \mu \mathrm{M}$ for ErbB2. Similar doses of PKI-166 have been reported to inhibit phosphorylation of ErbB1 and ErbB2 RTKs but not other tyrosine or serine/threonine kinases in nonprostatic human cancer cell lines (14-16). We also noted that PKI-166 treatment resulted in a dose-dependent increase in the level of ErbB1 protein in A431 cells and ErbB2 protein in LAPC4 cells. The increase in ErbB2 expression in LAPC4 cells was apparent at $0.5 \mu \mathrm{M}$ PKI-166, a concentration that predominantly inhibits phosphorylation of ErbB1.

Previous work has indicated that ErbBl protein is degraded after receptor activation by ligand, raising the possibility that the increased levels of ErbB1 and ErbB2 in PKI-166-treated cells are a reflection of 


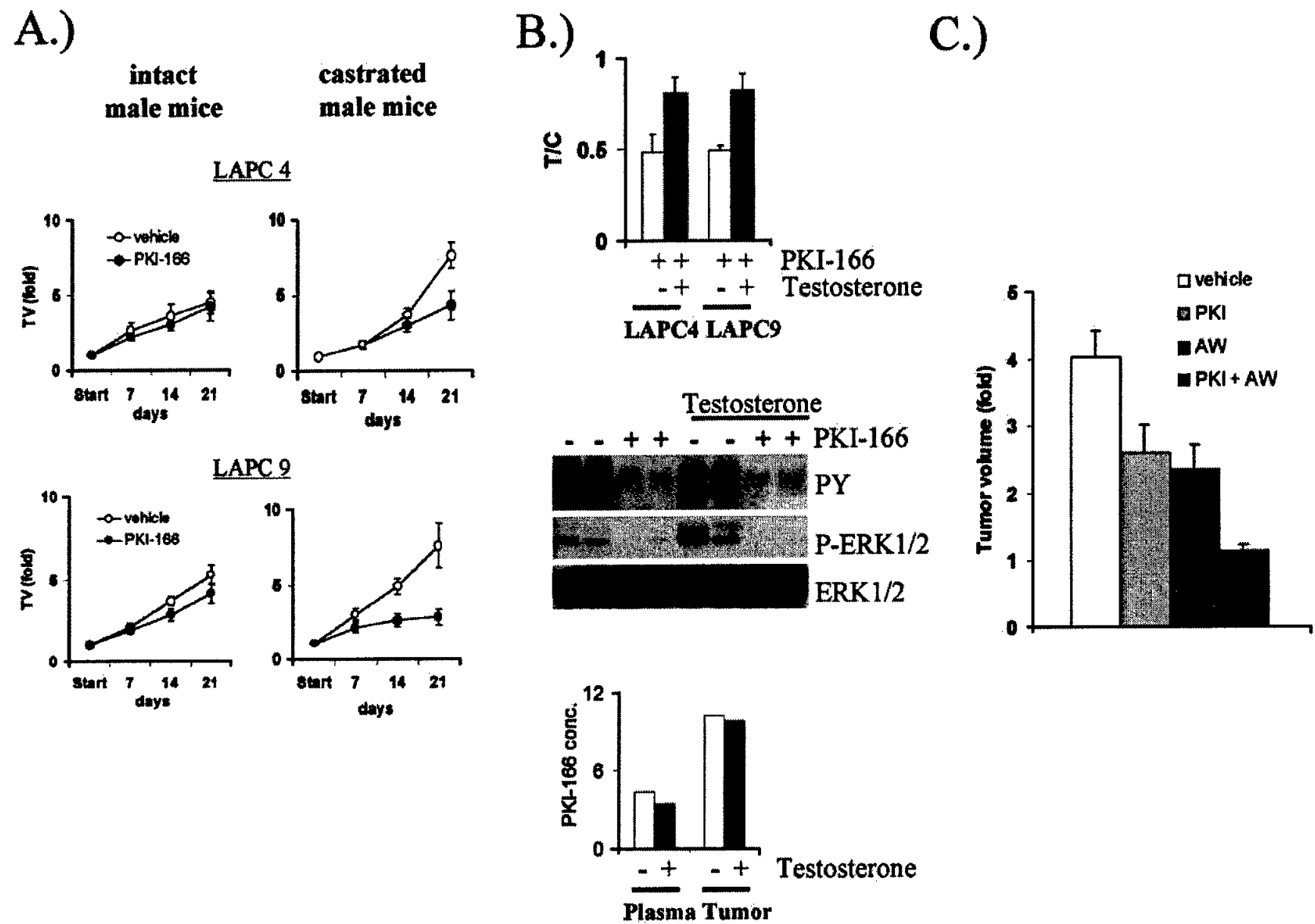

Fig. 2. Androgen modifies the growth response to PKI-166, A, PKI-166 inhibits the growth of human prostate cancer xenografts growing in castrated mice. Mice bearing LAPC4 or LAPC 9 xenograft tumors were treated daily for 3 weeks with $100 \mathrm{mg} / \mathrm{kg}$ PKI-166 versus vehicle ( $n=6-9$ per group). Data are expressed as fold tumor volume compared with day 1 ; bars, \pm SE. B, top panel, testosterone rescues growth inhibition by PKI-166 in castrated animals. Castrated male mice bearing androgen-independent xenografts were randomized to four treatment groups (vehicle, PKI-166, vehicle plus testosterone, and PKI plus testosterone). Data are expressed as ratio between the fold increase in tumor volume for PKI-166 treated mice and the fold increase in tumor volume for vehicle treated mice (T/C). Each treatment group consisted of $8-9$ mice. Middle panel, testosterone does not impair the ability of PKI-166 to inhibit ErbB1/ErbB2 signaling. Castrated male mice bearing LAPC 9 xenograft tumors were treated with PKI-166 +/- testosterone for 21 days, and EGF (0.1 mg) was administered i.p. $1 \mathrm{~h}$ after the last PKI-166 dose. Tumors $(n=2$ per treatment condition) were harvested 5 min later. Displayed are immunoblots for PY, ERK1/2, and total ERK1/2. Bottom panel, testosterone does not affect PKI-166 bioavailability in mice. PKI-166 levels in plasma ( $\mu \mathrm{M})$ and LAPC9 tumors (nmol/g) were determined by reversed-phase high-performance liquid chromatography in castrated mice after 21 days of treatment with PKI-166 (100 mg/kg) $+1-$ testosterone. Blood and tumors were collected $1 \mathrm{~h}$ after the last dose of PKI-166 and displayed as mean values ( $n=3$ per group). $C$, AW augments inhibitory effect of PKI-166 on LAPC4 xenografts in intact male mice. Surgical castration was performed on the same day as PKI-166 treatment was started. Data are expressed as fold tumor volume compared with day 1 . Six mice were treated per group; bars, \pm SE.

kinase inhibition. To determine whether pharmacologic inhibition of RTK activity delays receptor degradation, we measured the effect of PKI-166 on immunoprecipitated, $\left[{ }^{35} \mathrm{~S}\right]$ methionine/cysteine radiolabeled ErbB1 receptors in A431 cells (Fig. 1B, left panel). In the absence of PKI-166 and EGF, the receptor half-life of ErbB1 was between 6 and $12 \mathrm{~h}$, consistent with the half-life of $\sim 9 \mathrm{~h}$ published previously (17). Stimulation of A431 cells with EGF resulted in phosphorylation of ErbB1, as evidenced by retarded electrophoretic mobility compared with the unphosphorylated receptor, and shortening of the receptor half-life to $<6 \mathrm{~h}$. PKI-166 impaired the degradation of ErbB-1 receptor protein in both the presence and absence of EGF. These data support the concept that kinase activity is required for receptor degradation, consistent with prior work showing increased receptor half-life in ErbBl alleles containing point mutations within the ErbB1 ATP-binding site $(18,19)$. We also noted accumulation of a lower molecular weight protein in the ErbB1 immunoprecipitates from PKI-166-treated cells. This $M_{\mathrm{r}} 145,000$ protein was immunoprecipitated by an ErbB1 antibody directed against a cellsurface epitope but not by an antibody directed against a $\mathrm{COOH}-$ terminal epitope (Fig. 1B, right panel), indicating that it is likely to be a $\mathrm{COOH}$-terminal truncation of the receptor. Similarly sized bands have been observed previously after treatment of A431 cells with the lysosomal inhibitor methylamine (17) and presumably represent an intermediate step in receptor degradation.

Because many growth factor signals are transmitted to the nucleus through ERKs (20), we also measured the effect of PKI-166 on ERK $1 / 2$ activation. At a dose that inhibits ErbB1 phosphorylation, PKI-166 completely blocked basal and EGF-induced ERK1/2 activation in A431 cells (Fig. 1B). Similar results were obtained in LAPC4 and LNCaP prostate cancer cells (data not shown). These data establish the biochemical activity of PKI-166 against ErbB1/ErbB2 RTKs in vitro, including effects on receptor autophosphorylation, receptor degradation, and additional signal transduction.

PKI-166 Blocks ErbB1/ErbB2 Signal Transduction in Tumors in Mice. We next examined the effects of PKI-166 treatment on ErbB1/ErbB2-mediated signaling in vivo. SCID mice bearing tumors from the human prostate cancer xenografts LAPC4 (10) and LAPC9 (13) or from the A431 cell line were treated for 5 days with $0,1,10$, and $100 \mathrm{mg} / \mathrm{kg}$ of PKI-166, and tumor tissue was harvested $1 \mathrm{~h}$ after the last dose was administered. Lysates from A431 tumors displayed 
constitutive phosphorylation of ErbB-1 that was inhibited by treatment of mice with $100 \mathrm{mg} / \mathrm{kg}$ PKI-166. Similar analysis of ErbB phosphorylation in prostate cancer xenografts was not informative because of low basal levels of phosphotyrosine (data not shown). However, we did observe decreased ERK $1 / 2$ activation and increased levels of total ErbB1 and ErbB2 protein in the prostate cancer xenografts from mice treated with $100 \mathrm{mg} / \mathrm{kg}$ of PKI-166, providing indirect evidence for ErbB1/ErbB2 RTK inhibition at this dose (Fig. $1 C$, left panel). To obtain direct evidence of ErbB1/ErbB2 blockade in PKI-166-treated mice, we induced receptor activation by systemic administration of EGF (21). Two different doses of EGF were injected i.p. and resulted in dose-dependent receptor phosphorylation and ERK1/2 activation in LAPC9 tumors (Fig. 1C, right panel). PKI-166 given p.o. at a dose of $100 \mathrm{mg} / \mathrm{kg}$ markedly blunted this activation (Fig. 1C, right panel). Similar results were obtained in mice bearing LAPC4 or A431 xenografts (data not shown).

PKI-166 Blocks the Growth of Prostate Cancers in Mice in an Androgen-dependent Fashion. Having defined the dose of PKI-166 required to inhibit ErbB1/ErbB2 RTKs in vivo, we were now able to examine the role of these RTKs in the growth of human prostate cancer. We chose the LAPC xenograft model to address this question because of its similarity to clinical prostate cancer (10) and the convenience of monitoring drug effects on s.c. tumor volumes. Tumors derived from the A431 cell line were used as a positive control and were completely growth arrested by PKI-166 (data not shown). Androgen-independent sublines of the prostate cancer xenografts grown in castrated host mice were consistently more sensitive to growth inhibition by PKI-166 than androgen-dependent sublines of the same xenograft growing in intact male $(P<0.005)$. This observation was confirmed in multiple experiments and noted in both LAPC4 and LAPC9 xenografts (Fig. 2A).

The trend toward enhanced activity of PKI-166 in the absence of androgen was reminiscent of our previous data showing more dramatic effects of forced ErbB2 overexpression on prostate cancer growth in castrated versus intact male mice (2). At that time we postulated that the major effects of ErbB1/ErbB2 pathway activation might be mediated through AR but that these effects were most relevant in the setting of low (castrate) levels of androgen. To examine this hypothesis, we asked if the suppression of growth by PKI-166 in castrated male mice could be rescued by androgen supplementation, which was administered by s.c. implantation of slow release testosterone pellets. In both LAPC4 and LAPC9 xenografts (Fig. 2B, top panel), androgen add-back partially rescued the growth inhibitory effects of PKI-166 $(P<0.05)$. One potential explanation for this result is that androgen impairs the ability of PKI-166 to inhibit ErbB1/ErbB2 RTKs. To examine this possibility, we treated eight castrated male mice bearing LAPC tumors with PKI-166 in the presence or absence of supplemental testosterone, and measured ErbB receptor and ERK1 activation in tumor lysates after systemic administration of EGF. Androgen supplementation did not impair the ability of PKI-166 to inhibit EGF-induced signal transduction (Fig. 2B, middle panel) nor did androgen affect the bioavailability of PKI-166 as shown by similar mean plasma and tumor drug levels in castrated and androgen-supplemented mice (Fig. $2 B$, bottom panel). These data indicate that the rescue of PKI-166-induced growth suppression by androgen supplementation cannot be explained by a failure of PKI166 to inhibit its target. Rather, our findings suggest that ErbB1/ ErbB2 signaling is not required for prostate cancer growth when androgen is present at high levels.

If a threshold level of circulating androgen exists below which ErbB1/ErbB2 RTKs are required for prostate cancer growth, acute AW by surgical castration should increase the growth-inhibitory effects of PKI-166. To test this hypothesis, we randomized intact male
SCID mice bearing the LAPC4 xenograft to four treatment groups. Compared with vehicle-treated mice, AW by surgical castration slowed the growth of LAPC4 tumors $(P<0.05)$, as expected (10). Growth inhibition by PKI-166 given at $100 \mathrm{mg} / \mathrm{kg}$ daily did not reach statistical significance. However, the combination of PKI-166 with AW resulted in nearly complete growth suppression (Fig. $2 C$ ). The difference between the combined treatment group and any of the other three treatment groups was highly statistically significant $(P<0.001)$.

Sensitivity to Growth Inhibition by PKI-166 Is Correlated with ERK Activation. The LAPC-4 and LAPC-9 xenografts have been passaged in mice over multiple generations, and various androgendependent and androgen-independent subclones derived from the original parental lines have been maintained independently. In the course of these studies we noted that subclones derived from the same parental line occasionally displayed differences in their sensitivity to PKI-166. These sublines provide an opportunity, within an isogenic system, to examine variables in the ErbB1/ErbB2 signaling pathway that might determine response to ErbB1/ErbB2 inhibition. To address this question, we performed biochemical analysis on six LAPC xenograft clones, of which four were grown in intact male mice (clones 1 and 2 for both LAPC 4 and LAPC 9) and two in castrated male mice (clones 3 for both LAPC 4 and LAPC 9). We examined not only the expression levels of the direct PKI-166 targets ErbB1 and ErbB2, but also the activation state of the Ras/MAPK and phosphatidylinositol 3 '-kinase/Akt-pathways. Both pathways are considered central effectors of the ErbB signaling network (20) and have been implicated in the progression of human prostate cancer $(3,22-24)$. Expression of the ErbB-1 ligand TGF- $\alpha$ was included in the analysis because of its suggested role as an autocrine growth factor in androgen-independent prostate cancer (25). To be able to correlate for each subline the expression of these biochemical parameters with the growth response to PKI-166, we quantified the relevant immunoblot bands (Fig. $3 A$ ) by densitometry. Despite differences in the magnitude of ERK1/2-activation between the LAPC4 and LAPC9 xenograft models, we found within each model a positive correlation between the degree of growth-inhibition by PKI-166 and the level of ERK1/2-activation (Fig. $3 B$ ). No such correlation was found for expression levels of ErbB1, ErbB2, TGF- $\alpha$, or activation level of Akt. Whereas the number of available sublines for each xenograft was not sufficient to perform a multivariate analysis, our results in an isogenic system suggest that expression levels of ErbB-1 or ErbB-2 are not sufficient to determine sensitivity to PKI-166 and are consistent with studies using the ErbB-1 inhibitor ZD1839 (26) or the anti-ErbB-2 monoclonal antibody Mab 4D5 (27).

We also noted that androgen-independent tumors (clones 3 ) showed increased activation of ERK $1 / 2$ when compared with tumors grown in intact male mice (Fig. $3 A$ ). This observation was confirmed by serial analysis of androgen-dependent LAPC4 xenografts at various times postcastration during the evolution to androgen independence (Fig. $3 B$ ). This data are consistent with results of immunohistochemical analyses of human prostate cancer specimens using phosphospecific antibodies to ERK1/2 (28).

\section{DISCUSSION}

In conclusion, our study shows that ErbB1/ErbB2 RTKs contribute to the growth of human prostate cancer and that this contribution is greatest when levels of androgen are limiting. The nature of the interaction between AR pathway and ErbB1/ErbB2 RTKs remains to be defined. It is conceivable that ErbB-RTKs provide growth and survival signals for prostate cancer cells, which are completely independent of AR and only biologically relevant under the selective pressure of androgen deprivation. Alternatively, ErbB-RTKs might 

2. Craft, N., Shostak, Y., Carey, M., and Sawyers, C. L. A mechanism for hormoneindependent prostate cancer through modulation of androgen receptor signaling by the HER-2/neu tyrosine kinase. Nat. Med., 5: 280-285, 1999.

3. Yeh, S., Lin, H. K., Kang, H. Y., Thin, T. H., Lin, M. F., and Chang, C. From HER2/Neu signal cascade to androgen receptor and its coactivators: a novel pathway by induction of androgen target genes through MAP kinase in prostate cancer cells. Proc. Natl. Acad. Sci. USA, 96: 5458-5463, 1999.

4. Culig, Z., Hobisch, A., Cronauer, M. V., Radmayr, C., Trapman, J., Hittmair, A., Bartsch, $G$., and $\mathrm{Klocker}, \mathrm{H}$. Androgen receptor activation in prostatic tumor cell lines by insulin- like growth factor-I, keratinocyte growth factor, and epidermal growth factor. Cancer Res., 54: 5474-5478, 1994.

5. Signoretti, S., Montironi, R., Manola, J., Altimari, A., Tam, C., Bubley, G., Balk, S., Thomas, G., Kaplan, I., Hlatky, L., Hahnfeldt, P., Kantoff, P., and Loda, M. Her-2neu expression and progression toward androgen independence in human prostate cancer. J. Natl. Cancer Inst., 92: 1918-1925, 2000.

6. Osman, I., Scher, H. I., Drobnjak, M., Verbel, D., Morris, M., Agus, D., Ross, J. S., and Cordon-Cardo, C. HER-2/neu (p185neu) protein expression in the natural or treated history of prostate cancer. Clin. Cancer Res., 7: 2643-2647, 2001.

7. Shi, Y., Brands, F. H., Chatterjee, S., Feng, A. C., Groshen, S., Schewe, J., Lieskovsky, G., and Cote, R. J. Her-2/neu expression in prostate cancer: high level of expression associated with exposure to hormone therapy and androgen independent disease. J. Urol., 166: 1514-1519, 2001.

8. Slamon, D. J., Clark, G. M., Wong, S. G., Levin, W. J., Ullich, A., and McGuire, W. L. Human breast cancer: correlation of relapse and survival with amplification of the HER-2/neu oncogene. Science (Wash. DC), 235: 177-182, 1987.

9. Mendelsohn, J. The epidermal growth factor receptor as a target for cancer therapy. Endocr. Relat. Cancer, 8: 3-9, 2001.

10. Klein, K. A., Reiter, R. E., Redula, J., Moradi, H., Zhu, X. L., Brothman, A. R., Lamb, D. J., Marcelli, M., Belldegrun, A., Witte, O. N., and Sawyers, C. L. Progression of metastatic human prostate cancer to androgen independence in immunodeficient SCID mice. Nat. Med., 3: 402-408, 1997.

11. Daub, H., Wallasch, C., Lankenau, A., Herrlich, A., and Ullrich, A. Signal characteristics of G protein-transactivated EGF receptor. EMBO J., 16: 7032-7044, 1997.

12. Chackal-Roy, M., Niemeyer, C., Moore, M., and Zetter, B. R. Stimulation of human prostatic carcinoma cell growth by factors present in human bone marrow. J. Clin. Investig., 84: 43-50, 1989

13. Craft, N., Chhor, C., Tran, C., Belldegrun, A., DeKernion, J., Witte, O. N., Said, J., Reiter, R. E., and Sawyers, C. L. Evidence for clonal outgrowth of androgenindependent prostate cancer cells from androgen-dependent tumors through a twostep process. Cancer Res., 59: 5030-5036, 1999.

14. Bruns, C. J., Solorzano, C. C., Harbison, M. T., Ozawa, S., Tsan, R., Fan, D., Abbruzzese, J., Traxler, P., Buchdunger, E., Radinsky, R., and Fidler, I. J. Blockade of the epidermal growth factor receptor signaling by a novel tyrosine kinase inhibitor leads to apoptosis of endothelial cells and therapy of human pancreatic carcinoma. Cancer Res., 60: 2926-2935, 2000.

15. Brandt, R., Wong, A. M., and Hynes, N. E. Mammary glands reconstituted with Neu/ErbB2 transformed HC11 cells provide a novel orthotopic tumor model for testing anti-cancer agents. Oncogene, 20: 5459-5465, 2001.
16. Scheving, L. A., Stevenson, M. C., Taylormoore, J. M., Traxler, P., and Russell, W.E. Integral role of the EGF receptor in HGF-mediated hepatocyte proliferation. Biochem. Biophys. Res. Commun., 290: 197-203, 2002.

17. Stoscheck, C. M., and Carpenter, G. Down regulation of epidermal growth factor receptors: direct demonstration of receptor degradation in human fibroblasts. J. Cell Biol., 98: 1048-1053, 1984

18. Honegger, A. M., Dull, T. J., Felder, S., Van Obberghen, E., Bellot, F., Szapary, D., Schmidt, A., Ullrich, A., and Schlessinger, J. Point mutation at the ATP binding site of EGF receptor abolishes protein-tyrosine kinase activity and alters cellular routing. Cell, 51: 199-209, 1987.

19. Chen, W. S., Lazar, C. S., Poenie, M., Tsien, R. Y., Gill, G. N., and Rosenfeld, M. G. Requirement for intrinsic protein tyrosine kinase in the immediate and late actions of the EGF receptor. Nature (Lond.), 328: 820-823, 1987.

20. Yarden, Y., and Sliwkowski, M. X. Untangling the ErbB signalling network. Nat. Rev. Mol. Cell. Biol, 2: 127-137, 2001.

21. Donaldson, R. W., and Cohen, S. Epidermal growth factor stimulates tyrosine phosphorylation in the neonatal mouse: association of a M(r) 55,000 substrate with the receptor. Proc. Natl. Acad. Sci. USA, 89: 8477-8481, 1992.

22. Gioeli, D., Zecevic, M., and Weber, M. J. Immunostaining for activated extracellular signal-regulated kinases in cells and tissues. Methods Enzymol., 332: 343-353, 2001.

23. Wen, Y., Hu, M. C., Makino, K., Spohn, B., Bartholomeusz, G., Yan, D. H., and Hung, M. C. HER-2/neu promotes androgen-independent survival and growth of prostate cancer cells through the Akt pathway. Cancer Res., 60: 6841-6845, 2000.

24. Malik, S. N., Brattain, M., Ghosh, P. M., Troyer, D. A., Prihoda, T., Bedolla, R., and Kreisberg, J. I. Immunohistochemical demonstration of phospho-akt in high Gleason grade prostate cancer. Clin. Cancer Res., 8: 1168-1171, 2002

25. Scher, H. I., Sarkis, A., Reuter, V., Cohen, D., Netto, G., Petrylak, D., Lianes, P., Fuks, Z., Mendelsohn, J., and Cordon-Cardo, C. Changing pattern of expression of the epidermal growth factor receptor and transforming growth factor $\alpha$ in the progression of prostatic neoplasms. Clin. Cancer Res., 1: 545-550, 1995.

26. Moasser, M. M., Basso, A., Averbuch, S. D., and Rosen, N. The tyrosine kinase inhibitor ZD1839 ("Iressa") inhibits HER2-driven signaling and suppresses the growth of HER2-overexpressing tumor cells. Cancer Res., 61: 7184-7188, 2001.

27. Lane, H. A., Beuvink, I., Motoyama, A. B., Daly, J. M., Neve, R. M., and Hynes, N. E. ErbB2 potentiates breast tumor proliferation through modulation of $\mathrm{p} 27(\mathrm{Kip} 1)-$ Cdk2 complex formation: receptor overexpression does not determine growth dependency. Mol. Cell. Biol., 20: 3210-3223, 2000.

28. Gioeli, D., Mandell, J. W., Petroni, G. R., Frierson, H. F., Jr., and Weber, M. J. Activation of mitogen-activated protein kinase associated with prostate cancer progression. Cancer Res., 59: 279-284, 1999.

29. Kato, S., Endoh, H., Masuhiro, Y., Kitamoto, T., Uchiyama, S., Sasaki, H., Masushige, S., Gotoh, Y., Nishida, E., Kawashima, H., and et al. Activation of the estrogen receptor through phosphorylation by mitogen-activated protein kinase. Science (Wash. DC), 270: 1491-1494, 1995.

30. Agus, D. B., Scher, H. I., Higgins, B., Fox, W. D., Heller, G., Fazzari, M., CordonCardo, C., and Golde, D. W. Response of prostate cancer to anti-Her-2/neu antibody in androgen-dependent and -independent human xenograft models. Cancer Res., 59: 4761-4764, 1999. 


\title{
NF-кB Activates Prostate-Specific Antigen Expression and Is Upregulated in Androgen-Independent Prostate Cancer
}

\author{
Charlie D. Chen and Charles L. Sawyers* \\ Division of Hematology/Oncology, Department of Medicine, University of California at Los Angeles, \\ Los Angeles, California 90095-1678
}

Received 12 December 2001/Accepted 19 January 2002

\begin{abstract}
The transcription factor $\mathrm{NF}-\mathrm{kB}$ regulates gene expression involved in cell growth and survival and has been implicated in progression of hormone-independent breast cancer. By expressing a dominant-active form of mitogen-activated protein kinase kinase kinase 1 , by exposure to tumor necrosis factor alpha, or by overexpression of $\mathbf{p 5 0 / p 6 5}$, we show that $\mathrm{NF}-\mathrm{\kappa} B$ activates a transcription regulatory element of the prostate-specific antigen (PSA)-encoding gene, a marker for prostate cancer development, treatment, and progression. By DNase I footprinting, we identified four NF-KB binding sites in the PSA core enhancer. We also demonstrate that androgen-independent prostate cancer xenografts have higher constitutive NF-kB binding activity than their androgen-dependent counterparts. These results suggest a role of NF- $\mathrm{KB}$ in prostate cancer progression.
\end{abstract}

Prostate cancer begins as an androgen-dependent (AD) tumor and regresses in response to androgen ablation therapy. This therapy eventually fails, and the tumor progresses despite castrate levels of androgen. This stage of the disease is referred to as androgen-independent (AI) or hormone-refractory prostate cancer. The prostate-specific antigen (PSA) level in serum is a clinical marker for prostate cancer progression and effectiveness of treatment. Rising PSA levels typically signal progression from androgen dependence to androgen independence. Biochemical and genetic analyses have identified two regulatory regions responsible for androgen-regulated, tissuespecific PSA expression-the proximal promoter containing a core TATA box and an enhancer region located approximately $4.2 \mathrm{~kb}$ upstream of the transcription start site $(7,19,33)$. We have used these regions as tools with which to identify molecular mechanisms responsible for PSA expression at castrate levels of androgen to gain insight into mechanisms of prostate cancer progression $(2,9)$.

The NF-kB/Rel genes encode a family of heterodimeric transcription factors that share a 300-amino-acid Rel homology domain (RHD) $(16,26)$. Classical NF-KB is a heterodimer composed of a $50-\mathrm{kDa}(\mathrm{p} 50)$ subunit and a $65-\mathrm{kDa}$ (p65 or RelA) subunit and was discovered as a $\mathrm{k}$-immunoglobulin enhancer DNA binding protein (38). c-Rel, another member of
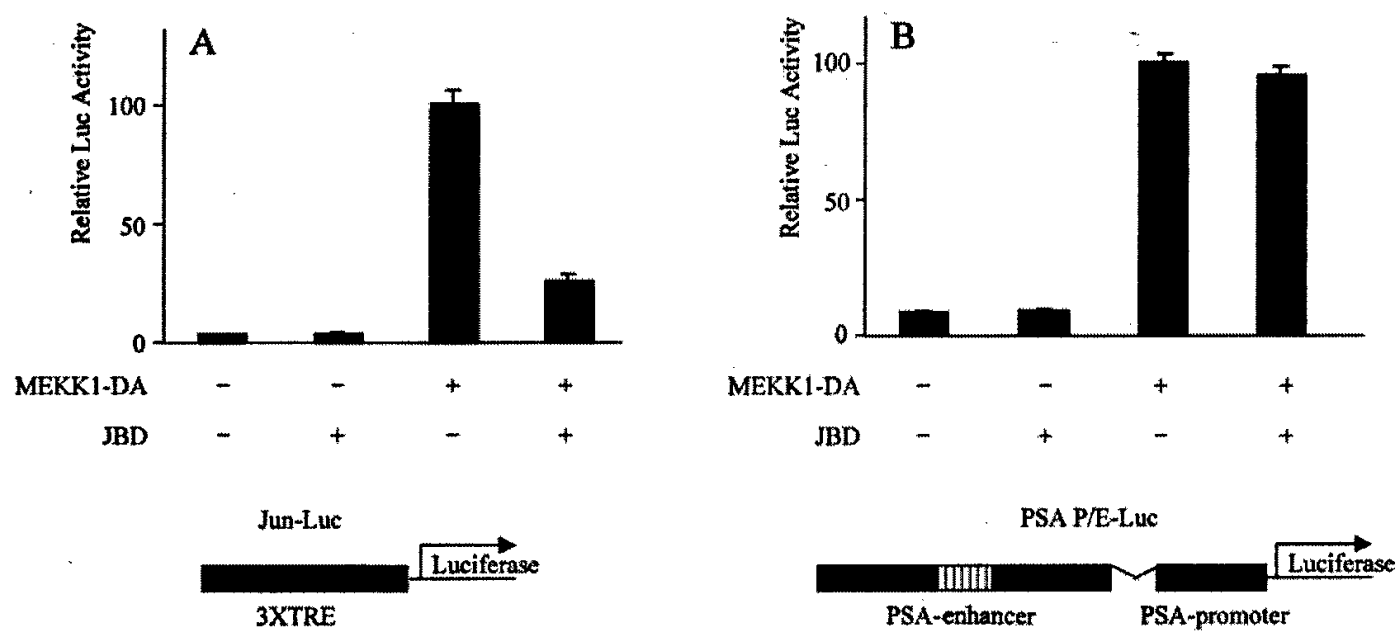

FIG. 1. JBD does not inhibit MEKK1-mediated activation of PSA. LNCaP cells were transfected with empty vector pcDNA3, JBD (500 ng), MEKK1-DA (400 ng), or JBD with MEKK1-DA, together with the reporter construct driven either by a Jun-responsive element (Jun-Luc; 200 ng) (A) or by PSA-P/E-Luc ( $200 \mathrm{ng}$ ) (B). Luciferase activity was measured 2 days after transfection and normalized by transfection efficiency, which was determined by GFP cotransfection. The data shown represent three experiments.

\footnotetext{
* Correspondent author. Mailing address: 11-934 Factor Building, UCLA-Hematology-Oncology, 10833 Le Conte Ave., Los Angeles, CA 90095-1678. Phone: (310) 206-5585. Fax: (310) 206-8502. E-mail: csawyers@mednet.ucla.edu.
} 

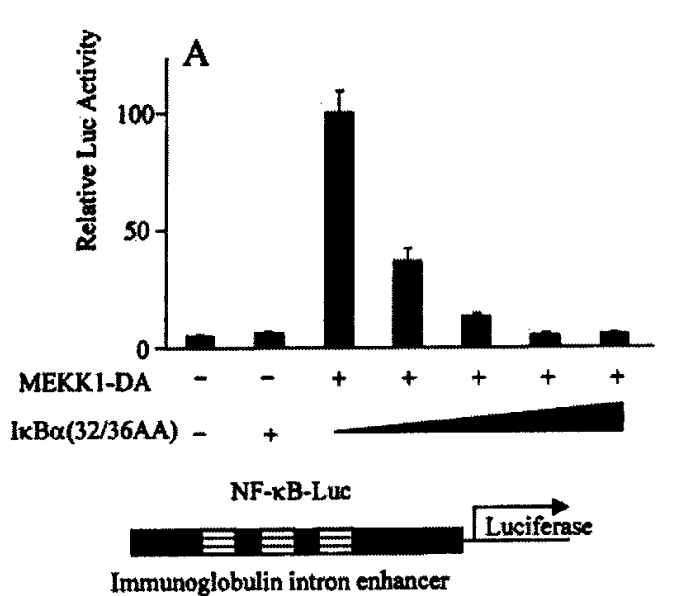

C

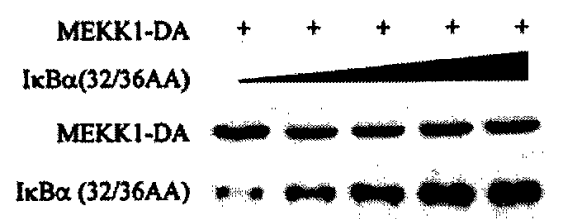

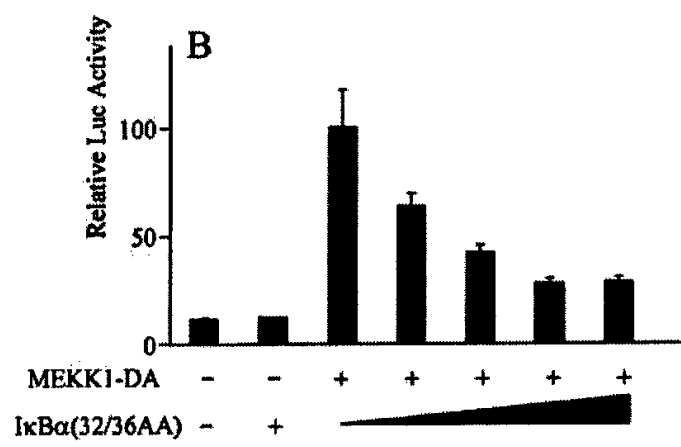

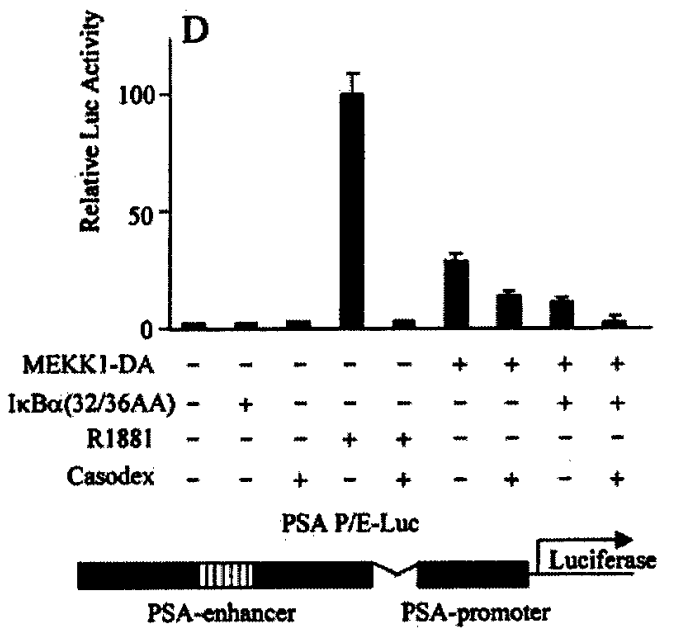

FIG. 2. Dominant-active IKB $\alpha$ mutant inhibits MEKK1-mediated activation of PSA. LNCaP cells were transfected with empty vector pcDNA3, the mutant form IKB $\alpha(32 / 36 \mathrm{AA})(800 \mathrm{ng})$, MEKK1-DA (300 ng), or MEKK1-DA with increasing amounts $(100,200,400$, and $800 \mathrm{ng})$ of the mutant form I $\mathrm{kB} \alpha(32 / 36 \mathrm{AA})$, together with the reporter construct driven either by an NF-kB-responsive element (NF-kB-Luc; $200 \mathrm{ng})(\mathrm{A})$ or by PSA-P/E-Luc (200 ng) (B and D). (C) Lysates from the transfected cells were examined for MEKK1-DA expression. Bicalutamide was used as indicated in the experiment whose results are shown in panel $D$. Luciferase activity was measured 2 days after transfection and normalized by transfection efficiency, which was determined by GFP cotransfection. The data shown represent three experiments.

this family, was originally identified as a proto-oncogene. The activity of these proteins is regulated primarily through posttranslational modification. In unstimulated cells, the NF-kB/ Rel proteins are sequestered in the cytoplasm by association with inhibitory proteins, termed inhibitor of NF-кB (IкB $\alpha$ and

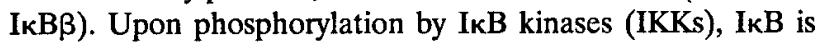
modified by ubiquitination and degraded, allowing NF- $\mathrm{KB}$ to translocate into the nucleus and activate target gene transcription (16).

Breast cancer studies have proposed a role for NF- $\kappa$ B in the progression of hormone-dependent cancers to hormone independence. Constitutive activation of NF-kB was found in estrogen receptor (ER)-negative breast cancer cell lines and poorly differentiated primary tumors (29). Progression of the rat mammary carcinoma cell line RM22-F5 from an ER-positive, nonmalignant phenotype to an ER-negative, malignant phenotype was accompanied by constitutive activation of NF-кB (29). The current data on prostate cancer are less certain. In the AI prostate cell lines PC-3 and DU-145, the DNA binding activity of NF- $\mathrm{KB}$ is constitutively activated whereas the androgen-sensitive prostate cancer cell line $\mathrm{LNCaP}$ has a low level of NF- $\mathrm{KB}$ binding activity (31). However, PC-3 and DU-145 do not express androgen receptor (AR) and PSA; therefore, the relevance of this finding to clinical AI prostate cancer progression is not clear. In a different set of studies, the RelA subunit of NF- $\mathrm{kB}$ was shown to inhibit $\mathrm{AR}$ function by competing for the coactivator CREB binding protein (CBP) $(1,32)$. This result suggests that $N F-\kappa B$ may play a negative role in $\mathrm{AI}$ progression since AR activation (not suppression) is associated with prostate cancer progression.

We have examined this issue in two xenograft models of AD-to-AI prostate cancer progression in which AR expression and PSA expression are retained $(8,23)$. We showed previously that mitogen-activated protein kinase kinase kinase 1 (MEKK1) activates PSA expression in prostate cancer cells (2). This activation is only partially abolished by the AR inhibitor bicalutamide (Casodex), suggesting that pathways other than AR may be involved in this activation. MEKK1 can activate Jun $\mathrm{N}$-terminal kinase (JNK) or IKB kinase (IKK), resulting in activation of the AP-1 or NF-kB transcription factor complex, respectively. In this report, we demonstrate that NF$\kappa B$, but not AP-1, is required for MEKK1 to fully activate PSA transcription. We also identify previously unrecognized NF-кB binding sites in the PSA enhancer and show that progression to 


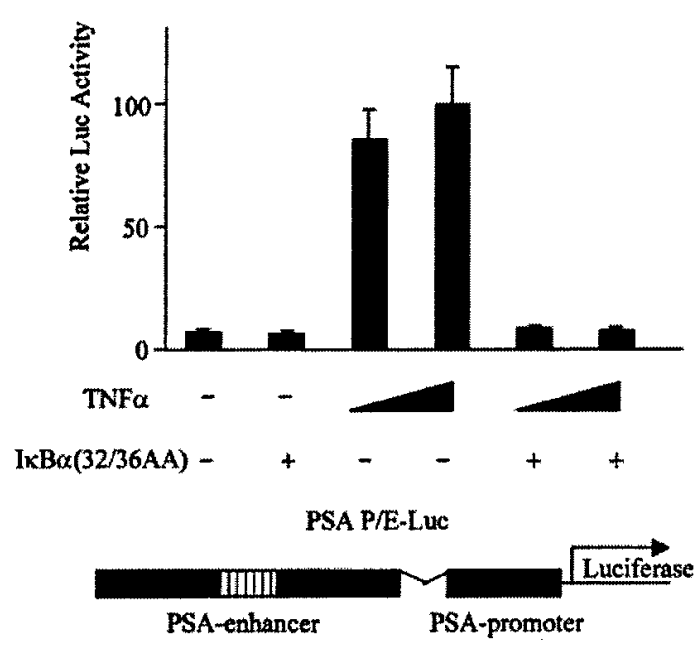

FIG. 3. TNF- $\alpha$ activates PSA expression through the NF- $k B$ pathway. LNCaP cells were transfected with the reporter construct PSA-

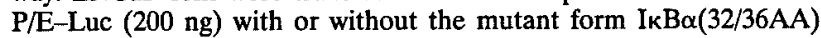
$(800 \mathrm{ng})$ as indicated. After transfection, cells were treated with or without TNF- $\alpha(10$ or $50 \mathrm{ng} / \mathrm{ml})$ as indicated. Luciferase activity was measured 2 days after transfection and normalized to Renilla luciferase. The data shown represent two experiments.

AI is associated with increased constitutive NF- $\mathrm{KB}$ binding activity in both xenograft models.

\section{MATERIALS AND METHODS}

Cell culture and xenograft. The human prostate cancer cell lines LNCaP and DU145 were obtained from the American Type Culture Collection and maintained in RPMI 1640 medium supplemented with $10 \%$ fetal bovine serum (FBS). For phorbol 12-myristate 13-acetate (PMA) and tumor necrosis factor alpha (TNF- $\alpha$ ) treatment, LNCaP cells were grown in the presence of $10 \%$ FBS overnight and subsequently in the absence of serum for 2 days. The serumstarved LNCaP cells were challenged with $5 \%$ charcoal-stripped FBS with or without PMA (10 ng/ml) or TNF- $\alpha(50 \mathrm{ng} / \mathrm{ml})$ overnight, and the media were subjected to enzyme-linked immunosorbent assay (ELISA; American Qualex) to determine PSA expression. The LAPC-4 and LAPC-9 xenograft models were established as previously described $(9,23)$ and maintained subcutaneously in mice. Progression to $\mathrm{AI}$ was modeled by castration of mice bearing $\mathrm{AD}$ tumors.

Plasmids. The cDNA of MEKK1-DA (MEKK1 dominant active) was subcloned into pcDNA3 as previously described (2). MEKK1-DA is a truncated form of MEKK1 in which the N-terminal 351 amino acids were deleted. The PSA promoter enhancer luciferase reporter (PSA-P/E-Luc) was constructed by inserting a 600 -bp fragment of the PSA promoter and a 2.4-kb enhancer sequence upstream of luciferase (pSE) as previously described $(2,9,33)$. Constructs containing mutations in the NF-KB binding sites on PSA-P/E-Luc were kindly provided by Michael Carey (University of California at Los Angeles) and were prepared as previously described (19). The I $\mathrm{k} \alpha \boldsymbol{\alpha}$ mutant contains amino acid substitutions of serines 32 and 36 to alanine. Plasmids encoding the IkB $\alpha$ mutant, p50, p65, and c-Rel were kindly provided by Genhong Cheng (University of California at Los Angeles).

Transfection. LNCaP or DU145 cells were plated at 40 to $50 \%$ confluency and transfected 1 day later in accordance with the manufacturer's instructions using TFX-50 (Promega) for LNCaP and Lipofectamine plus (Promega) for DU145. To minimize interference from androgen, transfected cells were maintained in RPMI 1640 medium supplemented with $5 \%$ charcoal-stripped serum. Two days after transfection, cells were harvested and the luciferase activity of the reporter constructs was measured with a luciferase assay kit or a dual luciferase assay kit (Promega). Luciferase activity was normalized to the percentage of green fluorescent protein (GFP)-positive cells in transfections that included pcDNA3enhanced GFP or to Renilla luciferase when the pRL-TK plasmid was used as the normalization control.
DNase I footprinting. Probes were created by PCR with the reporter plasmid PSA-P/E-Luc, which contains the PSA core enhancer, as a template. The 3' primers were ACCAGCTCAATCAGTCAC, CATGTTCACATTAGTACACC, AACCTGAGATTAGGAATCC, and TGAGAGAGATATCATCTTGC. The common $5^{\prime}$ primer was CGTTGAGACTGTCCTGCAG. The $3^{\prime}$ primers were end labeled by $\mathrm{T} 4$ polymerase kinase with $\left[\gamma^{32} \mathrm{P}\right] \mathrm{ATP}$, and each $3^{\prime}$ primer was combined with the common $5^{\prime}$ primer to $P C R$ amplify DNA probe for footprinting. The binding reactions for DNase footprinting were as previously described (13). The DNA was precipitated and resolved on a 6 to $8 \%$ polyacrylamide $-7 \mathrm{M}$ urea sequencing gel. Recombinant human p50 was purchased from Promega.

EMSAs. Concentrated nuclear extracts for electrophoretic mobility shift assays (EMSAs) were prepared as previously described (6). Nuclear extracts were diluted in buffer containing $2 \mathrm{mM}$ EDTA, $25 \mathrm{mM}$ HEPES (pH 7.5), $150 \mathrm{mM}$ $\mathrm{NaCl}, 1 \%$ Triton $\mathrm{X}-100$, and $10 \%$ glycerol. The wild-type and mutant doublestrand probes were purchased from Operon. They are GCCATGGGGGGATC CCCGAAGTCC and GCCATGGGCCGATCCCCGAAGTCC. The probes were end labeled by $\mathrm{T} 4$ polymerase kinase with $\left[\gamma^{32} \mathrm{P}\right] \mathrm{ATP}$. Diluted nuclear extracts were incubated with the indicated probe in the same buffer as for DNase I footprinting (13), except that glycerol was added to a final concentration of $1 \%$. Antibodies against NF-кB p50 (SC-114 X), p65 (SC-372-G), and AR (SC-816) were also incubated in supershift experiments. After $1 \mathrm{~h}$ of incubation, the reaction mixture was resolved in a $6 \%$ native polyacrylamide electrophoresis gel in buffer containing $0.5 \times$ Tris-borate-EDTA and $1 \%$ glycerol.

Western blot analysis. Nuclear extracts and cytoplasmic fractions of xenograft tumors were prepared as previously described (6). Western blot analysis was performed in accordance with standard procedures (35). The antibodies used in this study were SC-1643 against IKB $\alpha$, SC-945 against IKB $\beta$, SC-372-G against NF- $\mathrm{B}$ p 65 , SC-1190 against NF- $\kappa$ B p50 (Santa Cruz Biotechnology), and AC-15 against $\beta$-actin (Sigma).

\section{RESULTS}

NF-אB, but not AP-1, is required for MEKK1-mediated activation of the PSA-P/E. Previously, we demonstrated that a constitutively active form of MEKK1 (MEKK1-DA) induces AR-independent activation of the PSA promoter-enhancer (PSA-P/E) (2). To identify mechanisms responsible for this activation, we used dominant-negative mutant forms to examine downstream pathways of MEKK1.

An AP-1 binding site was previously identified in the PSA enhancer by sequence inspection (36). Because MEKK1 activates AP-1 through JNK, we asked if JNK is required for MEKK1-mediated induction of PSA. LNCaP cells were cotransfected with MEKK1-DA and JBD, a truncated form of JIP-1 that selectively inhibits JNK (11). In a titration experiment, the minimal dose of plasmid MEKK1-DA required to fully activate the PSA-P/E was defined (data not shown). Transfected cells were maintained in 5\% charcoal-stripped serum to minimize interference from androgen. As expected, MEKK1 stimulated transcription of a c-Jun-responsive element and the activation was inhibited by JBD (Fig. 1A). MEKK1-DA activated the PSA-P/E, but this activation could not be blocked by JBD (Fig. 1B). This result is consistent with our previous finding that JBD does not impair the effect of MEKK1 on prostate cancer cell survival (2) and suggests that AP-1 is not involved in MEKK1-mediated activation of PSA.

Another target of MEKK1 is IKK. MEKK1 activates IKK, which phosphorylates $I \kappa B$, leading to NF- $\mathbf{B}$ activation. To determine if NF-KB is involved in MEKK1-mediated activation of PSA, LNCaP cells were transfected with MEKK1-DA and a dominant-active form of $I_{\kappa} B \alpha$ containing alanine substitutions at serines 32 and 36 . These mutations prevent phosphorylation by IKK, thereby preventing NF- $\mathrm{KB}$ translocation to the nucleus to activate transcription. Cotransfection of the mutant IKB $\alpha$ 


\section{$\because \quad:$}

1.

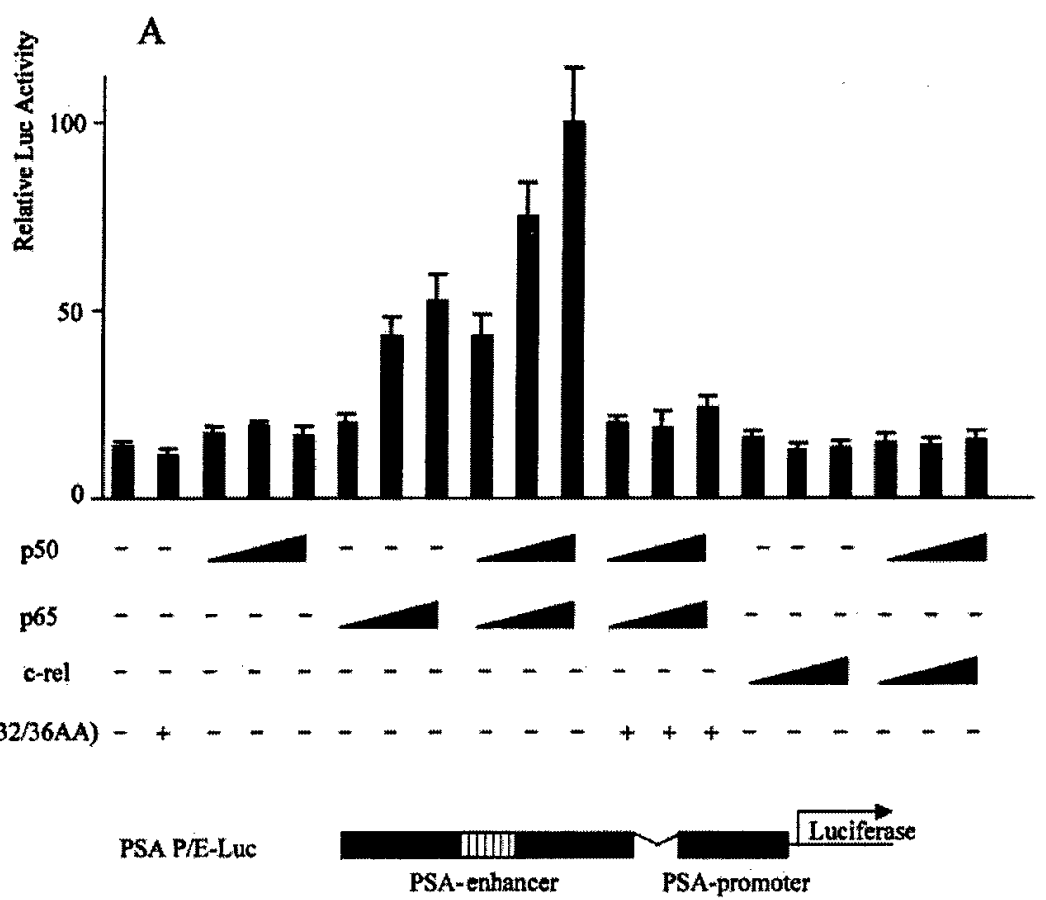

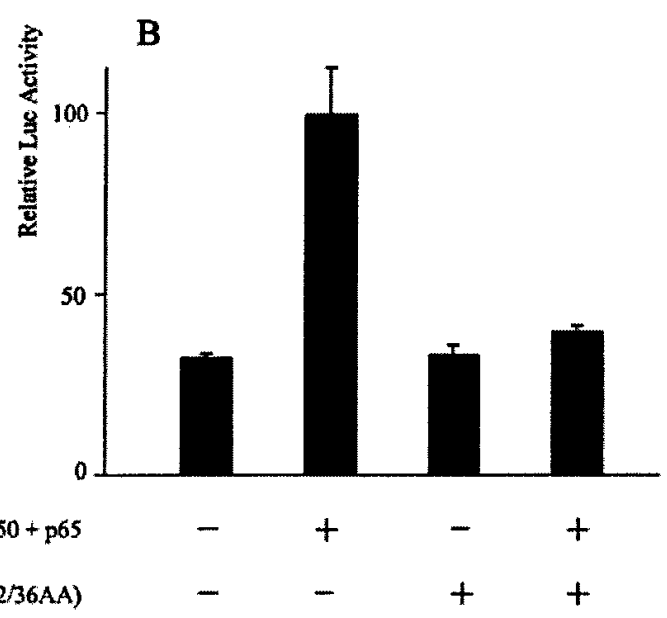

$1 \times B \alpha(32 / 36 \mathrm{AA})$

PSA P/E-LuC

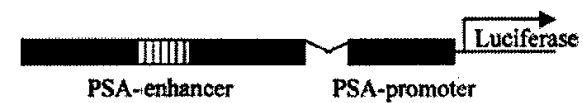

blocked the effect of MEKK-DA on an NF-kB-responsive element (Fig. 2A) and on the PSA-P/E (Fig. 2B) in a dosedependent manner. The expression level of MEKK-DA did not change when the mutant IкB $\alpha$ was cotransfected (Fig. 2C).

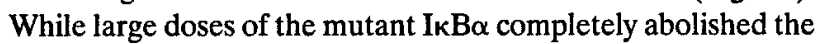
effect of MEKK1-DA on the NF-кB-responsive element (Fig. $2 \mathrm{~A}$ ), the maximal effect on the PSA-P/E was a reduction by $65 \%$ (Fig. 2B). However, PSA activation was completely abolished when both bicalutamide and the mutant IкB $\alpha$ were used
FIG. 4. Overexpression of NF-kB activated PSA expression, and the activation was abolished by mutant $\mathrm{I} \kappa B \alpha$. (A) LNCaP cells were transfected with the reporter construct PSA-P/E-Luc (200 ng) with increasing amounts of human p50 (p50) $(25,50$, and $100 \mathrm{ng}$ ), human p65 (p65) (25, 50, and $100 \mathrm{ng})$, a combination of p50 and p65, c-Rel $(25,50$, and $100 \mathrm{ng})$, or a combination of p50 and c-Rel and with or without the mutant form $I \kappa B \alpha(32 / 36 \mathrm{AA})$ ( $800 \mathrm{ng}$ ) as indicated. (B) DU145 cells were cotransfected with the reporter construct PSAP/C-Luc (200 ng) and p50 (50 ng) and p65 (50 ng) and with or without the mutant form IKB $\alpha(32 / 36 \mathrm{AA})(800 \mathrm{ng})$ as indicated. Luciferase activity was measured 2 days after transfection and normalized to Renilla luciferase. The data shown represent two experiments.

(Fig. 2D), consistent with our previous observation that MEKK1-DA also activates AR (2).

NF-kB activates the PSA-P/E. If NF- $\mathrm{KB}$ is required for transcriptional activation of PSA by MEKK1-DA, we reasoned

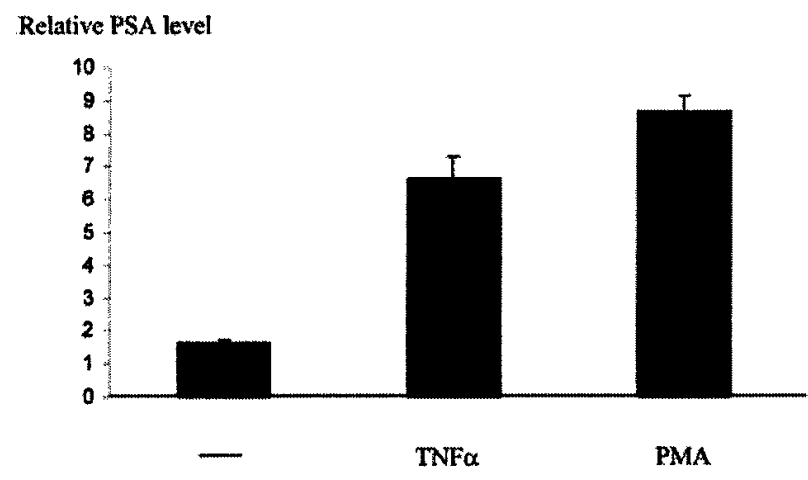

FIG. 5. TNF- $\alpha$ and PMA induce endogenous PSA expression. Serum-starved LNCaP cells were grown in 5\% charcoal-stripped FBS with or without TNF- $\alpha(50 \mathrm{nM})$ or PMA $(10 \mathrm{ng} / \mathrm{ml})$ overnight, and the media were subjected to ELISA to determine PSA expression. 
1.

A
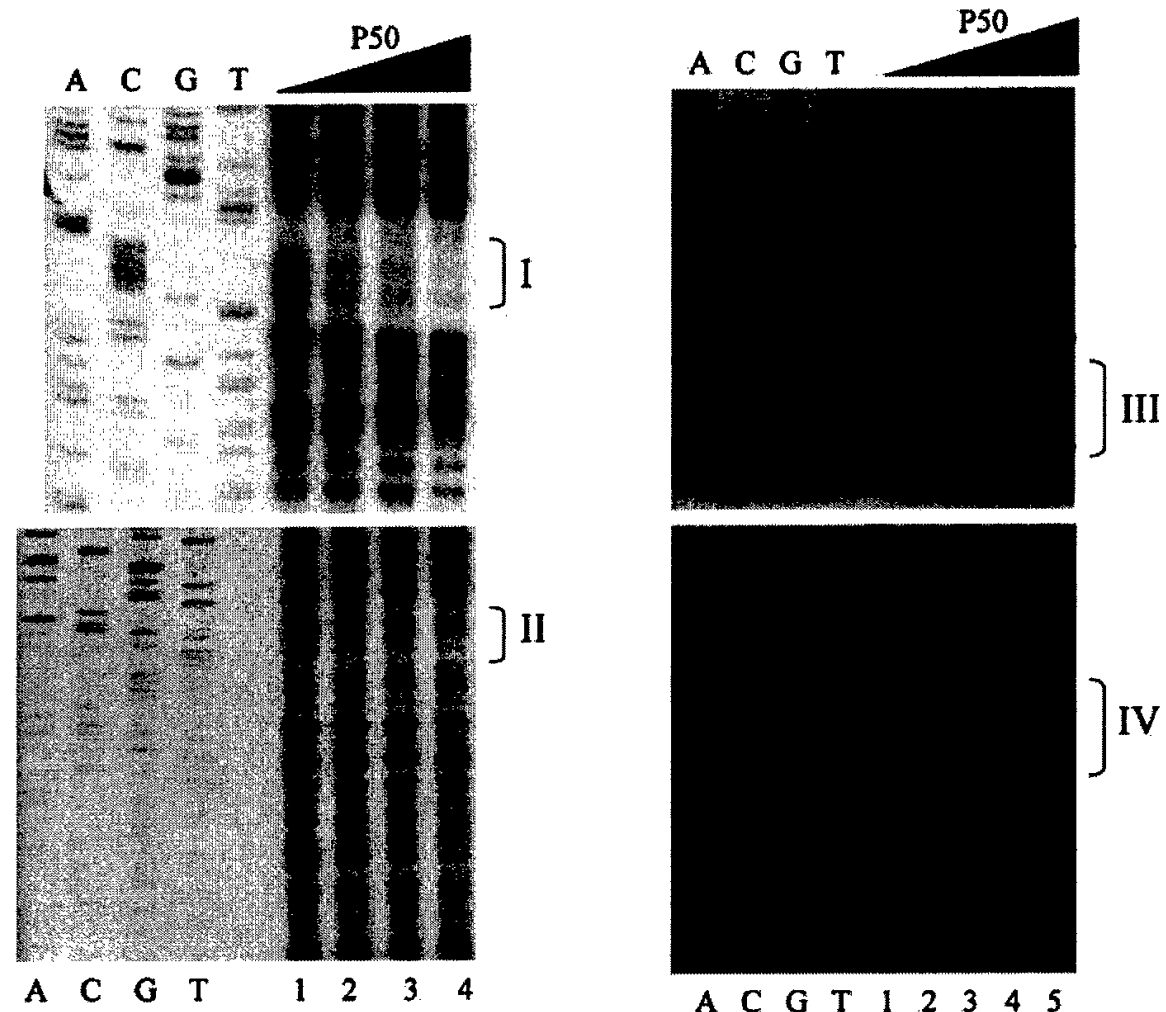

$\begin{array}{lllllllll}A & C & G & T & 1 & 2 & 3 & 4 & 5\end{array}$

B

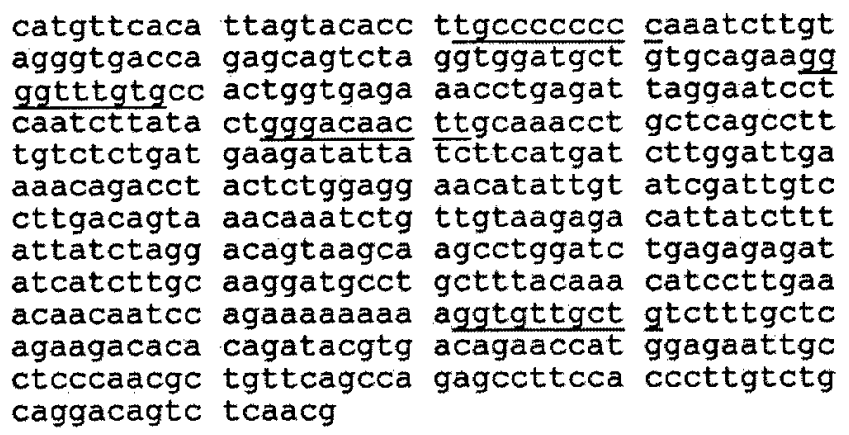

\section{NF-KB consensus sequence}

\section{GGGRNNYYCC}

Protected sites

GGGGGGggCa

I (reversed)

GGGGTIgtg

GGGACAaCt III

GGtGTTgCtg IV 



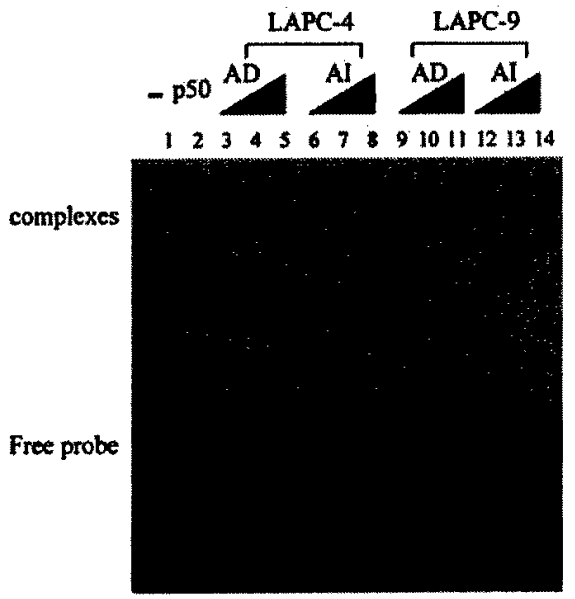

\section{B}

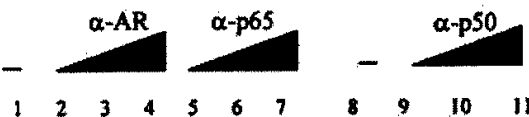

1234567

891011

\section{A}

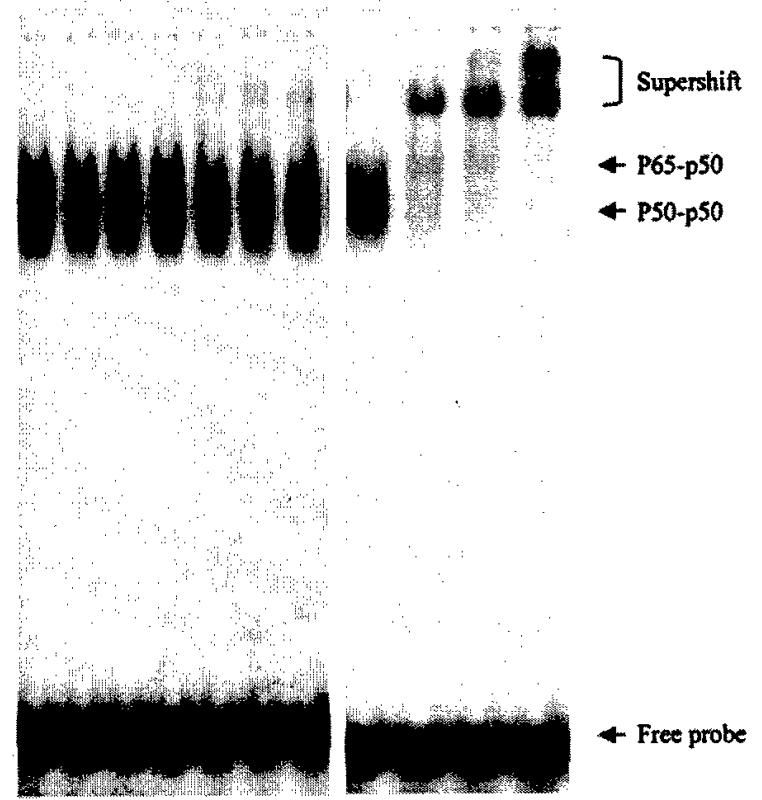

C

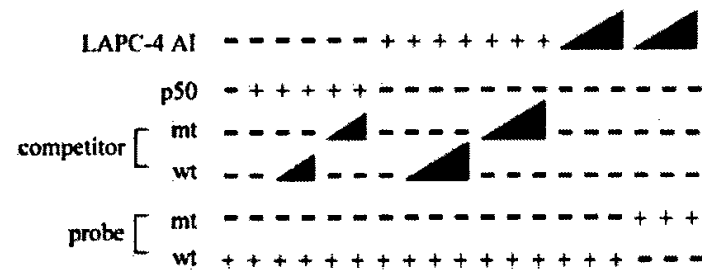

FIG. 7. AI tumors have a higher level of constitutive NF- $\mathrm{kB}$ binding activity than do $A D$ tumors. (A) Increasing amounts $(0.5,1.0$, and $2.0 \mu \mathrm{g}$ ) of nuclear extracts from both AD and AI LAPC-4 and LAPC-9 tumors were incubated with a ${ }^{32} \mathrm{P}$-labeled NF- $\mathrm{KB}$ binding sequence to detect NF-KB binding by gel shift analysis. The shifted complex and free probe are indicated. (B) Identity of the shifted complexes. Two micrograms of LAPC-4 AI tumor nuclear extract was incubated with a ${ }^{32} \mathrm{P}$-labeled NF-кB binding sequence with or without increasing amounts of antibodies against AR, p65, or p50. (C) Specificity of the shifted complexes. Shifted complexes (lane 2 ) formed by the recombinant p 50 protein were competed away by increasing amounts of the unlabeled wild-type (wt) probe (lanes 3 and 4) but not by the unlabeled mutant (mt) probe (lanes 5 and 6). LAPC-4 AI tumor nuclear extracts $(0.5,1.0$, and $2.0 \mu \mathrm{g}$ ) formed a band shift with the wild-type probe (lanes 14 to 16) and but not with the mutant probe (lanes 17 to 19). The band shift was competed away by increasing amounts of the unlabeled wild-type probe (lanes 8 to 10) but not by the unlabeled mutant probe (lanes 11 to 13). 
A

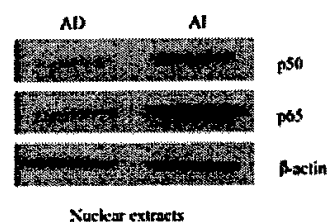

B

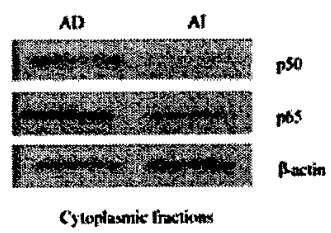

FIG. 8. Western blot analysis of NF-kB and IkB protein levels in LAPC-4 xenograft tumors. (A) Nuclear extracts were subjected to Western blot analysis with antibodies against p50 and p65. (B) Cytoplasmic fractions were subjected to Western blot analysis with antibodies against p50 and p65. (C) Cytoplasmic fractions were subjected to Western blot analysis with antibodies against I $\mathrm{B} \alpha$ and $\mathrm{I} \kappa \mathrm{B} \beta$.

The band shift pattern was similar to that of previous reports describing the $\mathrm{p} 65 / \mathrm{p} 50$ heterodimer and $\mathrm{p} 50 / \mathrm{p} 50$ homodimer complexes $(10,29,41)$. To confirm the identities of the shifted complexes, we performed antibody supershift experiments with nuclear extracts from LAPC-4 AI tumor tissue. Addition of p65 antibody caused the upper band to shift (Fig. 7B, lanes 5 to 7), and addition of p50 antibody shifted both complexes to higher positions in a dose-dependent fashion (Fig. 7B, lanes 9 to 11). The supershift was specific because antibody against an unrelated protein (AR) did not alter the mobility of the complexes (Fig. 7B, lanes 2 to 4 ). These results indicated that the upper complex contains the p65/p50 heterodimer and the lower band contains p50.

Binding specificity was determined by using nuclear extracts from LAPC-4 AI tumor tissue. One-half to two micrograms of nuclear extracts produced the band shift with the wild-type probe (Fig. 7C, lanes 14 to 17 ) but not with a mutant probe (Fig. 7C, lanes 17 to 19). The shifted complex was competed away by a 5 - to 80 -fold excess of unlabeled wild-type probe (Fig. 7B, lanes 8 to 10 ) but not by unlabeled mutant probe (Fig. $7 \mathrm{C}$, lanes 11 to 13 ). The wild-type, but not the mutant, competitor also competed away the shifted complex from recombinant p50 (Fig. 7C, lanes 2 to 6) with comparable efficiency. These results demonstrate an increase in constitutive NF- $k B$ binding activity during progression to androgen independence.

Nuclear accumulation of NF-кB correlates with its binding activity. To examine the mechanism for the elevated $N F-k B$ binding activity in the AI xenografts, we measured the levels of p50, p65, and $1 \times B$ in nuclear and cytoplasmic extracts of LAPC-4 AD and AI tumors. p50 and p65 protein levels were higher in nuclear extracts and lower in cytoplasmic extracts from AI tumors (Fig. 8A and B). Therefore, the higher NF- $\mathrm{BB}$ binding activity in LAPC-4 AI tumor tissue is associated with an increased concentration of NF- $\mathrm{KB}$ proteins in the nucleus. We also noted that the level of the $I_{\kappa} B \beta$ protein, but not that of the IKB $\alpha$ protein, was lower in cytoplasmic extracts from AI tumor (Fig. 8C), raising the possibility that an increased level of NF- $\mathrm{kB}$ in the AI tumor nucleus results from a decreased level of $\mathrm{I} K \mathrm{~B} \beta$ in the cytoplasm. A full understanding of the mechanism for increased NF- $\mathrm{KB}$ activity in these xenografts requires further study.

\section{DISCUSSION}

Our data from analysis of prostate cancer cell lines and xenografts support a role for NF-kB in prostate cancer progression. We demonstrate that $\mathrm{NF}-\mathrm{kB}$ regulates the expression of PSA, an important clinical marker of prostate cancer progression. We also show that NF-кB directly binds to the PSA core enhancer. By using matched $\mathrm{AD}$ and $\mathrm{AI}$ prostate cancers derived from two xenograft models, we demonstrated that $\mathrm{NF}-\kappa \mathrm{B}$ binding activity is upregulated in AI tumors.

Previous work has shown that NF-kB negatively regulates AR function. This conclusion is based on cotransfection studies showing that NF-kB and AR are mutually inhibitory due to competition for a common transcriptional coactivator, $\mathrm{CBP}(1$, 32). Because $\mathrm{AR}$ is activated in $\mathrm{AI}$ prostate cancer $(9,17,25)$, these findings imply an inhibitory role for NF- $\mathrm{kB}$ in prostate cancer progression. However, NF-KB inhibition of AR was observed when artificial promoters containing either consensus AR response element (ARE) or NF- $\mathrm{NB}$ binding sites were used. Natural promoters are more complex and typically contain cis-acting elements for different transcription factors. The PSA core enhancer studied here contains multiple low-affinity AREs that act synergistically (19). Among the four NF-kB binding sites we identified (Fig. 5B), three (I, II, and IV) are adjacent to AREs and NF- $\mathrm{KB}$ binding site III overlaps an ARE (19). These observations raise the possibility that cooperative NF- $\kappa B$ and AR binding contributes to PSA transcriptional regulation. Cooperation between nuclear receptors and NF-кB has been demonstrated in other systems $(1,5,21,32)$. For example, retinoid receptors and NF- $\mathrm{BB}$ synergistically induce ICAM-1 expression, which promotes metastasis potential (5). NF-kB and the aryl hydrocarbon receptor cooperate to activate c-myc expression in mammary cells (21).

The transition from $\mathrm{AD}$ to $\mathrm{AI}$ prostate cancer is a multistep process (8). AI cells must first survive androgen deprivation and then grow to become AI tumors. NF- $\kappa \mathrm{B}$ may participate in both processes. NF- $\mathrm{kB}$ is known to be a critical regulator of survival (3). p65/RelA knockout mice die from extensive liver apoptosis during embryogenesis (4). NF- $\mathrm{kB}$ also functions as a survival factor in neurons in response to cell injury through the upregulation of antiapoptotic genes (27). Accumulating evidence indicates that NF- $\mathrm{kB}$ also promotes proliferation. Inhibiting $\mathrm{NF}-\mathrm{kB}$ activation by dominant-negative p 65 blocks cell cycle progression in human glioma cells (30). Lymphocytes lacking p50, p65, or c-Rel show defective responses to mitogenic stimulation $(12,24,39,40)$. Inhibiting NF- $\mathrm{B}$ activation by $I_{\kappa} B \alpha$ expression, or by phenylarsine oxide, blocks focus formation in NIH 3T3 cells (15) and colony-forming cell proliferation of acute myelogenous leukemia cells (14). The proliferation-promoting effect of NF- $\mathrm{NB}$ may result from its ability to activate c-myc expression (22) and/or cyclin D1 expression $(18,34)$.

The link between NF- $\mathrm{B}$ activation and prostate cancer androgen independence may provide an opportunity for drug 
development. Therapeutic interventions might target upstream pathways that lead to activation of NF- $\mathrm{BB}, \mathrm{NF}-\mathrm{kB}$ itself, or downstream effectors that participate in cancer progression. Because NF-кB is involved in multiple signal transduction pathways, identification of the pathway(s) responsible for increased activity of NF-kB in AI progression will be of great interest.

\section{ACKNOWLEDGMENTS}

We thank Genhong Cheng for expression vectors of mutant IкB $\alpha$, p50, p65, and c-Rel, Michael Carey for wild-type and mutant PSA-P/ E-Luc reporters, and Katherine Ellwood for assistant in DNase I footprinting and EMSA. We also thank Ke Shuai, Mitch Gross, and Ingo Mellinghoff for critical reading of the manuscript.

This work was supported by a postdoctoral award from the DOD (C.D.C.) and by grants from the DOD, the NCI, and CaPCure (C.L.S.)

\section{REFERENCES}

1. Aarnisalo, P., H. Santti, H. Poukka, J. J. Palvimo, and O. A. Janne. 1999. Transcription activating and repressing functions of the androgen receptor are differentially influenced by mutations in the deoxyribonucleic acid binding domain. Endocrinology 140:3097-3105.

2. Abreu-Martin, M. T., A. Chari, A. A. Palladino, N. A. Craft, and C. L Sawyers. 1999. Mitogen-activated protein kinase kinase kinase 1 activates androgen receptor-dependent transcription and apoptosis in prostate cancer. Mol. Cell. Biol. 19:5143-5154.

3. Baldwin, A. S., Jr. 2001. Series introduction: the transcription factor NF+kB and human disease. J. Clin. Investig. 107:3-6.

4. Beg, A. A., W. C. Sha, R. T. Bronson, S. Ghosh, and D. Baltimore. 1995 Embryonic lethality and liver degeneration in mice lacking the RelA component of NF-кB. Nature 376:167-170.

5. Chadwick, C. C., L. J. Shaw, and R. C. Winneker. 1998. TNF- $\alpha$ and 9-cisretinoic acid synergistically induce ICAM-1 expression: evidence for interaction of retinoid receptors with NF-кB. Exp. Cell Res. 239:423-429.

6. Chen, C. D., and D. M. Helfman. 1999. Donor site competition is involved in the regulation of alternative splicing of the rat $\beta$-tropomyosin pre-mRNA. RNA 5:290-301.

7. Cleutjens, K. B., H. A. van der Korput, C. C. Ehren-van Eekelen, R. A. Sikes, C. Fasciana, L. W. Chung, and J. Trapman. 1997. A 6-kb promoter fragment mimics in transgenic mice the prostate-specific and androgen-regulated expression of the endogenous prostate-specific antigen gene in humans. Mol. Endocrinol. 11:1256-1265.

8. Craft, N., C. Chhor, C. Tran, A. Belldegrun, J. DeKernion, O. N. Witte, J. Said, R. E. Reiter, and C. L. Sawyers. 1999. Evidence for clonal outgrowth of androgen-independent prostate cancer cells from androgen-dependent tumors through a two-step process. Cancer Res. 59:5030-5036.

9. Craft, N., Y. Shostak, M. Carey, and C. L. Sawyers. 1999. A mechanism for hormone-independent prostate cancer through modulation of androgen re ceptor signaling by the HER-2/neu tyrosine kinase. Nat. Med. 5:280-285.

10. Davis, J. N., O. Kucuk, and F. H. Sarkar. 1999. Genistein inhibits NF-kB activation in prostate cancer cells. Nutr. Cancer 35:167-174.

11. Dickens, M., J. S. Rogers, J. Cavanagh, A. Raitano, Z. Xia, J. R. Halpern, M. E. Greenberg, C. L. Sawyers, and R. J. Davis. 1997. A cytoplasmic inhibitor of the JNK signal transduction pathway. Science 277:693-696.

12. Doi, T. S., T. Takahashi, O. Taguchi, T. Azuma, and Y. Obata. 1997. NF-кB RelA-deficient lymphocytes: normal development of $T$ cells and $B$ cells, impaired production of $\mathrm{IgA}$ and $\mathrm{IgG1}$ and reduced proliferative responses. J. Exp. Med. 185:953-961.

13. Ellwood, K., W. Huang, R. Johnson, and M. Carey. 1999. Multiple layers of cooperativity regulate enhanceosome-responsive RNA polymerase II transcription complex assembly. Mol. Cell. Biol. 19:2613-2623.

14. Estrov, Z., S. K. Manna, D. Harris, Q. Van, E. H. Estey, H. M. Kantarjian, M. Talpaz, and B. B. Aggarwal. 1999. Phenylarsine oxide blocks interleukin$1 \beta$-induced activation of the nuclear transcription factor NF-кB, inhibits proliferation, and induces apoptosis of acute myelogenous leukemia cells. Blood 94:2844-2853.

15. Finco, T. S., J. K. Westwick, J. L. Norris, A. A. Beg, C. J. Der, and A. S. Baldwin, Jr. 1997. Oncogenic Ha-Ras-induced signaling activates NF-kB transcriptional activity, which is required for cellular transformation. J. Biol. Chem. 272:24113-24116.

16. Ghosh, S., M. J. May, and E. B. Kopp. 1998. NF-кB and Rel proteins: evolutionarily conserved mediators of immune responses. Annu. Rev. Immunol. 16:225-260.

17. Gregory, C. W., R. T. Johnson, Jr., J. L. Mohler, F. S. French, and E. M. Wilson. 2001. Androgen receptor stabilization in recurrent prostate cancer is associated with hypersensitivity to low androgen. Cancer Res. 61:2892-2898.

18. Guttridge, D. C., C. Albanese, J. Y. Reuther, R. G. Pestell, and A. S. Baldwin,
Jr. 1999. NF-кB controls cell growth and differentiation through transcriptional regulation of cyclin D1. Mol. Cell. Biol. 19:5785-5799.

19. Huang, W., Y. Shostak, P. Tarr, C. Sawyers, and M. Carey. 1999. Cooperative assembly of androgen receptor into a nucleoprotein complex that regulates the prostate-specific antigen enhancer. J. Biol. Chem. 274:2575625768.

20. Keller, E. T., C. Chang, and W. B. Ershler. 1996. Inhibition of NF-kB activity through maintenance of $I_{\kappa} B \alpha$ levels contributes to dihydrotestosteronemediated repression of the interleukin-6 promoter. J. Biol. Chem. 271: $26267-26275$

21. Kim, D. W., L. Gazourian, S. A. Quadri, R. Romieu-Mourez, D. H. Sherr, and G. E. Sonenshein. 2000. The RelA NF-kB subunit and the aryl hydrocarbon receptor (AhR) cooperate to transactivate the c-myc promoter in mammary cells. Oncogene 19:5498-5506.

22. Kim, D. W., M. A. Sovak, G. Zanieski, G. Nonet, R. Romieu-Mourez, A. W. Lau, L. J. Hafer, P. Yaswen, M. Stampfer, A. E. Rogers, J. Russo, and G. E. Sonenshein. 2000. Activation of NF-KB/Rel occurs early during neoplastic transformation of mammary cells. Carcinogenesis 21:871-879.

23. Klein, K. A., R. E. Reiter, J. Redula, H. Moradi, X. L. Zhu, A. R. Brothman D. J. Lamb, M. Marcelli, A. Belldegrun, O. N. Witte, and C. L. Sawyers. 1997. Progression of metastatic human prostate cancer to androgen independence in immunodeficient SCID mice. Nat. Med. 3:402-408.

24. Kontgen, F., R. J. Grumont, A. Strasser, D. Metcalf, R. Li, D. Tarlinton, and S. Gerondakis. 1995. Mice lacking the c-rel proto-oncogene exhibit defects in lymphocyte proliferation, humoral immunity, and interleukin-2 expression. Genes Dev, 9:1965-1977.

25. Linja, M. J., K. J. Savinainen, O. R. Saramaki, T. L. Tammela, R. L. Vessella, and T. Visakorpi. 2001. Amplification and overexpression of androgen receptor gene in hormone-refractory prostate cancer. Cancer Res. 61:3550-3555.

26. Miyamoto, S., and I. M. Verma. 1995. Rel/NF- $\mathrm{BB} / \mathrm{\kappa B}$ story. Adv. Cancer Res. 66:255-292.

27. Moerman, A. M., X. Mao, M. M. Lucas, and S. W. Barger. 1999. Characterization of a neuronal $\mathrm{kB}$ binding factor distinct from NF- $\mathrm{kB}$. Brain Res. Mol. Brain Res. 67:303-315.

28. Muenchen, H. J., D. L. Lin, M. A. Walsh, E. T. Keller, and K. J. Pienta. 2000 Tumor necrosis factor- $\alpha$-induced apoptosis in prostate cancer cells through inhibition of nuclear factor-kB by an IkB $\alpha$ "super-repressor." Clin. Cancer Res. 6:1969-1977.

29. Nakshatri, H., P. Bhat-Nakshatri, D. A. Martin, R. J. Goulet, Jr., and G. W. Sledge, Jr. 1997. Constitutive activation of NF-kB during progression of breast cancer to hormone-independent growth. Mol. Cell. Biol. 17:3629 3639.

30. Otsuka, G., T. Nagaya, K. Saito, M. Mizuno, J. Yoshida, and H. Seo. 1999 Inhibition of nuclear factor- $\mathrm{kB}$ activation confers sensitivity to tumor necrosis factor- $\alpha$ by impairment of cell cycle progression in human glioma cells. Cancer Res. 59:4446-4452.

31. Palayoor, S. T., M. Y. Youmell, S. K. Calderwood, C. N. Coleman, and B. D. Price. 1999. Constitutive activation of IкB kinase $\alpha$ and NF-kB in prostate cancer cells is inhibited by ibuprofen. Oncogene 18:7389-7394.

32. Palvimo, J. J., P. Reinikainen, T. Ikonen, P. J. Kallio, A. Moilanen, and O. A. Janne. 1996. Mutual transcriptional interference between RelA and androgen receptor. J. Biol. Chem. 271:24151-24156.

33. Pang, S., J. Dannull, R. Kaboo, Y. Xie, C. L. Tso, K. Michel, J. B. deKernion, and A. S. Belldegrun. 1997. Identification of a positive regulatory element responsible for tissue-specific expression of prostate-specific antigen. Cancer Res. 57:495-499.

34. Rayet, B., and C. Gelinas. 1999. Aberrant rel/nfkb genes and activity in human cancer. Oncogene 18:6938-6947.

35. Sambrook, J., E. Fritsch, and T. Maniatis. 1989. Molecular cloning: a laboratory manual, 2nd ed. Cold Spring Harbor Laboratory Press, Cold Spring Harbor, N.Y.

36. Schuur, E. R., G. A. Henderson, L. A. Kmetec, J. D. Miller, H. G. Lamparski, and D. R. Henderson. 1996. Prostate-specific antigen expression is regulated by an upstream enhancer. J. Biol. Chem. 271:7043-7051.

37. Sen, R., and D. Baltimore. 1986. Inducibility of $\kappa$ immunoglobulin enhancer binding protein NF- $\mathrm{KB}$ by a posttranslational mechanism. Cell 47:921-928.

38. Sen, R., and D. Baltimore. 1986. Multiple nuclear factors interact with the immunoglobulin enhancer sequences. Cell 46:705-716.

39. Sha, W. C., H. C. Liou, E. I. Tuomanen, and D. Baltimore. 1995. Targeted disruption of the $\mathrm{p} 50$ subunit of NF- $\mathrm{kB}$ leads to multifocal defects in immune responses. Cell 80:321-330.

40. Snapper, C. M., P. Zelazowski, F. R. Rosas, M. R. Kehry, M. Tian, D. Baltimore, and W. C. Sha. 1996. B cells from p50/NF-kB knockout mice have selective defects in proliferation, differentiation, germ-line $\mathrm{CH}$ transcription, and Ig class switching. J. Immunol 156:183-191.

41. Van Antwerp, D. J., S. J. Martin, T. Kafri, D. R. Green, and I. M. Verma 1996. Suppression of TNF- $\alpha$-induced apoptosis by NF-кB. Science 274:787789.

42. Zabel, U., R. Schreck, and P. A. Baeuerle. 1991. DNA binding of purified transcription factor NF- $\mathrm{kB}$. Affinity, specificity, $\mathrm{Zn}^{2+}$ dependence, and differential half-site recognition. J. Biol. Chem. 266:252-260. 
- In Vivo Progression of LAPC-9 and LNCaP Prostate Cancer Models to Androgen Independence Is Associated with Increased Expression of Insulin-like Growth Factor I (IGF-I) and IGF-I Receptor (IGF-IR) ${ }^{1}$

\author{
Tara Nickerson, Francis Chang, Donald Lorimer, Steven P. Smeekens, Charles L. Sawyers, and Michael Pollak ${ }^{2}$ \\ Cancer Prevention Research Unit of the Jewish General Hospital and McGill University, Montreal, Quebec, H3T IE2 Canada [T. N., M. P.]; Department of Hematology- \\ Oncology, UCLA School of Medicine, Los Angeles, California, 90095-1678 [F. C., C. L. S.]; and Axys Pharmaceuticals, Inc., San Francisco, California 94080 [S. P. S., D. L.]
}

\begin{abstract}
Androgen deprivation therapies for metastatic prostate cancer are useful initially, but progression to androgen independence usually results in relapse within 2 years. The molecular mechanisms underlying the clinically important transition from androgen dependence to androgen independence are poorly described. Several lines of investigation have suggested that insulin-like growth factors (IGFs) are involved in the biology of prostate cancer, but little is known about their relevance to progression to androgen independence. We used three in vivo models of androgen-dependent (AD) human prostate cancer to study this issue. Progression to androgen-independent (AI) growth was associated with a 60-fold increase in expression of IGF-I mRNA in LAPC-9 xenografts and a 28-fold increase in IGF-I expression in LNCAP xenografts, relative to the initial AD neoplasms. IGF type I receptor (IGF-IR) mRNA levels were $\sim 2.5$-fold and $\sim 5$-fold higher, respectively, in AI LAPC-9 and LNCaP tumors compared with the original AD neoplasms. AI growth of these renografts was also associated with significant reductions in IGF binding protein-3 expression. LAPC-4 xenografts, which previously have been shown to exhibit molecular pathology related to HER-2/neu expression with progression to AI, showed relatively minor changes in expression of the genes investigated, but we nevertheless found evidence of increased IGF-IR phosphorylation with progression to androgen independence in this model. Taken together with prior observations, our results suggest that deregulation of expression of genes related to any one of several critical receptor tyrosine kinase regulatory systems, including IGF signaling, may confer androgen independence.
\end{abstract}

\section{INTRODUCTION}

$\mathrm{AD}^{3}$ prostate cancer can be treated with androgen deprivation strategies such as castration or antiandrogens, but progression to $\mathrm{AI}$ cancer, for which there are no satisfactory treatments, usually occurs. There is a clear need to identify molecular targets for novel therapeutic approaches to either prevent the progression of prostate cancer to androgen independence or to treat AI cancers.

Study of the molecular mechanisms associated with progression to androgen independence has been limited by the availability of suitable models. The work we report here is based on three human prostate cancer models of in vivo progression to androgen independence, LAPC-9, LNCaP, and LAPC-4. The recently described LAPC-9 model is a human prostate cancer xenograft that requires androgens for growth in SCID mice, secretes PSA, and expresses a normal

Received 8/13/00; accepted 6/15/01.

The costs of publication of this article were defrayed in part by the payment of page charges. This article must therefore be hereby marked advertisement in accordance with 18 U.S.C. Section 1734 solely to indicate this fact.

1 Supported by grants from the National Cancer Institute of Canada (to M. P.) and from the National Cancer Institute, Department of Defense, and CapCURE (to C. L. S.) C. L. S. is a Leukemia Society of America scholar.

${ }^{2}$ To whom requests for reprints should be addressed, at Lady Davis Institute for Medical Research, 3755 Cote Ste Catherine Road, Montreal, Quebec, H3T 1E2 Canada Phone: (514) 340-8222, extension 5527; Fax: (514) 340-8302; E-mail: michael. pollak@mcgill.ca.

${ }^{3}$ The abbreviations used are: $\mathrm{AD}$, androgen dependent; $\mathrm{AI}$, androgen independent PSA, prostate-specific antigen; SCID, severe combined immunodeficient; IGFBP, IGF binding protein; IGF-I, insulin-like growth factor type I; IGF-IR, IGF-I receptor; RT-PCR, reverse transcription-PCR. androgen receptor. LAPC-9 tumor cells enter a dormant state in response to castration of the host, and a subset of tumors resumes growth with an AI phenotype after prolonged androgen deprivation (1). The LNCaP model is an androgen-sensitive, PSA-secreting, immortalized prostate cancer cell line (2). A mutation in the hormonebinding domain of the androgen receptor has been demonstrated in LNCaP cells (3). LNCaP cells readily form tumors in SCID mice when co-injected with Matrigel and are associated with serum PSA levels that are directly proportional to tumor volume in intact hosts (4). After castration, the growth of LNCaP tumors is arrested, and serum PSA levels decrease significantly. Although this aspect of the model has been studied in some detail, less attention has been given to the finding that prolonged androgen deprivation leads to AI growth of LNCaP tumors, which is accompanied by PSA production similar to precastrate levels (5). The LAPC-4 human prostate cancer xenograft model has been used previously to study molecular changes associated with transition from $\mathrm{AD}$ to $\mathrm{AI}$ growth $(6,7)$.

IGF-I has well-characterized mitogenic and antiapoptotic effects that are mediated through the IGF-IR $(8,9)$. Ligand-receptor interactions are modulated by a family of high-affinity IGFBPs (reviewed in Ref. 10). There is considerable evidence from both laboratory and population studies that IGF physiology is relevant to prostate cancer. For example, it has been shown that both normal prostate epithelial cells and prostate cancer cells exhibit IGF responsiveness in vitro (11, 12), that IGF-IR inhibition inhibits prostate cancer cell proliferation (13), and that overexpression of IGF-I in prostate epithelial cells in a transgenic model leads to transformation (14). We (15) and others (16, 17) have demonstrated in prospective studies that a positive correlation exists between circulating IGF-I concentration in healthy men and risk of subsequent prostate cancer. This finding is consistent with results from many (but not all) case-control studies (reviewed in Refs. 18, 19).

A precedent for the importance of peptide growth factors in progression of prostate cancer to androgen independence is provided by the association of androgen independence in LAPC-4 human tumor xenografts with overexpression of HER-2/neu, a tyrosine kinase receptor activated by ligands in the epidermal growth factor family $(6,7)$. The evidence that both epidermal growth factor and IGF-I can directly activate the androgen receptor in the absence of androgens $(20,21)$ raises the possibility that IGF receptor signaling may also be involved in progression of prostate cancer to androgen independence. We undertook experiments to determine whether progression to $\mathrm{AI}$ growth in vivo is related to changes in expression of genes encoding key molecules involved in IGF signaling.

\section{MATERIALS AND METHODS}

Tumor Xenografts. The LAPC-4 and LAPC-9 xenografts were derived as described $(1,6)$. The clinical material was minced into 2 -mm chunks and implanted with $200 \mu \mathrm{l}$ of Matrigel (Collaborative Research, Bedford, MA) s.c. into male SCID mice. After initial tumor formation, tumors were harvested, minced, and reimplanted into SCID mice. The $\mathrm{LNCaP}$ xenograft was derived from the LNCAP cell line obtained from American Type Culture Collection, 
which was injected $\left(1 \times 10^{6}\right.$ cells $)$ with Matrigel into flanks of male SCID mice. Once tumors formed, the tumors were serially passaged into male mice as described for the LAPC-9 xenograft.

AD xenografts were removed from mice either before or after castration or after acquiring an AI phenotype, and mRNA was extracted for quantification of mRNA abundance by quantitative RT-PCR and Northern blotting as described previously (22).

Quantitative RT-PCR. Quantitative RT-PCR was performed using TaqMan technology. First-strand cDNA was synthesized from $5 \mu \mathrm{g}$ of total RNA. PCR reactions $(50 \mu \mathrm{l})$ were performed in a buffer containing $50 \mathrm{mM} \mathrm{KCl}, 10$ mM Tris-HCl, $10 \mathrm{mM}$ EDTA, $5 \mathrm{~mm} \mathrm{MgCl}, 200 \mu \mathrm{m}$ each of dATP, dCTP and dGTP, $400 \mu \mathrm{M}$ dUTP, $300 \mu \mathrm{M}$ each of forward and reverse primers, $200 \mu \mathrm{M}$ probe, 1.25 units of AmpliTaq Gold, 0.5 unit of uracil- $N$-glycosylase and $\sim 150$ ng of cDNA. Primers and probes were designed using Primer Express (ABI-Perkin-Elmer) and are listed in Table 1. Thermal cycling was performed using an ABI-7700 under the following reaction conditions: $50^{\circ} \mathrm{C}$ for $2 \mathrm{~min}$, $95^{\circ} \mathrm{C}$ for $10 \mathrm{~min}$, followed by 40 cycles of $95^{\circ} \mathrm{C}$ for $15 \mathrm{~s}$ and $60^{\circ} \mathrm{C}$ for $60 \mathrm{~s}$. Data were normalized to rRNA and calculated as described (23). Changes in gene expression patterns were confirmed by Northern blot analysis. Control studies were carried out to demonstrate assay reproducibility by showing similar results from multiple RNA samples derived from a single tissue sample.

Western Blotting. Cell culture and tumor lysates were prepared with $1 \%$ Triton buffer [12.5 mM EDTA (pH 8.0), $25 \mathrm{~mm}$ HEPES (pH 7.5), $150 \mathrm{~mm}$ $\mathrm{NaCl}, 1 \%$ Triton $\mathrm{X}-100$, and $1 \%$ glycerol) with protease and phosphatase inhibitors. The antibodies used were rabbit anti-IGF-IR (1:1000; Santa Cruz Biotechnology, Inc. Santa Cruz, CA), rabbit anti-IRS-1 (1:100; Santa Cruz Biotechnology), and mouse anti- $\beta$-actin (1:2000; Promega Corp., Madison, WI). Phosphotyrosine was detected with mouse antibody 4G10 (1:2000; Upstate Biotechnologies, Inc., Lake Placid, NY). RIG cells (Rat-1 fibroblasts overexpressing IGF-IR) were a kind gift of Michael Weber (University of Virginia Health Sciences Center, Charlottesville, VA).

\section{RESULTS}

In Vivo Progression to Androgen Independence. We confirmed that LAPC-9 tumor xenografts (1) grow readily in intact SCID mice, remain static after castration, and in some cases eventually develop an AI phenotype associated with growth in castrated mice (Fig. 1). Similar observations have been reported for the LAPC-4 and LNCaP models (5-7).

Changes in Expression of IGF-I, IGF-II, and IGF-IR Associated with Progression to Androgen Independence. Castration resulted in decreased $I G F-I$ gene expression in AD LAPC-9 tumors, with mRNA levels dropping to $\sim 10 \%$ of control (Fig. $2 A$ ). Emergence of AI growth of LAPC-9 tumors was associated with a dramatic increase in $I G F-I$ gene expression. IGF-I mRNA in AI LAPC-9

Table 1 Sequences of primers/probes used for quantitative RT-PCR

The primers and probes were designed with Primer Express (ABI-Perkin-Elmer) using the Genbank Accession number, which appears in parentheses.

\begin{tabular}{lll}
\hline \multicolumn{1}{c}{ Gene } & & \multicolumn{1}{c}{ Oligonucleotide sequence } \\
\hline$I G F-I$ (M27544) & Forward & 5'-AAGTCAGCTCGCTCTGTCCG-3' \\
& Reverse & 5'-TTCCTGCACTCCCTCTACTTGC-3' \\
& Probe & 5'-TCTGGGTCTTGGGCATGTCGGTGT-3' \\
IGF-IR (X04434) & Forward & 5'-GTGAAAGTGACGTCCTGCATTTC-3' \\
& Reverse & 5'-CCTTGTAGTAAACGGTGAAGCTGA-3' \\
& Probe & 5'-CACCACCACGTCGAAGAATCGCATC-3' \\
IGFBP-3 (X64875) & Forward & 5'-CGCCAGCTCCAGGAAATG-3' \\
& Reverse & 5'-GCATGCCCTTCTTGATGATG-3' \\
& Probe & 5'-CAGCACGCACCGGGTGTCTGATC-3' \\
IGFBP-5 (M62782) & Forward & 5'-AAAGAGCTACCGCGAGCAAG-3' \\
& Reverse & 5'-GGAGATGCGGGTGTGTTTG-3' \\
& Probe & 5'-ACGAGGAGCCCACCACCTCTGAGA-3' \\
& Forward & 5'-CGGCTACCACATCCAAGGAA-3' \\
rRNA $(\mathrm{M10098)}$ & Reverse & 5'-GCTGGAATTACCGCGGCT-3' \\
& Probe & 5'-TGCTGGCACCAGACTTGCCCTC-3' \\
\end{tabular}

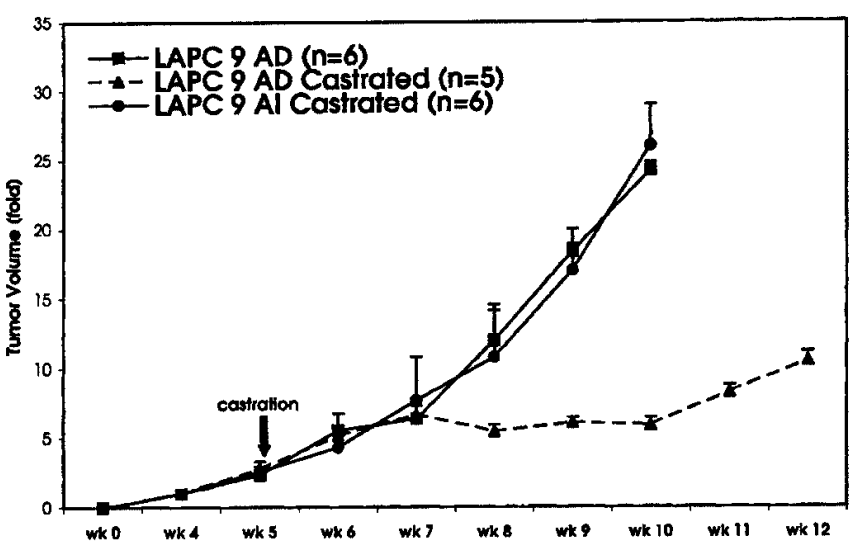

Fig. 1. Growth of AD and AI LAPC-9 tumor xenografts. LAPC-9 xenografts were established as described in "Materials and Methods." The growth of AD LAPC-9 tumors in intact mice is shown plotted as means; bars, SE. Some animals were castrated 5 weeks after tumor implantation (arrow), and the growth of $\mathrm{AD}$ and $\mathrm{AI}$ tumors after castration is shown.

tumors is $\sim 60$-fold higher than the level in $\mathrm{AD}$ tumors, as determined by quantitative RT-PCR (Fig. $2 A$ ). Northern blot analysis of the same RNA confirmed a significant increase in IGF-I mRNA abundance. Progression to androgen independence in LAPC-9 tumors was also accompanied by a $\sim 2.5$-fold increase in $I G F-I R$ mRNA abundance relative to that in AI tumors (Fig. $2 B$ ).

The effects of castration on expression of IGF-I and its receptor in LNCaP tumor xenografts were remarkably similar to those observed in the LAPC-9 model. IGF-I mRNA decreased to $<40 \%$ of control values in $\mathrm{LNCaP}$ tumors within 2 weeks after castration, whereas $\mathrm{AI}$ $\mathrm{LNCaP}$ tumors were found to have $\sim 28$-fold higher $I G F-I \mathrm{mRNA}$ levels than AD control tumors (Fig. 2A). IGF-IR gene expression increased $\sim 5$-fold in $\mathrm{AI} \mathrm{LNCaP}$ tumors compared with $\mathrm{AD}$ tumors (Fig. 2B).

In contrast, progression to androgen independence in the LAPC-4 model was not associated with major increases in expression of $I G F-I$ (Fig. 2A). IGF-IR mRNA levels decreased to $\sim 15 \%$ of control after castration and remained low in AI tumors (Fig. $2 B$ ).

$I G F-I I$ mRNA levels in LAPC-9, LNCaP, and LAPC-4 xenografts were also quantitated by RT-PCR. AI growth of LNCaP tumors was associated with up-regulation of $I G F-I I \mathrm{mRNA}$, with levels $\sim 5$-fold higher than control. No difference in IGF-II mRNA level was observed between AD and AI tumors in the LAPC-9 or LAPC- 4 models (data not shown).

Fig. $3 A$ shows that the $\sim 5$-fold increase in $I G F-I R$ mRNA abundance associated with acquisition of $\mathrm{Al}$ in the $\mathrm{LNCaP}$ model is associated with an increase in IGF-IR expression at the protein level. Neither the $\sim 2.5$-fold increase in $I G F-I R$ mRNA abundance in the LAPC-9 model nor the decrease in IGF-IR mRNA in the LAPC-4 model were associated with a detectable change in IGF-IR protein level, as estimated by Western blot (Fig. $3 A$ ). Interestingly, however, phosphotyrosine immunoblots of LAPC-4 AI xenografts showed an increase in tyrosine phosphorylation of IGF-IR relative to $A D$ LAPC-4 (Fig. 3B). Lysates immunoprecipitated with IGF-IR and blotted with anti-phosphotyrosine $4 \mathrm{Gi} 10$ antibody confirm this observation. Upon ligand binding and activation, IGF-IR autophosphorylates cytoplasmic tyrosine residues. The observation that LAPC-4 AI tumors have increased phosphorylation but decreased expression of IGF-IR suggests that IGF signaling pathway may be up-regulated in LAPC-4 AI tumors relative to the AD LAPC-4 tumors.

One of the main signaling effectors of IGF-IR is IRS-1. LNCaP has been shown recently to lack IRS-1 expression along with lack of PTEN expression (24). Surprisingly, IRS-1 could not be detected in 
(A) IGF-I

LAPC-9 Tumors

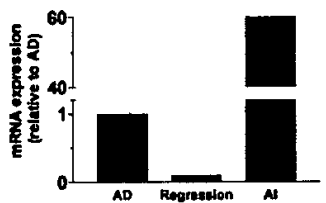

LNCaP Tumors

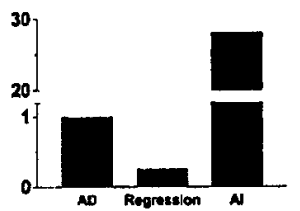

LAPC-4 Tumors

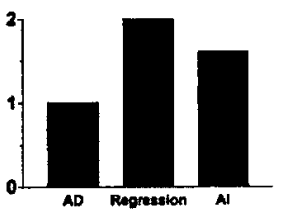

(B) IGF-IR

LAPC-9 Tumors

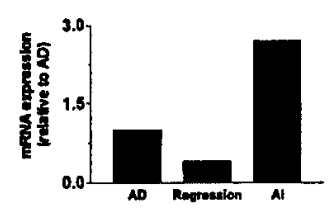

(C) IGFBP-3 malized to levels of rRNA and are shown expressed relative to expression in AD tumors at day 0. Quantitation of gene expression was repeated on at least three separate tumors derived from independent experiments and yielded similar results. Regression, AD tumors 14 days after castration. IGFBP-3 $(C$, and IGFBP-5 $(D)$ in prostate tumor xenografts after castration. Quantitative RT-PCR was used to measure mRNA levels in tumors at was used to measure mRNA levels in tumors at
various times after castration. Gene expression was various times after castration. Gene expression was
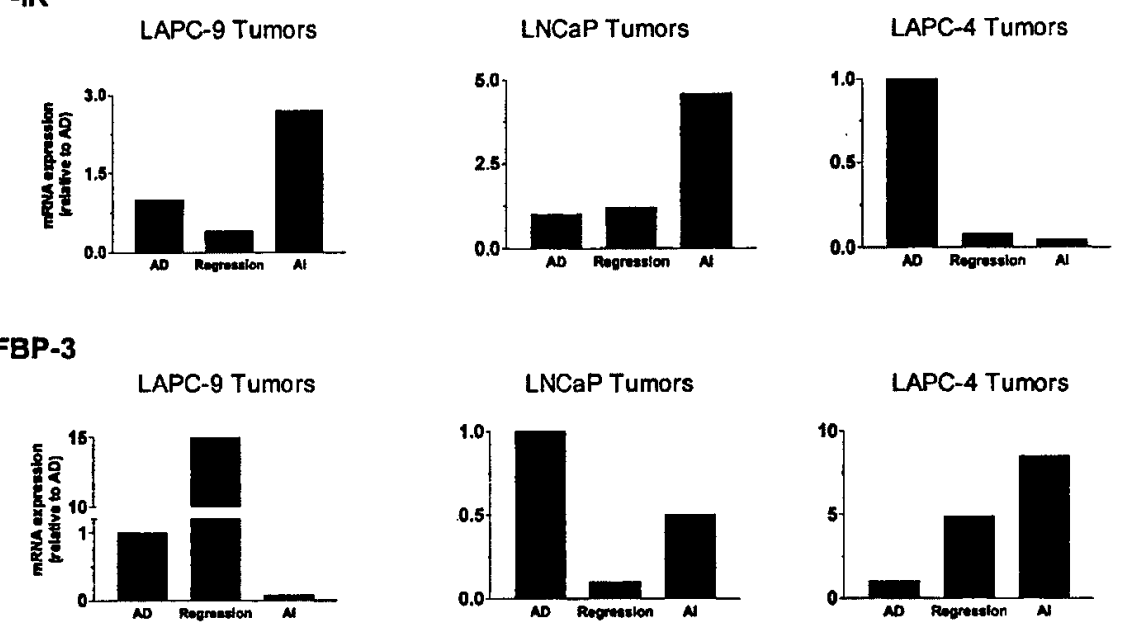

(D) IGFBP-5

LAPC- 9 Tumors

LNCaP Tumors

LAPC-4 Tumors
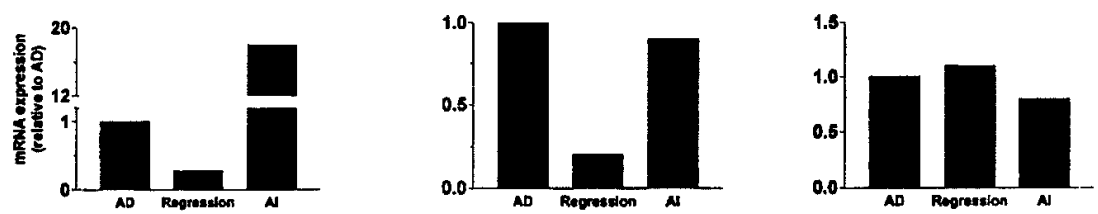

LAPC-4 and LAPC-9 xenografts either (Fig. 3C). In addition, IRS-1 mRNA was undetectable in these xenografts by oligonucleotide microarray analysis (data not shown). This suggests that IGF-IR substrates other than IRS-1 may be important in prostate cancer.

Changes in Expression of IGFBPs Associated with Progression to Androgen Independence. IGFBP-3 mRNA levels in LAPC-9 tumors increased $\sim 15$-fold by 14 days after castration, consistent with our prior results $(22,25)$. With emergence of androgen independence, however, $I G F B P-3 \mathrm{mRNA}$ abundance decreased to $<20 \%$ of levels present in AD tumors (Fig. 2C). In contrast, AI LAPC-9 tumors expressed $\sim 18$-fold higher IGFBP-5 mRNA than AD tumors (Fig. $2 D$ ).

The findings concerning IGFBP expression in the LNCaP model were different in some respects to those seen in the LAPC-9 system. In the LNCaP model, IGFBP-3 mRNA was relatively abundant in $\mathrm{AD}$ tumors and decreased to $\sim 15 \%$ of control by 14 days after castration (Fig. 2C). At the time of progression to an AI phenotype, a reduction in IGFBP-3 expression compared with control was seen (as in the LAPC-9 model). Relatively minor changes in IGFBP-5 gene expression with progression to AI were observed in the LNCaP model (Fig. 2D).

In contrast to the decrease in $I G F B P-3$ expression observed during progression to androgen independence in the LAPC-9 and LNCaP models, AI LAPC-4 tumors expressed $\sim 8$-fold higher levels of $I G$ $F B P-3$ mRNA than AD tumors (Fig. $2 C$ ). Androgen independence in the LAPC-4 model was not associated with significant changes in IGFBP-5 expression (Fig. $2 D$ ).

$I G F B P-2$ mRNA levels were $\sim 10$-fold higher in AI LNCaP tumors compared with $\mathrm{AD} \mathrm{LNCaP}$ tumors, and no changes in IGFBP-2 were observed in either the LAPC-9 or LAPC-4 model (data not shown). We also measured mRNA levels of IGFBPs 1, 4, and 6 in AI LAPC-9, LNCaP, and LAPC-4 xenografts but found no significant differences in gene expression compared with AD tumors (data not shown).

\section{DISCUSSION}

Our major finding is that progression of both LAPC-9 and LNCaP tumors to AI growth after castration is associated with a major increase in $I G F-I$ gene expression in the neoplastic tissue. AI growth in these tumor models is also associated with up-regulation of $I G F-I R$ gene expression and decreased expression of IGFBP-3. These changes could contribute to increased IGF bioactivity in the tumor microenvironment. This in turn could contribute to androgen independence by androgen receptor-independent changes related to hyperstimulation of the signaling pathways distal to the IGF-IR and/or by mechanisms related to IGF-mediated activation of the androgen receptor (20).

It seems plausible that increased IGF signaling, which is associated with mitogenic and antiapoptotic effects in most experimental systems $(8,9)$, could be a mechanism that would enable prostate cells to 


\section{$\because \cdots$

A

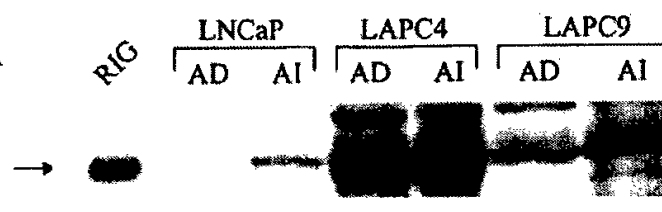

IGF-IR

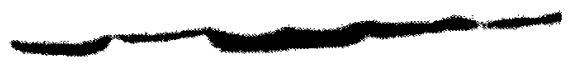

B-actin

B

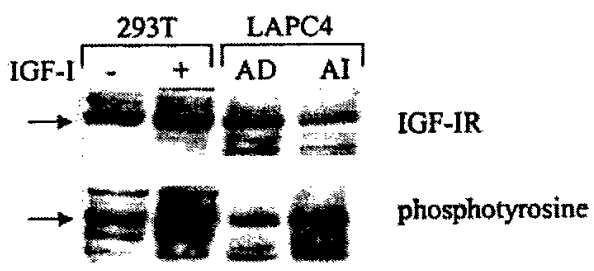

$\mathrm{C}$

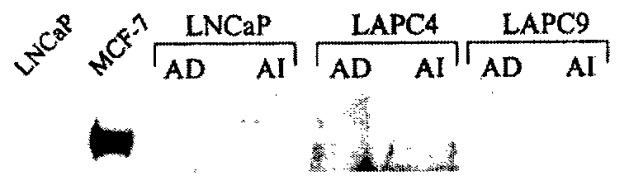

IRS-1

B-actin

Fig. 3. Western blots for IGF-IR and IRS-1 expression in human prostate xenografts. $A$, IGF-IR Western blots for positive control RIG cells (Rat-1 fibroblasts engineered to overexpress IGF-IR) and lysates from different xenografts. $\beta$-actin staining of each lane was used as loading control. $B$, IGF-IR and phosphotyrosine Western blots for LAPC-4 xenografts. 293T cell cultures were serum starved and then exposed to vehicle or to 500 $\mathrm{ng} / \mathrm{ml}$ IGF-I and served as negative and positive controls, respectively. $C$, IRS-1 Western blots for xenografts. LNCaP and MCF-7 cell cultures were used as negative and positive controls, respectively. $\beta$-actin staining of each lane was used as loading control. Lysates and immunoblots were prepared as detailed in "Materials and Methods."

survive and proliferate in an androgen-deficient environment. Our data from the $\mathrm{LnCaP}$ and LAPC-9 in vivo neoplastic progression models of human prostate cancer suggest that up-regulation of expression of $I G F-I$ and to a lesser extent $I G F-I R$ are indeed associated with progression to androgen independence. It has been shown recently (24) that AI proliferation of $\mathrm{LnCaP}$ cells is increased after transfection with IGF-IR together with the IGF-IR substrate IRS-1.

In experimental systems based on SV40-transformed human prostate epithelial cells, paradoxical down-regulation of IGF-IR expression has been found to be associated with transformation (26-29), raising the possibility that IGF-IR exerts a negative influence on tumor progression, which is overcome by reduced expression. Our results showing up-regulation of IGF-IR are distinct from these reports in that our models compare AD human prostate cancer xenografts and spontaneously arising AI cancers, while prior work compared IGF-IR expression in normal prostate epithelial cells with that in prostate epithelial cells transformed by SV40 transfection. SV40 expression in prostate epithelial cells clearly leads to transformation, but it is not certain that the molecular mechanisms underlying SV40 transformation reflect the molecular pathology of all human prostate cancers. Clearly, prostate neoplasia may involve more than one type of IGF receptor dysregulation mechanism. Taken together, the data encourage additional studies of IGF signal transduction in primary $\mathrm{AD}$ and $\mathrm{AI}$ human prostate cancer tissue.

Several molecular mechanisms have been proposed to account for the ability of prostate cancer cells to overcome the growth-inhibitory effects of androgen withdrawal and develop a more aggressive neoplastic phenotype characterized by rapid proliferation in the absence of androgenic stimulation. For example, overexpression of Her-2/neu
(7) and overexpression of Bcl-2 (30) have been linked to progression of prostate cancer to androgen independence. It is possible that molecular changes in any one of several critical regulatory pathways would be sufficient to confer AI growth. Our demonstration that progression to androgen independence is associated with changes in expression of IGF-I, IGF-IR, and IGFBP-3 provides evidence that IGF signaling pathways are relevant to neoplastic progression of prostate cancer. In the LAPC-4 model, although AI was associated with no major changes in expression of IGF ligands and an decrease in IGF-IR expression, we obtained evidence for increased phosphorylation of the IGF-I receptor. The basis for this observation requires further investigation, but one possibility involves deficiency of a phosphotyrosine phosphatase activity that normally reduces the halflife of activated receptors. There is a precedent for this type of mechanism in other systems $(31,32)$. Furthermore, there is prior evidence that in the LAPC-4 model a separate regulatory abnormality (up-regulation of Her-2/neu) is involved in progression to androgen independence (7), and this could affect IGF-IR phosphorylation through cross-talk receptor tyrosine kinases.

It is unclear whether critical changes in gene expression that occur during prostate cancer progression arise from epigenetic mechanisms resulting from adaptation of dormant $\mathrm{AD}$ cells to growth after androgen depletion or whether AI cancers represent the outgrowth by clonal selection of a subset of cells within the tumor population with a preexisting pattern of gene expression that confers a growth advantage in the absence of androgens (33). Previous evidence that androgen independence in the LAPC-9 model arises from clonal expansion (1) suggests that the observed deregulation of IGF signaling in AI LAPC-9 tumors existed in a fraction of the cells present in the $\mathrm{AD}$ tumor prior to castration.

IGFBP-3 has been associated with direct and indirect growthinhibitory actions (34-37). We reported previously that increases in IGFBP-3 expression are associated with apoptotic regression of the normal rat ventral prostate induced by either castration (22) or the antiandrogen bicalutamide (25). The data demonstrating increased IGFBP-3 expression in the LAPC-9 system after castration extend these findings to certain human prostate cancer models and are consistent with the possibility of a functional role of IGFBP-3 expression in mediating the apoptosis that follows castration. In view of the growth-inhibitory actions of IGFBP-3, it is not surprising that expression of this gene is greatly reduced when LAPC-9 tumors achieve AI growth.

Less is known about the role of IGFBP-5 in prostate cancer. Castration-induced apoptotic regression of AD Shionogi tumors is associated with up-regulation of IGFBP-5 (38). In the Shionogi model, both induction of IGFBP-5 and apoptosis can be inhibited by treating mice with calcium channel blockers prior to castration. Although this suggests the possibility that IGFBP-5 may be involved in mediating castration-induced apoptosis, recent reports demonstrating that IGFBP-5 actually confers protection from apoptosis $(39,40)$ suggest the possibility that up-regulation of expression of IGFBP-5 may represent an attempt to survive despite the presence of other signals favoring apoptosis. Our observation that IGFBP-5 is upregulated during AI growth of LAPC-9 also suggests the possibility that in certain physiological contexts, IGFBP-5 expression enhances cell survival.

The hypothesis that any one of several sets of molecular derangements is sufficient to confer an AI phenotype is consistent with the clinical observation that progression to androgen independence is a common rather than a rare event. Our data provide evidence that changes in expression of genes in the IGF regulatory system within prostate cancers are associated with acquisition of androgen independence. The results are in keeping with the general hypothesis (41) that 
receptor kinases are important determinants of neoplastic behavior and provide a rationale for studies concerning molecular pathology of IGF signaling in paired clinical $\mathrm{AD}$ and $\mathrm{AI}$ prostate cancer specimens. Finally, the data raise the possibility that novel pharmacological approaches that target IGF signaling may be of therapeutic value for at least a subset of AI prostate cancers.

\section{ACKNOWLEDGMENTS}

We thank M. J. Blouin for assistance in preparation of the manuscript.

\section{REFERENCES}

1. Craft, N., Chhor, C., Tran, C., Belldegrun, A., DeKernion, J., Witte, O. N., Said, J. Reiter, R. E., and Sawyers, C. L. Evidence for clonal outgrowth of androgenindependent prostate cancer cells from androgen-dependent tumors through a twostep process. Cancer Res., 59: 5030-5036, 1999.

2. Horoszewicz, J. S., Leong, S. S., Kawinski, E., Karr, J. P., Rosenthal, Chu, T. M., Mirand, E. A., and Murphy, G. P. LNCaP model of human prostatic carcinoma. Cancer Res., 43: 1809-1818, 1983.

3. Veldscholte, J., Berrevoets, C. A., Ris-Stalpers, C., Kuiper, G. G., Jenster, G., Trapman, J., Brinkmann, A. O., and Mulder, E. The androgen receptor in LNCaP cells contains a mutation in the ligand binding domain which affects steroid binding characteristics and response to antiandrogens. J. Steroid Biochem. Mol. Biol., 4I: 665-669, 1992.

4. Sato, N., Gleave, M. E., Bruchovsky, N., Rennie, P. S., Beraldi, E., and Sullivan L. D. A metastatic and androgen-sensitive human prostate cancer model using intraprostatic inoculation of LNCaP cells in SCID mice. Cancer Res., 57: 1584-1589, 1997.

5. Gleave, M. E., Hsieh, J. T., Wu, H-C., and Chung, L. W. K. Serum PSA levels in mice bearing human prostate $\mathrm{LNCaP}$ tumor are determined by tumor volume and endocrine and growth factors. Cancer Res., 52: 1598-1605, 1992.

6. Klein, K. A., Reiter, R. E., Redula, J., Moradi, H., Zhu, X. L., Brothman, A. R., Lamb, D. J., Marcelli, M., Belldegrun, A., Witte, O. N., and Sawyers, C. L. Progression of metastatic human prostate cancer to androgen independence in immunodeficient SCID mice. Nat. Med., 3: 402-408, 1997.

7. Craft, N., Shostak, Y., Carey, M., and Sawyers, C. L. A mechanism for hormoneindependent prostate cancer through modulation of androgen receptor signaling by the HER-2/ncu tyrosine kinase. Nat. Med., 5: 280-285, 1999.

8. Baserga, R. The insulin-like growth factor I receptor: a key to tumor growth? Cancer Res., 55: 249-252, 1995.

9. Peruzzi, F., Prisco, M., Dews, M., Salomoni, P., Grassilli, G., Romano, G., Calabretta, B., and Baserga, R. Multiple signaling pathways of the insulin-like growth factor 1 receptor in protection from apoptosis. Mol. Cell. Biol., 19: 7203-7215, 1999.

10. Clemmons, D. R. Insulin-like growth factor binding proteins and their role in controlling IGF actions. Cytokine Growth Factor Rev., 8: 45-62, 1997.

11. Cohen, P., Peeh1, D. M., Lamson, G., and Rosenfeld, R. G. Insulin-like growth factors (IGFs), IGF receptors, and IGF-binding proteins in primary cultures of prostate epithelial cells. J. Clin. Endocrinol. Metab., 73: 401-407, 1991.

12. Peehl, D. M., Cohen, P., and Rosenfeld, R. G. Role of insulin-like growth factors in prostate biology. J. Androl., 17: 2-4, 1996.

13. Burfeind, P., Chernicky, C. L., Rininsland, F., and Ilan, J. Antisense RNA to the type I insulin-like growth factor receptor suppresses tumor growth and prevents invasio by rat prostate cancer cells in vivo. Proc. Natl. Acad. Sci. USA, 93: 7263-7268, 1996.

14. DiGiovanni, J., Kiguchi, K., Frijhoff, A., Wilker, E., Bol, D. K., Beltran, L., Moats S., Ramirez, A., Jorcano, J., and Conti, C. Deregulated expression of insulin-like growth factor 1 in prostate epithelium leads to neoplasia in transgenic mice. Proc Natl. Acad. Sci. USA, 97: 3455-3460, 2000.

15. Chan, J. M., Stampfer, M. K., Giovannucei, E., Gann, P. H., Ma, J., Wilkinson, P. Hennekens, C. H., and Pollak, M. Plasma insulin-like growth factor-I and prostate cancer risk: a prospective study. Science (Wash. DC), 279: 563-566, 1998.

16. Stattin, P., Bylund, A., Rinaldi, S., Biessy, C., Dechaud, H., Stenman, U. H., Egevad, L., Riboli, E., Hallmans, G., and Kaaks, R. Plasma insulin-like growth factor-I insulin-like growth factor-binding proteins, and prostate cancer risk: a prospective study. J. Natl. Cancer Inst. (Bethesda), 92: 1910-1917, 2000.

17. Harman, S. M., Metter, E. J., Blackman, M. R., Landis, P. K., and Carter, H. B. Serum levels of insulin-like growth factor I (IGF-I), IGF-II, IGF-binding protein-3, and prostate-specific antigen as predictors of clinical prostate cancer. J. Clin. Endocrinol Metab., 85: 4258-4265, 2000

18. Shaneyfelt, T., Husein, R., Bubley, G. J., and Mantzoros, C. S. Hormonal predictors of prostate cancer: a meta-analysis. J. Clin. Oncol., 18: 847-853, 2000.
19. Pollak, M. Insulin-like growth factors (IGFs) and prostate cancer. Epidemiol. Rev., in press, 2001.

20. Culig, Z., Hobisch, A. Cronauer, M. V., Radmayr, C., Trapman, J., Hittmair, A., Bartsch, G., and Klocker, $H$. Androgen receptor activation in prostatic tumor cell lines by insulin-like growth factor-I, keratinocyte growth factor, and epidermal growth factor. Cancer Res., 54: 5474-5478, 1994.

21. Putz T. Culig, Z., Eder, I. E., Nessler-Menardi, C., Bartsch, G., Grunicke, H., Uberall, F., and Klocker, H. Epidermal growth factor (EGF) receptor blockade inhibits the action of EGF, insulin-like growth factor I, and a protein kinase A activator on the mitogen-activated protein kinase pathway in prostate cancer cell lines. Cancer Res., 59: 227-233, 1999.

22. Nickerson, T., Pollak, M., and Huynh, H. Castration-induced apoptosis in the rat ventral prostate is associated with increased expression of genes encoding insulin-like growth factor binding proteins 2, 3, 4 and 5. Endocrinology, 139: 807-810, 1998.

23. Winer, J., Jung, C. K., and Williams, P. M. Development and validation of real-time quantitative reverse transcriptase-polymerase chain reaction for monitoring gene expression in cardiac myocytes in vitro. Anal. Biochem., 270: 41-49, 1999.

24. Reiss, K., Wang, J. Y., Romano, G., Fumari, F. B., Cavenee, W. K., Morrione, A., Tu, $X$, and Baserga, R. IGF-I receptor signaling in a prostatic cancer cell line with a PTEN mutation. Oncogene, 19: 2687-2694, 2000.

25. Nickerson, T., and Pollak, M. Bicalutamide (Casodex)-induced prostate regression involves increased expression of genes encoding insulin-like growth factor binding proteins. Urology, 54: 1120-1125, 1999.

26. Plymate, S. R., Bae, V. L., Maddison, L., Quinn, L. S., and Ware, J. L. Type-1 insulin-like growth factor receptor reexpression in the malignant phenotype of SV40T-immortalized human prostate epithelial cells enhances apoptosis. Endocrine, 7: 119-124, 1997.

27. Plymate, S. R., Bae, V. L., Maddison, L., Quinn, L. S., and Ware, J. L. Reexpression of the type 1 insulin-like growth factor receptor inhibits the malignant phenotype of simian virus $40 \mathrm{~T}$ antigen immortalized human prostate epithelial cells. Endocrinology, 138: 1728-1735, 1997.

28. Damon, S. E., Plymate, S. R., Carroll, J. M., Sprenger, C. C., Dechsukhum, C., Ware J. L., and Roberts, C. T., Jr. Transcriptional regulation of insulin-like growth factor-I receptor gene expression in prostate cancer cells. Endocrinology, 142: 21-27, 2001.

29. Plymate, S. R. Tennant, M., Birnbaum, R. S., Thrasher, J. B., Chatta, G., and Ware J. L. The effect of the insulin-like growth factor system in human prostate epithelial cells of immortalization and transformation by simian virus-40 $\mathrm{T}$ antigen. J. Clin. Endocrinol. Metab., 81: 3709-3716, 1996.

30. Miyake, $H$., Tolcher, A., and Gleave, M. E. Antisense Bcl-2 oligodeoxynucleotides inhibit progression to androgen-independence after castration in the Shionogi tumor model. Cancer Res., 59: 4030-4034, 1999.

31. Wu, X., Senechal, K., Neshat, M. S., Whang, Y. E., and Sawyers, C. L. The PTEN/MMAC1 tumor suppressor phosphatase functions as a negative regulator of the phosphoinositide 3-kinase/Akt pathway. Proc. Natl. Acad. Sci. USA, 95: 1558715591, 1998.

32. Whang, Y. E., Wu, X., Suzuki, H., Reiter, R. E., Tran, C., Vessella, R. L., Said, J. W. Isaacs, W. B., and Sawyers, C. L. Inactivation of the tumor suppressor PTEN/ MMACl in advanced human prostate cancer through loss of expression. Proc. Natl, Acad. Sci. USA, 95: 5246-5250, 1998.

33. Rennie, P. S., and Nelson, C. C. Epigenetic mechanisms for progression of prostate cancer. Cancer Metastasis Rev., I7: 401-409, 1998.

34. Oh, Y., Muller, H. L., Lamson, G., and Rosenfeld, R. G. Insulin-like growth factor (IGF)-independent action of IGF-binding protein-3 in Hs578T human breast cancer cells. J. Biol. Chem., 268: 14964-14971, 1993.

35. Rajah, R., Valentinis, B., and Cohen, $P$. Insulin-like growth factor binding protein-3 induces apoptosis and mediates the effects of transforming growth factor- $\beta 1$ on programmed cell death through a p53- and IGF-independent mechanism. J. Biol. Chem., 272: 12181-12188, 1997.

36. Nickerson, T., Huynh, H., and Pollak, M. Insulin-like growth factor binding protein-3 induces apoptosis in MCF7 breast cancer cells. Biochem. Biophys. Res. Commun., 237: $690-693,1997$

37. Hwa, V., Oh, Y., and Rosenfeld, R. G. The insulin-like growth factor-binding protein (IGFBP) superfamily. Endocr. Rev., 20: 761-787, 1999.

38. Nickerson, T., Miyake, H., Gleave, M. E., and Pollak, M. Castration-induced apoptosis of androgen-dependent Shionogi carcinoma is associated with increased expression of genes encoding IGF-binding proteins. Cancer Res., 59: 3392-3395, 1999.

39. Perks, C. M., Bowen, S., Gill, Z., Newcomb, P., and Holly, J. Differential IGFindependent effects of insulin-like growth factor binding proteins (1-6) on apoptosis of breast epithelial cells. J. Cell. Biochem., 75: 652-664, 1999.

40. Miyake, H., Pollak, M., and Gleave, M. E. Castration-induced up-regulation of insulin-like growth factor binding protein-5 potentiates insulin-like growth factor-I activity and accelerates progression to androgen independence in prostate cancer models. Cancer Res., 60: 3058-3064, 2000.

41. Blume-Jensen, P., and Hunter, T. Oncogenic kinase signalling. Nature (Lond.), 411 : 355-365, 2001. 
Myc-driven murine prostate cancer shares molecular features with human prostate tumors

Katherine Ellwood-Yen ${ }^{1}$, Thomas G. Graeber ${ }^{2,3}$, John Wongvipat ${ }^{1}$, M. Luisa IruelaArispe $^{6}$, JianFeng Zhang ${ }^{4}$, Robert Matusik ${ }^{4}$, George V. Thomas ${ }^{5 *}$ and Charles L. Sawyers ${ }^{1,3 *}$

Departments of Medicine, Urology, Molecular and Medical Pharmacology ${ }^{1}$ and Pathology ${ }^{5}$, UCLA-DOE Laboratory of Genomics and Proteomics ${ }^{2}$, Jonsson Comprehensive Cancer Center; David Geffen School of Medicine, University of California Los Angeles; Howard Hughes Medical Institute ${ }^{3}$; Department of Molecular, Cell and Developmental Biology ${ }^{6}$; Department of Urology; Vanderbilt University School of Medicine ${ }^{4}$

*Joint corresponding authors 


\section{Summary}

Increased c-Myc gene copy number is observed in human prostate cancer, even at the preneoplastic stage of prostatic intraepithelial neoplasia. We generated transgenic mice expressing human c-Myc in the mouse prostate using either of two promoters, the composite probasin promoter $\mathrm{ARR}_{2} \mathrm{~PB}$ or the core probasin promoter. Both strains developed murine prostatic intraepithelial neoplasia shortly after onset of transgene expression, followed by invasive adenocarcinoma within $6-12$ months that shares striking pathologic similarities to the human disease. Microarray-based expression profiling identified a Myc signature in the mouse prostate, including the putative human tumor suppressor NXK 3.1. Examination of human cancer databases with the murine Myc signature revealed gene clusters whose expression was tightly correlated in human prostate and breast cancer. The murine Myc signature genes most consistently coexpressed in the human cancers included the Pim1 kinase, which is known to cooperate with Myc in tumorigenisis. Genomic technologies applied to mouse cancer models can guide evaluation of human tumor tissue databases. 


\section{Significance}

Transgenic models of murine prostate cancer have relied upon the SV40 large T antigen to generate phenotypes resembling human prostatic intraepithelial neoplasia and invasive carcinoma. Previous attempts to model human prostate cancer by manipulating expression of genes implicated in human tumors have fallen short, in that most fail to give invasive carcinomas. Here we demonstrate that mice expressing human c-Myc in the prostate reliably develop murine prostatic intraepithelial neoplasia, then invasive adenocarcinomas, which account for $95 \%$ of human prostate cancers. These tumors share molecular features with human prostate cancer, as defined by array-based expression profiling, such as loss of the candidate human prostate tumor suppressor gene NKX 3.1 and upregulation of the serine/threonine kinase Pim1. This model provides a novel tool for identification and functional evaluation of genetic events in prostate cancer progression and for preclinical therapeutic studies. 


\section{Introduction}

The mouse has long been exploited as a model to study the molecular basis of human cancers and test novel therapies. Recent advances in mouse engineering techniques and in genomics tools to query mouse tumor tissue allow a more global comparison of these models to human cancer. We have addressed these issues in a novel transgenic model of mouse prostate cancer using the human c-Myc gene as the initiating event. Myc has been widely implicated in many human cancers (Nesbit et al., 1999) and is sufficient to give cancer phenotypes in various murine tissues when expressed as a transgene (Jensen et al., 2002; Moroy et al., 1991; Nesbit et al., 1999; Pelengaris et al., 2002a; Pelengaris et al., 2002b; Pelengaris et al., 1999; Zhang et al., 2000b). We focused our studies on the role of c-Myc in prostate cancer for two reasons. First, several independent, publicly available gene expression profiling datasets of human prostate tumors (Dhanasekaran et al., 2001; Magee et al., 2003; Singh et al., 2002; Welsh et al., 2001) are available for comparison to mouse models. Second, the functional role of Myc in human prostate cancer remains undefined. Numerous studies of human prostate cancer have demonstrated increased c-Myc gene copy number in up to $30 \%$ of tumors, even at the preneoplastic stage called prostate intraepithelial neoplasia (PIN) (Jenkins et al., 1997; Nesbit et al., 1999; Qian et al., 1997; Sato et al., 1999). But Myc is one of many genes localized to this 8q24 amplicon (Elo and Visakorpi, 2001).

Efforts to define the mechanism by which Myc induces cancer have found a number of effects such as increased cell proliferation that clearly contribute to tumorigenesis. Among the most perplexing has been the well documented pro-apoptotic activity of Myc, particularly when serum or other survival factors are limiting (Ahmed et 
al., 1997; Evan et al., 1992; Pelengaris et al., 2002b; Prendergast, 1999). Recent transgenic models have clarified how the seemingly paradoxical death-promoting activity of c-Myc can lead to cancer. Expression of a hormone-regulated Myc transgene in the skin rapidly induces epidermal hyperplasia and papillomas, with associated increases in cellular proliferation and minimal evidence of apoptosis (Pelengaris et al., 2002a; Pelengaris et al., 1999). However, these tumors rapidly apoptose when cultured ex vivo, presumably due to the lack of critical survival factors present in the mouse dermis. In contrast, transgenic expression of c-Myc in the pancreas caused rapid involution of insulin-producing islet cells, due to increased apoptosis, and subsequent onset of diabetes (Pelengaris et al., 2002a; Pelengaris et al., 2002b). When complemented with a BclX transgene, the mice no longer display the apoptotic phenotype, but develop aggressive islet cell cancers. These experiments demonstrate that the response to Myc expression in different tissues is critically dependent on associated survival signals and suggest a role for secondary cooperating events to rescue cells from Myc-induced apoptosis.

To determine the consequence of increased c-Myc expression in the prostate, we generated transgenic mice expressing human c-Myc from two different strength prostate specific promoters. In all founder lines, c-Myc expression resulted in complete penetrance of mouse prostatic intraepithelial neoplasia (mPIN), which progressed to invasive adenocarcinoma within 6-12 months of age. mPIN lesions were observed as early as 2-4 weeks, providing evidence that c-Myc is sufficient to induce a preneoplastic phenotype in the prostate. These cells demonstrated a high rate of proliferation that overcame the apoptotic effect of c-Myc expression suggesting that prostate tissue contains survival factors that allow the cells to tolerate increased Myc protein. 
Microarray expression profiling studies defined a Myc expression signature in the mouse prostate that shares features with human prostate cancer and implicates candidate genes in tumor progression. For example, expression of the putative human prostate tumor suppressor gene NXK3.1 (Bowen et al., 2000; He et al., 1997; Voeller et al., 1997) was detected in Myc-induced mPIN lesions but absent in invasive cancers. Furthermore, analysis of human cancer databases with the murine Myc gene signature uncovered gene clusters whose expression was tightly correlated in human prostate and breast cancer. The murine Myc signature genes most consistently coexpressed in the human cancers included Pim1 previously shown to cooperate with Myc in mouse tumor models.

Collectively, these findings define a novel transgenic mouse model of prostate cancer and demonstrate the utility of comparing mouse and human cancer expression databases.

\section{Results}

Transgenic expression of c-Myc in the prostate induces $\mathrm{MPIN}$, then invasive adenocarcinoma with reproducible kinetics and high penetrance.

Two different prostate-specific transgenic expression constructs (probasin-Myc and $\mathrm{ARR}_{2}$ /probasin-Myc, respectively), were used to vary the dosage of c-Myc expression specifically in the prostate (Figure 1A). Expression from the probasin promoter begins at a low level in the prostate at 1-2 weeks of age and increases with rising levels of androgen as the mice reach puberty between 4-8 weeks (Figure 1B). The $\mathrm{ARR}_{2} /$ probasin promoter contains two additional androgen response elements which boost the level of androgen-dependent expression (Figure 1B) (Wu et al., 2001; Zhang et al., 2000a). Multiple founders were obtained for each construct, prostate-specific c-Myc 
protein expression was confirmed and independent lines from each construct were expanded for phenotypic analysis. Based on the levels of transgene expression, the probasin-Myc mice and $\mathrm{ARR}_{2}$ /probasin-Myc mice are designated Lo-Myc and Hi-Myc, respectively. Both Lo-Myc and Hi-Myc mice showed histologic evidence of mouse PIN (mPIN) at 4 weeks of age. Of note, mPIN was present in the Hi-Myc mice as early as 2 weeks (Figure 1C, Table 1). Specifically, multifocal proliferative lesions affecting several ductules within the individual lobes were observed in the dorsolateral and ventral lobes and to a lesser extent in the anterior lobe. Cribiform and tufting growth patterns of the secretory epithelial layer were observed in the mPIN lesions. Unlike epithelial hyperplasia, which can also assume these architectural patterns, the cells that make up these lesions exhibited progressive nuclear atypia, demonstrated by the presence of large irregular nuclei, both hyperchromatic and a vesicular chromatin pattern, prominent nucleoli and an amphophilic cytoplasm. Finally, the in-situ nature of these lesions was confirmed by the presence of an intact fibromuscular layer, demonstrated by positive smooth muscle actin (SMA) immunohistochemical staining (Figure 2B, left panel).

The mPIN lesions in both Lo-Myc and Hi-Myc mice subsequently progressed to invasive adenocarcinomas, as seen by the extension of numerous nests of acini consisting of cytologically atypical cells into the prostatic stroma and periprostatic adipose tissue. These acini exhibit crowding, irregular contours and haphazard growth patterns (Figure 1C and 2A). The mPIN/cancer transition was evident by 3-6 months in the Hi-Myc mice and by 10-12 months in the Lo-Myc mice, suggesting that the dosage of Myc may affect the rate of disease progression (Figure 2A). Invasion was confirmed by the absence of SMA staining, which documents penetration through the fibromuscular layer (Figure 2B, 
right panel). Foci suggestive of lymphovascular invasion were also noted in some cancers (data not shown) and mPIN was identified focally in glands adjacent to the invasive tumor. The penetrance of mPIN and cancer was essentially 100 percent in all founder lines with reliable kinetics (Table 1), indicating the potential utility of this model for studying progression from mPIN to cancer and for preclinical therapeutic studies.

To date, the only known murine models of prostate cancer that progress beyond the mPIN stage are the SV40 large T antigen models of prostate cancer (TRAMP, C3Tag and LADY) (Garabedian et al., 1998; Greenberg et al., 1995; Kasper et al., 1998; Masumori et al., 2001; Shibata et al., 1996). One potential shortcoming of the $\mathrm{T}$ antigen models is the high frequency of neuroendocrine differentiation that occurs, as recognized by its typical histologic features and subsequent confirmation by immunohistochemical stains such as synaptophysin or chromogrannin A (Masumori et al., 2001). Although human prostate cancers can occasionally possess a completely neuroendocrine phenotype (e.g. small cell carcinoma), the majority do not. The mPIN and invasive carcinoma lesions detected in the Lo-Myc and Hi-Myc mice do not exhibit the morphologic features of neuroendocrine carcinomas and this is further confirmed by the lack of immunostaining with synaptophysin (Figure 2C). Therefore, the Lo- and Hi-Myc mice represent new models for human prostatic adenocarcinoma that may offer advantages over current models.

Myc expression in the mouse prostate induces proliferation, apoptosis and angiogenesis. Myc can induce both proliferation and apoptosis (Amati et al., 1998; Dang, 1999; Pelengaris et al., 2002a; Pelengaris et al., 2002b; Prendergast, 1999). To understand the cellular effects of c-Myc overexpression in the prostate, we tested for proliferation using 
Ki67 immunohistochemistry and apoptosis using TUNEL assays. Immunohistochemistry showed an increase in Ki67 staining in both mPIN and tumor lesions when compared to wildtype samples as shown in figure $3 \mathrm{~A}$. Ki67 staining was quantified by counting a total of 500 cells from 5 high power fields. The proliferative index increased from 20 in wildtype cells to $140 \mathrm{in} \mathrm{mPIN} \mathrm{lesions} \mathrm{and} 180$ in tumor tissue (Figure 3B). The increased number of Ki67 positive cells indicates that these are rapidly proliferating lesions (Figure 3A, B). TUNEL assays performed on the same tumor showed that c-Myc was also capable of inducing apoptosis in the mouse prostate. Similar to the Ki67 assay, 500 cells were counted and those exhibiting apoptosis were scored. Decreased numbers of positive apoptotic bodies were seen in both mPIN (100 vs. 140) and tumor tissue (100 vs. 175) when compared to Ki67 staining (Figure 3B). These results demonstrate that c-Myc induces both proliferation and apoptosis in the mouse prostate. The rapid development of mPIN suggests that, like epidermal cells, the prostate may contain survival signals that rescue much of the gland from Myc-induced apoptosis.

Myc can also induce angiogenesis in certain tissues, a property that likely contributes to tumor progression and metastasis (Elenbaas et al., 2001; Hurlin et al., 1995; Pelengaris et al., 1999; Watnick et al., 2003). To determine if Myc induces angiogenesis in the mouse prostate, wild-type and transgenic animals at age 2 months and 12 months were evaluated for alterations in the vascular pattern associated with tumor progression (Figure 4). Blood vessels were identified in green after perfusion with FITCconjugated Lycopersicum esculentum lectin as previously described (RodriguezManzaneque et al., 2001). An increase in vascular density was evident at age 2 months in transgenic animals and was associated with mPIN. Vascular density doubled with 
progression to invasive adenocarcinoma at the 1 year time point. These findings demonstrate that Myc can induce an angiogenesis program in the mouse prostate that is associated with disease progression.

Effects of hormone ablation on the initiation and maintenance of Myc-induced prostate lesions

Since hormone ablation therapy is the primary clinical treatment for prostate cancer patients with advanced stage disease, we examined the effect of castration on disease progression in the Hi-Myc transgenic mice. Since the $\mathrm{ARR}_{2} \mathrm{~Pb}$ promoter is regulated by androgen, interpretation of the effect of hormone ablation is confounded by potential silencing of the transgene. Mice were either castrated at 2 months when they had definite mPIN lesions or at 8 months after tumors had developed, then analyzed either one month or three months post-castration (Figure 5A). Complete regression of mPIN was observed in all three mice within one month of castration (Figure 5B) and was correlated with absence of detectable transgene expression by immunoblot (data not shown). This result indicates that Myc-induced mPIN is reversible, similar to other Mycinduced neoplastic phenotypes in tetracycline-regulated models (Jain et al., 2002; Karlsson et al., 2003). Conversely, mice with prostate cancer (castrated at 8 months of age) had residual tumor at one and three months post-castration, although there was histologic evidence of partial regression and fibrosis (Figure 5B). Immunoblot studies demonstrated evidence of Myc expression in residual tumor, but precise measures of transgene expression were complicated by sample heterogeniety (data not shown). The residual tumor foci retained high levels of proliferation post-castration that increased with time, as measured by Ki67 immunohistochemistry (Figure 5C). Larger cohorts of mice 
will be followed to determine if these mice eventually relapse with progressive, hormone refractory prostate cancer.

An expression signature for Myc-driven murine prostate cancer

The high penetrance and reliable kinetics of the PIN/cancer transition in these Myc models provides an experimental opportunity to define the cooperating molecular events involved in Myc-driven prostate cancer progression. We isolated dorsal, lateral and anterior prostate from Hi-Myc transgenic mice and non-transgenic littermate controls at various timepoints during the mPIN/cancer transition for gene expression profiling experiments. Samples were divided for parallel analysis by mouse Affymetrix arrays for gene expression and comparative genome hybridization arrays (array $\mathrm{CGH}$ ) for chromosomal gains and losses. Matched tissue was saved for histological and immunohistochemical studies. Remarkably, the expression signatures for wild-type, $\mathrm{mPIN}$ and cancer were strong enough to be recognized by unsupervised clustering with only one error (Figure 6A). Initially, we were puzzled by one potential outlier in the mPIN group - a Hi-Myc mouse harvested at age 9 months who was presumed to have cancer based on the kinetics of the model (Figure 6A, see asterisk). However, histologic review of the tissue sections showed that, in fact, this mouse had mPIN without cancer, indicating that the gene expression signature is extremely powerful at recognizing these distinct stages of tumor progression. Parallel array CGH experiments were also conducted using genomic DNA from these samples to look for evidence of chromosomal gains or losses that might accompany these expression changes. To date, we have not observed any genomic changes in $\mathrm{mPNN}$ lesions or cancers, but it is important to note that 
current mouse BAC arrays are limited to 3 megabase resolution and we cannot rule out smaller gains or losses (data not shown).

Next we generated a supervised gene list that distinguishes wild-type mice from Myc transgenic mice. We ranked genes by the degree of differential expression between wild-type and transgenic mice using the Student's t-test. The 60 most differentially expressed genes, excluding ESTs, are shown in Figure 6B, and the complete list is available in Supplementary Information. The genes on this list can potentially come from several categories, including genes modulated generally in tumorigenesis, or specifically (Coller et al., 2000) in prostate tumorigenesis or Myc-driven tumorigenesis.

Additionally, the Myc-specific genes can either be Myc transcriptional targets or genes whose up or down regulation complements Myc expression during tumorigenesis. Since the $M y c$ transgene is expressed as early as 1-2 weeks of age, the Myc target genes can be either directly or indirectly regulated by Myc transcription. In an attempt to address this issue, we compared our list of Myc-driven tumor associated gene changes to various lists of Myc target genes and found that some genes and gene families are in common, but we were unable to demonstrate any statistically significant overlap. Thus, not unexpectedly, our list does not appear to be dominated by direct Myc transcriptional targets.

Several genes of interest appeared on the list and include L-Myc, normally expressed at high levels in differentiated prostate tissue (Luo et al., 2001), Tmprss2, a serine protease overexpressed in a majority of prostate cancer patients (Vaarala et al., 2001), Sparc, an antiadhesive protein that is differentially expressed during human prostate cancer progression (Thomas et al., 2000), EGF which has been implicated in prostate cancer progression (Kim et al., 2003), and several Ly6 genes which belong to the 
same family as prostate stem cell antigen (PSCA), a cell surface antigen overexpressed in human prostate cancer (Jalkut and Reiter, 2002) (Figure 6B, asterisks). Among the most interesting genes are Nkx3.1 and Pim-1, for the reasons discussed below (Figure 6B, arrows).

Loss of Nkx3.1 protein expression marks the transition from mPIN to invasive cancer.

The microarray finding of reduced levels of NKX3.1 mRNA in transgenic mice is of particular interest because human NKX3.1 is a putative tumor suppressor gene in human prostate cancer (He et al., 1997). Loss of heterozygosity at the NKX3.1 locus occurs commonly in human prostate tumors due to large deletions at $8 \mathrm{p} 22$, but it has proved difficult to directly implicate NXK3.1 as the relevant gene since mutations do not occur in the remaining allele (Voeller et al., 1997). To distinguish between the possibility that NKX3.1 may be a Myc target gene (since decreased mRNA levels were found in transgenic mice with $\mathrm{mPIN}$ and cancer) versus a complementary secondary event, we examined NKX3.1 protein expression in situ using immunohistochemical studies. NKX3.1 protein expression was consistently present in $\mathrm{mPN}$ lesions at variable levels but was undetectable in all the cancers (Figure 6C). Immunoblot studies of prostate lysates from tumor-bearing mice also showed a marked decrease in Nkx3.1 protein expression when compared to lysates from wildtype or mPIN mice (Figure 6D). These results indicate that NKX3.1 loss is distinct from the onset of Myc expression and raises the possibility that Myc gain and NKX3.1 loss may be critical cooperating events in the $\mathrm{mPIN} /$ prostate cancer transition.

Cross species bioinformatic comparison of mouse and human datasets implicates Pim-1 in cancer progression 
The large number of genes in the Myc signature emphasizes the need for strategies to prioritize genes for functional evaluation. Accordingly, we searched for gene expression patterns common to both our Myc transgene model and human prostate cancer. A schematic of our 'cross-species expression module comparison' approach is shown in Figure 7. We began with our list of genes differentially expressed between wild-type and Myc-transgenic mice. We then identified the human orthologs for these genes using the HomoloGene database (http://www.ncbi.nlm.nih.gov/HomoloGene/), and determined which were present in several human cancer gene expression datasets. We ascertained whether the human tumors were more Myc-like or non-Myc-like using a weighted gene voting prediction algorithm (Golub et al., 1999), and then made ranked lists of the genes most differentially expressed between the human tumors in these two categories using the Student's t-test. Finally, we identified the genes most consistently differentially expressed between Myc-like and non-Myc-like human tumors based on the overlap between the ranked lists from different human datasets (Table 2a,b). In summary, this method investigates whether the coexpressed mouse Myc signature genes are also coexpressed in human cancers, and identifies the most consistently regulated genes in the Myc expression module.

We first performed this analysis using two publicly available prostate cancer datasets (Dhanasekaran et al., 2001; Welsh et al., 2001). The most striking result was the presence of Pim1 near the top of our list (Table 2, Fig. 7). Pim1 was on our original list of genes differentially expressed between wild-type and Myc transgenic prostates with a rank of 113 (Figure 5B, Supplementary Information). The reprioritization of Pim1 to a rank of 2 is noteworthy in that Pim1 has previously been shown to cooperate with Myc in 
lymphomagenesis (van Lohuizen et al., 1989; van Lohuizen et al., 1991), and suggests that this approach could be used with other transgenic cancer models to identify complementing oncogenes.

To investigate whether the Myc expression signature identified using our transgenic mice is prostate-specific, we added a breast cancer dataset to our cross-species comparison algorithm. We again found that one of the most consistently regulated genes in the Myc expression module is Pim1 (Table 2). This result is consistent with the fact that Myc expression is implicated in the progression of many tumor types (Nesbit et al., 1999).

\section{Discussion}

The Myc transgenic models of prostate cancer described here offer several advantages over current models in which the SV40 large T antigen serves as the initiating event. First, the histologic features of the mPIN and cancer lesions accurately reflect the predominant adenocarcinoma phenotype observed in human prostate cancer, with no evidence for the neuroendocrine phenotype observed in many of the $\mathrm{T}$ antigen models (Masumori et al., 2001; Perez-Stable et al., 1997). Second, the fact that mPIN lesions appear with essentially 100 percent penetrance and progress to invasive cancer with reliable kinetics should make this model suitable for preclinical therapeutic studies. In addition, the differences in progression time between the Lo-Myc and Hi-Myc models provides some flexibility in the design of secondary genetic mouse crosses to study the effects of complementing events.

One notable feature of the mPIN lesions observed in our models is their rapid onset relative to the timing of transgene expression. This raises the possibility that Myc 
is sufficient to induce preneoplastic lesions in the mouse prostate in the absence of any secondary changes, consistent with reports of Myc gene amplification in human PIN lesions (Bubendorf et al., 1999; Jenkins et al., 1997; Qian et al., 1997). The latency for disease onset in other transgenic Myc cancer models varies widely and presumably reflects the availability of cooperating survival signals, as seen in the skin versus pancreatic islet cell models discussed previously (Pelengaris et al., 2002b; Pelengaris et al., 1999). Further work with an inducible Myc transgene is required to directly address this question. Unfortunately, hormone-regulated Myc fusion genes cannot be used due to confounding effects of currently available inducing agents such as tamoxifen on prostate cells.

There is optimism in the mouse modeling community that genetically engineered mouse models of human cancer will have utility in the preclinical evaluation of new anticancer agents, perhaps serving as better predictors of clinical activity in humans. We explored this question using hormone ablation therapy, a conventional treatment approach for advanced prostate cancer. The initial results establish that mPIN lesions are reversible whereas advanced adenocarcinomas are not. Further studies are needed to determine if mice with advanced lesions eventually relapse with full-blown hormone refractory prostate cancer, but the increasing fraction of proliferating cells that we observed in these tumors suggests that this is only a matter of time. If so, these tumors could serve as models for dissecting mechanisms of resistance to hormone ablation therapy. An important caveat to this model is the hormone-dependent expression of the transgene. The fact that advanced tumors do not regress and retain some residual Myc expression suggests that transgene expression may have become hormone independent. 
There is growing evidence from human studies that hormone refractory prostate cancer is associated with, and perhaps caused by, restoration of androgen receptor signaling despite continued treatment with hormone ablation therapy. Postulated mechanisms include androgen receptor gene amplification or mutation, as well as activation of kinase pathways that alter androgen receptor (Craft et al., 1999; Taplin et al., 1995; Visakorpi, 1999). Further analysis of the transgenic Myc model may reveal similar or additional mechanisms that can be evaluated in human samples.

Another desired characteristic of mouse cancer models is that they recapitulate the molecular features of the human disease. Mouse-specific genomics tools for expression profiling allowed us to address this question using a global approach. Among the most interesting initial findings was reduced expression of NKX3.1 in Myc-induced prostate tumors. Our immunohistochemical results clearly demonstrate that Myc expression and NKX3.1 loss are distinct events, separated in time during the mPIN/cancer transition. Of note, our finding appears distinct from the NKX3.1 loss associated with PTEN loss in the accompanying paper (Wu et. al.) where reduced NKX3.1 expression is coincident with PTEN loss, implying coordinate regulation in a single pathway. One compelling explanation for our result is that loss of NKX3.1 complements increased Myc expression to promote the $\mathrm{mPIN} /$ cancer transition. Two additional findings support this hypothesis. First, comparative genomic hybridization studies of human prostate cancer often report the parallel presence of chromosome 8q24 gain (Myc) and 8p22 loss (NKX3.1) in the same tumor (Tsuchiya et al., 2002). Second, mice lacking NKX3.1 loss develop mPIN lesions but not cancer, suggesting that a rate-limiting second hit may be required for full blown tumorigenesis (Abdulkadir et al., 2002; Bhatia-Gaur et al., 1999; Kim et al., 2002). 
Alternatively, absence of NKX3.1 expression may be a marker for the cell of origin in the Myc and PTEN prostate cancer models and play no functional role in the transformation process. These and other hypotheses can now be tested through genetic crosses.

In addition to examining our mouse prostate cancer gene lists for known human prostate cancer orthologues, we asked whether the global Myc signature in the murine prostate can be observed in a subset of human prostate cancers. Despite current limitations due to different microarray expression profiling platforms and the limited number of orthologues represented on mouse and human chips, we were able to verify that genes correlated with Myc status in the mouse can be used to define Myc-like human tumors, and that at least one of the genes most consistently associated with the Myc signature in human tumors, Pim1, is also consistent with our knowledge about the role of Myc in tumorigenesis. Pim-1, a serine/threonine kinase, is known to cooperate with cMyc in murine lymphoma models (Moroy et al., 1991; van Lohuizen et al., 1989), and increased Pim1 expression was recently observed in a subset of human prostate cancers and shown to correlate with poor clinical outcome (Dhanasekaran et al., 2001). Although these investigators did not determine the Myc status of these tumors, our mouse model and subsequent analysis of human microarray datasets suggest that these genes are linked in prostate and breast cancer.

While our initial analysis demonstrates the utility of cross species comparisons of global datasets, a number of steps need to be taken to realize the full potential of this approach. It will be important to standardize expression analysis platforms to provide comprehensive coverage of the mouse and human transcriptome with appropriate cataloguing of orthologues for cross comparison. In addition, human datasets must be 
linked to independent tissue analysis for specific molecular lesions of interest, such as Myc amplification or PTEN loss for the examples discussed here. Parallel construction of tissue arrays from tumor samples analyzed by expression microarrays will allow such experiments to be performed. Ultimately, we envision using such cross species comparisons to validate the relevance of mouse models for human disease, to help prioritize lengthy gene lists for functional evaluation and to extend gene cohorts that segregate with a specific molecular lesion across multiple tissues.

Acknowledgements

The authors wish to thank Dr. Robert Cardiff and Dr. Scott Shappell for helpful discussions on mouse prostate pathology. K.E-Y. is supported by a fellowship grant from the California Cancer Research Program (00-00748V-20082). GVT is supported by a U.S Department of Defense prostate cancer research program (DAMD17-02-1-0027). CLS is an Investigator of the Howard Hughes Medical Institute and a Doris Duke Distinguished Scientist. Work in his laboratory is also supported by grants from the National Cancer Institute and the U.S. Department of Defense.

\section{Experimental Procedures}

Plasmids: The plasmids $\mathrm{AR}_{2} \mathrm{~Pb}-\mathrm{Flag}-\mathrm{Myc}-\mathrm{PAI}$ and $\mathrm{Pb}-\mathrm{Flag}-\mathrm{Myc}-\mathrm{PAI}$ were constructed by ligation of the following gene fragments into the Bluescript $(\mathrm{KS}+)$ backbone (Stratagene). For Pb-Flag-Myc-PAI: the poly(A) tail of the insulin receptor gene (PAI) 
was subcloned into the BamHI/NotI site of the bluscript KS+ multiple cloning site (MCS). The $5^{\prime}$ flanking promoter region $(-426 /+28)$ of the rat probasin gene was subcloned into the KpnI/EcoRV restriction sites located in the MCS. The human c-Myc c-DNA was amplified by PCR using a 5'primer containing the Bgl II restriction site and the consensus sequence for the FLAG epitope (5’GGGAGATTCTCATCGCCACCATGGACTACAAGGACGACG ACGACAAGGCCATGCCCCTCAACGTTAGCTTCACC). The epitope tag was engineered to aid with immunohistochemistry however, we were unable to detect it via western blot (data not shown) and relied on the human specific anti-9E10 c-Myc antibody (Santa Cruz) to detect transgene expression. The 3' primer contained a BamHI restriction site for cloning purposes (3'GGGGGATCCTTACGCACAAGAGTTC CGTAGCTGTTC). After PCR amplification, the product was gel purified, digested and filled in using the large fragment Klenow polymerase. Following gel purification, the blunt-ended product was subcloned into the EcoRV site of the bluescript $\mathrm{KS}+\mathrm{Pb}-\mathrm{PAI}$ backbone thus generating the PB-Flag-Myc-PAI transgenic construct. The $\mathrm{AR}_{2} \mathrm{~Pb}-\mathrm{Flag}-$ Myc-PAI was generated in the same way except the $\mathrm{AR}_{2} \mathrm{~Pb}$ promoter sequence was subcloned into the $\mathrm{KpnI} / \mathrm{EcoRV}$ site instead of $\mathrm{PB}$ promoter. The $\mathrm{AR}_{2} \mathrm{~PB}$ sequence contains the original probasin sequence $\mathrm{PB}(-426 /+28)$ plus two additional androgen response elements (Zhang et al., 2000a). The completed constructs were sequenced and tested for promoter inducibility by androgen in LNCaP cells by transient transfection before microinjection into FVB ova. By transient transfection, the $\mathrm{ARR}_{2} \mathrm{~Pb}$ promoter was able to confer approximately $20 \mathrm{x}$ higher levels of expression than the $\mathrm{Pb}$ promoter (data not shown). 
Generation of transgenic $\mathrm{ARR}_{2}{ }_{2} \mathrm{~Pb}-\mathrm{Myc}-\mathrm{PAI}$ and $\mathrm{Pb}-\mathrm{Myc}-\mathrm{PAI}$ mice: The $\mathrm{AR}_{2} \mathrm{~PB}-\mathrm{Myc}-$

PAI and PB-Myc-PAI constructs were linearized with KpnI/NotI, micro-injected into fertilized FVB ova and transplanted into a pseudo-pregnant female (University of Irvine Transgenic Facility). Transgenic founders were screened by PCR using genomic DNA isolated from tail snips. The 5' primer was specific to either the $\mathrm{AR}_{2} \mathrm{~Pb}$ promoter (5' $\mathrm{AR}_{2} \mathrm{~Pb}$-CAATGTCTGTGTACAACTGCCAACTGGGATGC) or the $\mathrm{Pb}$ promoter (5'Pb-CCGGTCGACCGGAAGCTTCCACAAGTGCATTTA) and the 3' primer for both reactions was located at the end of the c-Myc cDNA (5'-TTACGCACAA GAGTTCCGTAGCTGTTC). A PCR product of 1438 base pairs was generated from the $\mathrm{AR}_{2} \mathrm{~Pb}-\mathrm{Myc}-\mathrm{PAI}$ mice and a 1774 base pair product was produced by the $\mathrm{Pb}-\mathrm{Myc}-\mathrm{PAI}$ mice. Seven founder lines were obtained from the $\mathrm{AR}_{2} \mathrm{~Pb}-\mathrm{Myc}-\mathrm{PAI}$ construct (designated $1,2,4,7,8,11$ and 13) whereas three founders were generated with the Pb-Myc-PAI construct (designated \#6,9,10). Breedings were carried out and germline transmission was obtained by four $\mathrm{AR}_{2} \mathrm{~Pb}-\mathrm{Myc}-\mathrm{PAI}$ founders $(4,7,11$ and 13) and two $\mathrm{Pb}-\mathrm{Myc}-\mathrm{PAI}$ mice (6 and 9). These mice were bred and the offspring were aged to determine if prostate cancer developed in the transgene positive male mice. Prostates were isolated “en block" from transgenic and wildtype mice at 2-12 weeks as well as at 6, 9, 12 and 16 months and cut in half along the sagital plane. Superficial and deep H\&E sections were examined on the same tissue in order to document the presence/absence of $\mathrm{mPIN}$, microinvasion and invasive adenocarcinoma (described below). Mouse dissections, tissue isolation and castration: Urogenital organs were isolated and prostates were micro-dissected in a petri dish containing $10 \mathrm{mls}$ of cold phosphate buffered saline (1x PBS, Gibco-BRL 14190144) under a dissecting microscope. Adipose 
tissue surrounding the mouse prostates was cleared using forceps. The mouse prostate is composed of four pairs of lobes (ventral, dorsal, lateral and anterior lobes) which were separated from the urethra using dissecting shears. One half was used to obtain protein and RNA while the other half was fixed in $10 \%$ phosphate buffered formalin for histology (Fisher SF100-4). The liver, testes, bone from the spine, brain, kidneys and lungs were also isolated for both histological examination as well as protein analysis to check for non-specific expression of c-Myc. For castration experiments, mice were anesthetized using Isoflurane (Abbott Laboratories). The perineal region was cleaned three times with ethanol and a betadine scrub (VWR, AJ159778) and sterile dissecting shears were used to make a 4-5 mm incision in this region. Using two sterile forceps, the testes were located and a ligature was made around the testicular vessels and the tunica albugenea that encases the testes. The testes were amputated with dissecting shears and the scrotum sutured shut with 6-0 Ethilon black monofilament nylon (Ethicon Inc., 1665). A local triple antibiotic was applied over the region of the wound to facilitate healing. Pathological and immunohistochemical data: Mice were aged to the appropriate time point and then sacrificed for dissection. The prostate tissues that were sent for histology were marked with ink on one side (the cut side), splayed and embedded "en face" to maximize pathologic examination of each lobe. Sections were cut in the same manner on the microtome enabling us to orient the prostatic lobes with the bladder and the seminal vesicles as a reference point. Prostates, testes, lung, liver, bone (spine), kidney and brain were all harvested for western blot analysis and histology. The tissues that were kept for protein analysis were homogenized using a tissue grinder in 2x SDS buffer $(100 \mathrm{mM}$ Tris-Hcl pH=6.8, $200 \mathrm{mM}$ DTT, 4\% SDS, 20\% glycerol, $50 \mathrm{mM} \mathrm{B-gly-Phosphate,} 1 \mathrm{mM}$ 
NaVo4, and $40 \mathrm{ug} / \mathrm{ml}$ PMSF) and normalized for total protein via Bio-Rad assay. Tissue used for histology was fixed initially in $10 \%$ buffered formalin phosphate (Fisher SF1004) for eight hours followed by gentle washing in running water and finally transferred to $70 \%$ ethanol. Serial tissue sections ( $4 \mu \mathrm{m}$ thick) were cut from paraffin-embedded blocks and placed on charged glass slides. $H \& E$ and masson trichrome staining were performed using standard procedures. For immunohistochemical analysis using polyclonal antibodies the Vector Laboratories R.T.U. Vectastain Universal Elite ABC Kit (cat\# PK7200) was used and for monoclonal antibodies we used the Vector M.O.M. Basic Kit (BMK-2202). Briefly, sections were deparaffinized with xylene and rehydrated through graded alcohol washes followed by antigen retrieval in a pressure cooker for 30 minutes in sodium citrate buffer $(10 \mathrm{mM}, \mathrm{pH} 6.0)$. Slides were then incubated in $0.3 \%$ hydrogen peroxide to quench endogenous horseradish peroxidase for 30 minutes. The slides were then blocked by incubation in normal horse serum (dilution 1:20) in $0.1 \mathrm{M}$ Tris buffered saline $\mathrm{pH} 6.0$ and subsequently incubated for 30 minutes with the following antibodies diluted in Tris-buffered saline: anti-synaptophysin polyclonal antibody (Dako \# A0010) diluted (1:5000), anti-alpha smooth muscle actin monoclonal antibody (Dako \# M0851) diluted (1:1000), anti-Nkx3.1 polyclonal antibody (kindly provided by Dr. Cory AbateShen) diluted (1:6000), anti Ki67 polyclonal antibody (Novacastra Laboratories \#NCLKi67p) diluted $(1: 20,000)$. Negative controls were included in each assay. Slides were then treated with biotin labeled anti-mouse IgG and incubated with preformed avidin biotin peroxidase complex. Metal enhanced diaminobenzidine substrate was added in the presence of horseradish peroxidase and finally, sections were counter stained with hematoxylin, dehydrated and mounted. 
TUNEL Assays: TUNEL assays were performed as described in the In Situ Cell Death Detection Kit, POD from Roche. Prior to the addition of TdT enzyme, sections were deparaffinized with xylene and rehydrated through graded alcohol washes. Antigen retrieval was performed in sodium citrate buffer $(10 \mathrm{mM}, \mathrm{pH} 6.0)$ by applying microwave irradiation $(750 \mathrm{~W})$ for 1 minute. The slides where then incubated for 5 minutes in $3 \%$ hydrogen peroxide to quench endogenou $\mu$ s horseradish peroxidase. Next, slides were immersed for 30 minutes at room temperature in Tris- $\mathrm{HCl}, 0.1 \mathrm{M} \mathrm{pH}=7.5$ containing $3 \%$ BSA and 20\% normal bovine serum. TUNEL reaction mixture containing a 1:20 dilution of TdT enzyme was added to the slides for 2 hours at $37^{\circ} \mathrm{C}$ in a humidified atmoshphere chamber. $50 \mu 1$ of Converter-POD was then added to each slide and incubated at $37^{\circ} \mathrm{C}$ for 45 minutes in a humidified atmosphere chamber. DAB substrate was applied for 1 minute followed by counterstaining in hematoxylin.

Microarray Measurements: Total RNA was isolated from gross prostate tissue following microdissection using the Tri-Reagent RNA Isolation Reagent (Sigma-Aldrich cat\# T9424) as described by the manufacturer. Biotin labeled cRNA was generated following Affymetrix protocols. Briefly, first strand cDNA synthesis was carried out by reverse transcribing total RNA using Superscript Reverse Transcriptase (Gibco cat\# 18064-014). Second strand synthesis was performed using $10 \mathrm{U} / \mu 1$ DNA ligase (Gibco cat\# 18052019) 10 U/ $\mu$ l DNA Pol I (Gibco cat\# 18005-025) and 2 U/ $\mu 1$ RNase H (Gibco cat\# 18021-014). Double stranded cDNA cleanup was done using the GeneChip Sample Cleanup Module (Affymetrix cat\# P/N 900371). Synthesis of biotin-labeled cRNA was carried out using the Enzo Bioarray Kit (Enzo Diagnostics Inc. cat\# 42655-20) and following fragmentation, was hybridized to Affymetrix murine chips (U74Av2). 
Data analysis: Hierarchical clustering analysis was preformed using the genes with significant variation across all samples (standard deviation $(\sigma)>2000$, coefficient of variation $(\sigma /$ mean $)>0.05$, fraction above background $>0.5)$ (Eisen et al., 1998). To identify the most informative set of differentially expressed genes between two sets of samples, we ranked each gene by the probability that the means of its expression values in each set are statistically distinct using the Student's t-test.

Cross-species expression module comparison algorithm: A schematic of our approach is shown in Figure 7. We first generated a ranked list of mouse genes differentially expressed between wild-type and Myc-transgenic mice using the Student's t-test. Each gene on this list was assigned a weighting factor (Golub et al., 1999). We then identified the human orthologs for these genes using the HomoloGene database (http://www.ncbi.nlm.nih.gov/HomoloGene/). We assigned human tumors Myc-like or non-Myc-like status using a weighted gene voting prediction algorithm (Golub et al., 1999) using the ranked and weighted mouse gene list. Before applying the algorithm, we normalized the expression of each gene to a mean of zero and a standard deviation of one separately in the mouse dataset and each of the human datasets.

For each gene in the human dataset, multiple prediction pairs of Myc-like and non-Myc-like groups were made, using all possible numbers of orthologous genes corresponding to the ranked and weighted mouse gene list, but always excluding the current gene of interest (if it exists in the mouse dataset) from the prediction calculations. Then for each of the resulting prediction pairs we calculated the Student's t-test P-value for the current gene, and kept the minimal value. Thus, for each gene we retained the minimal P-value possible using the prediction algorithm and the ranked and weighted 


\section{Figure Legends}

Figure 1 - Generation and Characterization of c-Myc Transgenic Mice

(A) Construction of the c-Myc-Lo and c-Myc Hi transgene. cDNA encoding human cMyc was cloned along with the Insulin polyA site downstream of either the rat probasin or the modified small composite probasin promoters. Primers specific to each promoter and human c-Myc were used to confirm germline transmission of the transgene.

(B) Comparative expression of c-Myc in the mouse prostate. Total protein was isolated from 2 and 4 week old wildtype, Myc-Hi and Myc-Lo mice. c-Myc expression was determined by western blot using the human specific $\alpha 9 \mathrm{E} 10 \mathrm{c}-\mathrm{Myc}$ antibody. Transgene expression is seen as early as 2 weeks in both transgenic mice and expression increases as mice reach puberty by 4 weeks. $\beta$-actin was used as a loading control.

(C) Kinetics of mPIN and Cancer progression in Myc-Hi and Myc-Lo transgenic mice. Myc-Hi mice exhibit mPIN as early as 2 weeks compared to 4 weeks in the Myc-Lo transgenic animals. Myc-Hi mice go on to develop invasive prostatic adenocarcinoma by 6 months whereas the Myc-Lo animals continue to exhibit mPIN at the same timepoint (H\&E).

Figure 2 - Development of Cancer in Myc-Hi and Myc-Lo Transgenic Animals without

\section{Neuroendocrine Differentiation}

(A) Longer latency for cancer progression in Myc-Lo mice. Prostates from 6 and 12 month transgenic mice reveal invasive adenocarcinoma at 12 months in the Myc-Lo animals. In contrast, invasive tumor is already apparent at 6 months in the Myc-Hi mice (H\&E). 
(B) Presence of an intact fibromuscular layer, as shown by the positive smooth muscle actin (SMA) immunostaining (arrow, left panel) confirms the in-situ nature of the mPIN lesions. In contrast, SMA staining is absent in the invasive tumors (contractile smooth muscle surrounding blood vessels serve as an internal positive control, arrow-right panel) (C) Tumors do not undergo neuroendocrine differentiation. Synaptophysin immunostaining identifies the rare neuroendocrine cell normally present in murine prostates (positive staining is also seen in periprostatic ganglion, insert right panel). The invasive adenocarcinoma shows absence of synapthophysin immunostaining (right panel).

Figure 3 - c-Myc Expression gives a Prolifeative Advantage to Prostate Tissue

(A) Ki67 and TUNEL labeling revealed an increase in both proliferation and apoptosis as cells progress from normal to mPIN and finally invasive cancer.

(B) Proliferation outpaces apoptosis in $\mathrm{mPIN}$ and invasive cancer. A total of 500 cells were counted from 5 high power fields and the number of Ki67 positive cells (proliferative index) and apoptotic bodies (apoptotic index) were scored and graphed.

Figure 4 - Evaluation of vascular profile in myc tumors

(A-I) Mice were injected with FITC-conjugated Lycopersicum esculentum lectin that binds to the luminal surface of blood vessels. Animals were subsequently perfused with paraformaldehyde, prostates were dissected, sectioned on vibrotome and mounted on histological slides with glycerol containing Topo 3 for visualization of nuclei (in blue). A-C, wild-type animals (A- 2 month, B and C - 1 year). Note that the blood vessels travel in the stroma justaposed to the prostate epithelium. There is no increase in vascular density in the prostate of 2 month versus 1 year old wild-type mice; D-F - 
transgenic animals ( 2 months). Increased vascular density and tortuosity in vessels is associated with early transformation stages, G-I - transgenic animals (1 year).

(J) Higher degree of vascular density and disorganization characterizes late stage tumors.

Figure 5. - Effects of castration on Myc-induced mPIN and prostate cancer

(A) Schematic of castration experiment on Myc-Hi transgenic mice. Mice were either castrated at 2 months $\left({ }^{*}\right)$ of age with mPIN or castrated at 8 months $\left({ }^{*}\right)$ after tumors had developed.

(B) Castration causes the reversion of mPIN lesions 1 month post-surgery. However, once invasive tumors are established, castration results in only partial regression of the primary lesion, when examined at 1 and 3 months post-surgery.

(C) Androgen independent tumor formation following castration at 8 months. Ki67 immunohistochemistry shows a dramatic decrease in the proliferative rate in 3 month castrates. The decrease was not as evident in 8 month castrates and proliferation began to increase 3 months post surgery indicating the regrowth of androgen independent tumors.

Figure 6 - Microarray Analysis Identifies a Distinct Expression Signature of Genes in cMyc Transgenic Animals.

(A) Unsupervised clustering classifies samples as either wild-type (wt) or transgenic (mPIN and cancer) with one exception.

(B) Genes differentially expressed between wild-type and transgenic mice. The top 60 non-EST genes are included, a full list is available in Supplementary Information. The list includes two genes known to be involved in human prostate cancer, Nkx3.1 and Pim1 (arrows). Nkx3.1 expression is lost in transgenic samples and Pim-1 is upregulated consistent with published human data (Bowen et al., 2000; Dhanasekaran et al., 2001). 
Expression values of each gene are normalized to have a mean of zero and standard deviation of one across the samples.

(C, D) Nkx3.1 protein levels diminish in mPIN lesions and are lost in tumors samples consistent with microarray data. Immunohistochemistry (C) and western blot analysis (D) using Nkx3.1 antibody shows a consistent loss of Nkx3.1 expression as tumors progress.

Figure 7. Cross-species expression module comparison algorithm

(A) Schematic of experimental design.

(B) Identification of genes differentially expressed between Myc-like and non-Myc-like human tumors in multiple datasets. In the graph, each point represents a gene found in both the Prostate A (Dhanasekaran et al., 2001) and Prostate B (Welsh et al., 2001) human cancer datasets. For each gene, the Student t-test P-values reflecting the degree of differential gene expression between Myc-like and non-Myc-like human tumors (see schematic) were determined and plotted. Genes below the line have a P-value product less than $5 \times 10^{-7}$ and are listed in Table 2 (red squares and yellow triangle (Pim1) (scatter plot). 
Table 1 - High Penetrance of mPIN and Cancer in c-Myc Transgenic Mice.

Mice were aged to the appropriate time point and sacrificed for histological analysis.

Age, phenotype and number of mice are listed for both the Myc-Hi and Myc-Lo

transgenic models. Generally, in the Myc-Hi model, all mice $\leq$ months developed

mPIN and all animals older than 6 months developed cancer. In the Myc-Lo model, most animals less than 12 months developed mPIN and cancer after 1 year. Only a few exceptions (*) are observed.

\section{References}

Abdulkadir, S. A., Magee, J. A., Peters, T. J., Kaleem, Z., Naughton, C. K., Humphrey, P. A., and Milbrandt, J. (2002). Conditional loss of Nkx3.1 in adult mice induces prostatic intraepithelial neoplasia. Mol Cell Biol 22, 1495-1503.

Ahmed, N. N., Grimes, H. L., Bellacosa, A., Chan, T. O., and Tsichlis, P. N. (1997). Transduction of interleukin-2 antiapoptotic and proliferative signals via Akt protein kinase. Proc Natl Acad Sci U S A 94, 3627-3632.

Amati, B., Alevizopoulos, K., and Vlach, J. (1998). Myc and the cell cycle [In Process Citation]. Front Biosci 3, D250-268.

Bhatia-Gaur, R., Donjacour, A. A., Sciavolino, P. J., Kim, M., Desai, N., Young, P., Norton, C. R., Gridley, T., Cardiff, R. D., Cunha, G. R., et al. (1999). Roles for Nkx3.1 in prostate development and cancer. Genes Dev 13, 966-977.

Bowen, C., Bubendorf, L., Voeller, H. J., Slack, R., Willi, N., Sauter, G., Gasser, T. C., Koivisto, P., Lack, E. E., Kononen, J., et al. (2000). Loss of NKX3.1 expression in human prostate cancers correlates with tumor progression. Cancer Res 60, 6111-6115.

Bubendorf, L., Kononen, J., Koivisto, P., Schraml, P., Moch, H., Gasser, T. C., Willi, N., Mihatsch, M. J., Sauter, G., and Kallioniemi, O. P. (1999). Survey of gene amplifications during prostate cancer progression by high-throughout fluorescence in situ hybridization on tissue microarrays [published erratum appears in Cancer Res $1999 \mathrm{Mar}$ 15;59(6):1388]. Cancer Res 59, 803-806. 
Coller, H. A., Grandori, C., Tamayo, P., Colbert, T., Lander, E. S., Eisenman, R. N., and Golub, T. R. (2000). Expression analysis with oligonucleotide microarrays reveals that MYC regulates genes involved in growth, cell cycle, signaling, and adhesion. Proc Natl Acad Sci U S A 97, 3260-3265.

Craft, N., Shostak, Y., Carey, M., and Sawyers, C. L. (1999). A mechanism for hormoneindependent prostate cancer through modulation of androgen receptor signaling by the HER-2/neu tyrosine kinase [see comments]. Nat Med 5, 280-285.

Dang, C. V. (1999). c-Myc target genes involved in cell growth, apoptosis, and metabolism. Mol Cell Biol 19, 1-11.

Dhanasekaran, S. M., Barrette, T. R., Ghosh, D., Shah, R., Varambally, S., Kurachi, K., Pienta, K. J., Rubin, M. A., and Chinnaiyan, A. M. (2001). Delineation of prognostic biomarkers in prostate cancer. Nature 412, 822-826.

Eisen, M. B., Spellman, P. T., Brown, P. O., and Botstein, D. (1998). Cluster analysis and display of genome-wide expression patterns. Proc Natl Acad Sci U S A 95, 14863-14868.

Elenbaas, B., Spirio, L., Koerner, F., Fleming, M. D., Zimonjic, D. B., Donaher, J. L., Popescu, N. C., Hahn, W. C., and Weinberg, R. A. (2001). Human breast cancer cells generated by oncogenic transformation of primary mammary epithelial cells. Genes Dev $15,50-65$.

Elo, J. P., and Visakorpi, T. (2001). Molecular genetics of prostate cancer. Ann Med 33, 130-141.

Evan, G. I., Wyllie, A. H., Gilbert, C. S., Littlewood, T. D., Land, H., Brooks, M., Waters, C. M., Penn, L. Z., and Hancock, D. C. (1992). Induction of apoptosis in fibroblasts by c-myc protein. Cell 69, 119-128.

Garabedian, E. M., Humphrey, P. A., and Gordon, J. I. (1998). A transgenic mouse model of metastatic prostate cancer originating from neuroendocrine cells. Proc Natl Acad Sci U S A 95, 15382-15387.

Golub, T. R., Slonim, D. K., Tamayo, P., Huard, C., Gaasenbeek, M., Mesirov, J. P., Coller, H., Loh, M. L., Downing, J. R., Caligiuri, M. A., et al. (1999). Molecular classification of cancer: class discovery and class prediction by gene expression monitoring. Science 286, 531-537.

Greenberg, N. M., DeMayo, F., Finegold, M. J., Medina, D., Tilley, W. D., Aspinall, J. O., Cunha, G. R., Donjacour, A. A., Matusik, R. J., and Rosen, J. M. (1995). Prostate cancer in a transgenic mouse. Proc Natl Acad Sci U S A 92, 3439-3443.

He, W. W., Sciavolino, P. J., Wing, J., Augustus, M., Hudson, P., Meissner, P. S., Curtis, R. T., Shell, B. K., Bostwick, D. G., Tindall, D. J., et al. (1997). A novel human prostate- 
specific, androgen-regulated homeobox gene (NKX3.1) that maps to $8 \mathrm{p} 21$, a region frequently deleted in prostate cancer. Genomics $43,69-77$.

Hurlin, P. J., Foley, K. P., Ayer, D. E., Eisenman, R. N., Hanahan, D., and Arbeit, J. M. (1995). Regulation of Myc and Mad during epidermal differentiation and HPVassociated tumorigenesis. Oncogene 11, 2487-2501.

Jain, M., Arvanitis, C., Chu, K., Dewey, W., Leonhardt, E., Trinh, M., Sundberg, C. D., Bishop, J. M., and Felsher, D. W. (2002). Sustained loss of a neoplastic phenotype by brief inactivation of MYC. Science 297, 102-104.

Jalkut, M. W., and Reiter, R. E. (2002). Role of prostate stem cell antigen in prostate cancer research. Curr Opin Urol 12, 401-406.

Jenkins, R. B., Qian, J., Lieber, M. M., and Bostwick, D. G. (1997). Detection of c-myc oncogene amplification and chromosomal anomalies in metastatic prostatic carcinoma by fluorescence in situ hybridization. Cancer Res 57, 524-531.

Jensen, N. A., Pedersen, K. M., Lihme, F., Rask, L., Nielsen, J. V., Rasmussen, T. E., and Mitchelmore, C. (2002). Astroglial c-Myc overexpression predisposes mice to primary malignant gliomas. J Biol Chem.

Karlsson, A., Giuriato, S., Tang, F., Fung-Weier, J., Levan, G., and Felsher, D. W. (2003). Genomically complex lymphomas undergo sustained tumor regression upon MYC inactivation unless they acquire novel chromosomal translocations. Blood 101, 2797-2803.

Kasper, S., Sheppard, P. C., Yan, Y., Pettigrew, N., Borowsky, A. D., Prins, G. S., Dodd, J. G., Duckworth, M. L., and Matusik, R. J. (1998). Development, progression, and androgen-dependence of prostate tumors in probasin-large $T$ antigen transgenic mice: a model for prostate cancer. Lab Invest 78 , i-xv.

Kim, M. J., Bhatia-Gaur, R., Banach-Petrosky, W. A., Desai, N., Wang, Y., Hayward, S. W., Cunha, G. R., Cardiff, R. D., Shen, M. M., and Abate-Shen, C. (2002). Nkx3.1 mutant mice recapitulate early stages of prostate carcinogenesis. Cancer Res 62, 29993004.

Kim, S. J., Uehara, H., Karashima, T., Shepherd, D. L., Killion, J. J., and Fidler, I. J. (2003). Blockade of Epidermal Growth Factor Receptor Signaling in Tumor Cells and Tumor-associated Endothelial Cells for Therapy of Androgen- independent Human Prostate Cancer Growing in the Bone of Nude Mice. Clin Cancer Res 9, 1200-1210.

Luo, Q., Harmon, E., Timms, B. G., and Kretzner, L. (2001). Novel expression patterns of the $\mathrm{myc} / \mathrm{max} / \mathrm{mad}$ transcription factor network in developing murine prostate gland. $\mathrm{J}$ Urol 166, 1071-1077. 
Magee, J. A., Abdulkadir, S. A., and Milbrandt, J. (2003). Haploinsufficiency at the Nkx3.1 locus. A paradigm for stochastic, dosage-sensitive gene regulation during tumor initiation. Cancer Cell 3, 273-283.

Masumori, N., Thomas, T. Z., Chaurand, P., Case, T., Paul, M., Kasper, S., Caprioli, R. M., Tsukamoto, T., Shappell, S. B., and Matusik, R. J. (2001). A probasin-large T antigen transgenic mouse line develops prostate adenocarcinoma and neuroendocrine carcinoma with metastatic potential. Cancer Res 61, 2239-2249.

Moroy, T., Verbeek, S., Ma, A., Achacoso, P., Berns, A., and Alt, F. (1991). E mu N- and $\mathrm{E}$ mu L-myc cooperate with $\mathrm{E}$ mu pim-1 to generate lymphoid tumors at high frequency in double-transgenic mice. Oncogene 6, 1941-1948.

Nesbit, C. E., Tersak, J. M., and Prochownik, E. V. (1999). MYC oncogenes and human neoplastic disease. Oncogene 18, 3004-3016.

Pelengaris, S., Khan, M., and Evan, G. (2002a). c-MYC: more than just a matter of life and death. Nat Rev Cancer 2, 764-776.

Pelengaris, S., Khan, M., and Evan, G. I. (2002b). Suppression of myc-induced apoptosis in Beta cells exposes multiple oncogenic properties of myc and triggers carcinogenic progression. Cell 109, 321-334.

Pelengaris, S., Littlewood, T., Khan, M., Elia, G., and Evan, G. (1999). Reversible activation of c-Myc in skin: induction of a complex neoplastic phenotype by a single oncogenic lesion. Mol Cell 3, 565-577.

Perez-Stable, C., Altman, N. H., Mehta, P. P., Deftos, L. J., and Roos, B. A. (1997). Prostate cancer progression, metastasis, and gene expression in transgenic mice. Cancer Res 57, 900-906.

Prendergast, G. C. (1999). Mechanisms of apoptosis by c-Myc. Oncogene 18, 2967-2987. Qian, J., Jenkins, R. B., and Bostwick, D. G. (1997). Detection of chromosomal anomalies and c-myc gene amplification in the cribriform pattern of prostatic intraepithelial neoplasia and carcinoma by fluorescence in situ hybridization. Mod Pathol 10, 1113-1119.

Rodriguez-Manzaneque, J. C., Lane, T. F., Ortega, M. A., Hynes, R. O., Lawler, J., and Iruela-Arispe, M. L. (2001). Thrombospondin-1 suppresses spontaneous tumor growth and inhibits activation of matrix metalloproteinase- 9 and mobilization of vascular endothelial growth factor. Proc Natl Acad Sci U S A 98, 12485-12490.

Sato, K., Qian, J., Slezak, J. M., Lieber, M. M., Bostwick, D. G., Bergstralh, E. J., and Jenkins, R. B. (1999). Clinical significance of alterations of chromosome 8 in high-grade, advanced, nonmetastatic prostate carcinoma. J Natl Cancer Inst 91, 1574-1580. 
Shibata, M. A., Ward, J. M., Devor, D. E., Liu, M. L., and Green, J. E. (1996).

Progression of prostatic intraepithelial neoplasia to invasive carcinoma in C3(1)/SV40 large $\mathrm{T}$ antigen transgenic mice: histopathological and molecular biological alterations. Cancer Res 56, 4894-4903.

Singh, D., Febbo, P. G., Ross, K., Jackson, D. G., Manola, J., Ladd, C., Tamayo, P., Renshaw, A. A., D'Amico, A. V., Richie, J. P., et al. (2002). Gene expression correlates of clinical prostate cancer behavior. Cancer Cell 1, 203-209.

Taplin, M. E., Bubley, G. J., Shuster, T. D., Frantz, M. E., Spooner, A. E., Ogata, G. K., Keer, H. N., and Balk, S. P. (1995). Mutation of the androgen-receptor gene in metastatic androgen- independent prostate cancer [see comments]. N Engl J Med 332, 1393-1398.

Thomas, R., True, L. D., Bassuk, J. A., Lange, P. H., and Vessella, R. L. (2000). Differential expression of osteonectin/SPARC during human prostate cancer progression. Clin Cancer Res 6, 1140-1149.

Tsuchiya, N., Slezak, J. M., Lieber, M. M., Bergstralh, E. J., and Jenkins, R. B. (2002). Clinical significance of alterations of chromosome 8 detected by fluorescence in situ hybridization analysis in pathologic organ- confined prostate cancer. Genes Chromosomes Cancer 34, 363-371.

Vaarala, M. H., Porvari, K., Kyllonen, A., Lukkarinen, O., and Vihko, P. (2001). The TMPRSS2 gene encoding transmembrane serine protease is overexpressed in a majority of prostate cancer patients: detection of mutated TMPRSS2 form in a case of aggressive disease. Int J Cancer 94, 705-710.

van Lohuizen, M., Verbeek, S., Krimpenfort, P., Domen, J., Saris, C., Radaszkiewicz, T., and Berns, A. (1989). Predisposition to lymphomagenesis in pim-1 transgenic mice: cooperation with c-myc and $\mathrm{N}$-myc in murine leukemia virus-induced tumors. Cell 56 , 673-682.

van Lohuizen, M., Verbeek, S., Scheijen, B., Wientjens, E., van der Gulden, H., and Berns, A. (1991). Identification of cooperating oncogenes in $\mathrm{E}$ mu-myc transgenic mice by provirus tagging. Cell $65,737-752$.

Visakorpi, T. (1999). Molecular genetics of prostate cancer. Ann Chir Gynaecol 88, 11 16.

Voeller, H. J., Augustus, M., Madike, V., Bova, G. S., Carter, K. C., and Gelmann, E. P. (1997). Coding region of NKX3.1, a prostate-specific homeobox gene on $8 \mathrm{p} 21$, is not mutated in human prostate cancers. Cancer Res $57,4455-4459$.

Watnick, R. S., Cheng, Y. N., Rangarajan, A., Ince, T. A., and Weinberg, R. A. (2003). Ras modulates Myc activity to repress thrombospondin-1 expression and increase tumor angiogenesis. Cancer Cell 3, 219-231. 
Welsh, J. B., Sapinoso, L. M., Su, A. I., Kern, S. G., Wang-Rodriguez, J., Moskaluk, C. A., Frierson, H. F., Jr., and Hampton, G. M. (2001). Analysis of gene expression identifies candidate markers and pharmacological targets in prostate cancer. Cancer Res 61, 5974-5978.

Wu, X., Wu, J., Huang, J., Powell, W. C., Zhang, J., Matusik, R. J., Sangiorgi, F. O., Maxson, R. E., Sucov, H. M., and Roy-Burman, P. (2001). Generation of a prostate epithelial cell-specific Cre transgenic mouse model for tissue-specific gene ablation. Mech Dev 101, 61-69.

Zhang, J., Thomas, T. Z., Kasper, S., and Matusik, R. J. (2000a). A small composite probasin promoter confers high levels of prostate- specific gene expression through regulation by androgens and glucocorticoids in vitro and in vivo. Endocrinology 141 , 4698-4710.

Zhang, X., Lee, C., Ng, P. Y., Rubin, M., Shabsigh, A., and Buttyan, R. (2000b). Prostatic neoplasia in transgenic mice with prostate-directed overexpression of the c-myc oncoprotein. Prostate 43, 278-285. 


\section{Figure 1}

A.

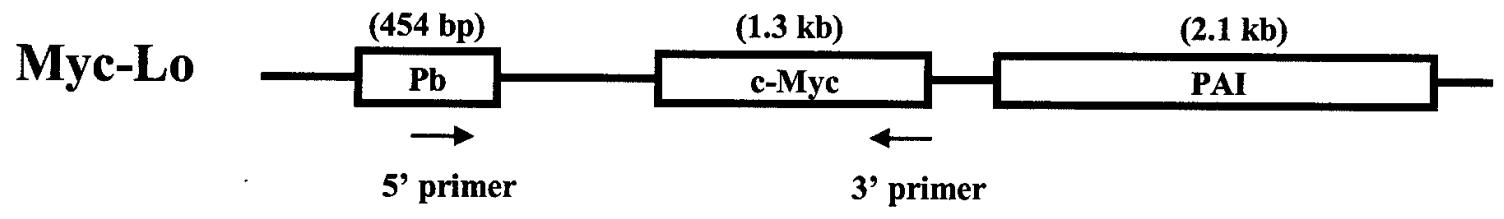

B.

$$
\text { Myc-Hi }
$$
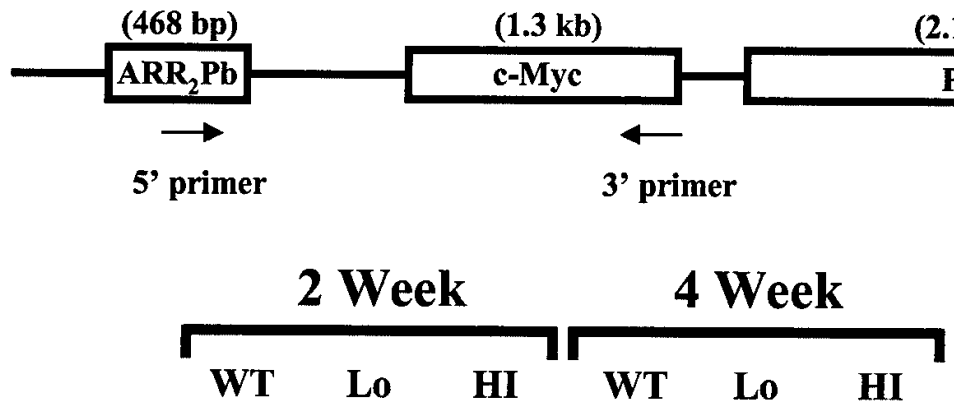

(1.3 kb)

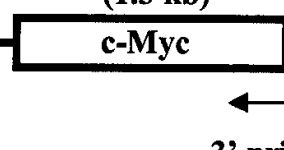

3' prime

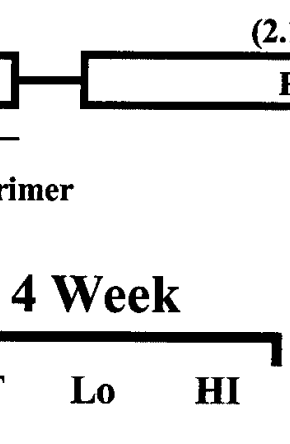

(2.1 kb)

$\alpha$ 9E10

$\alpha$ Actin

C.

WT
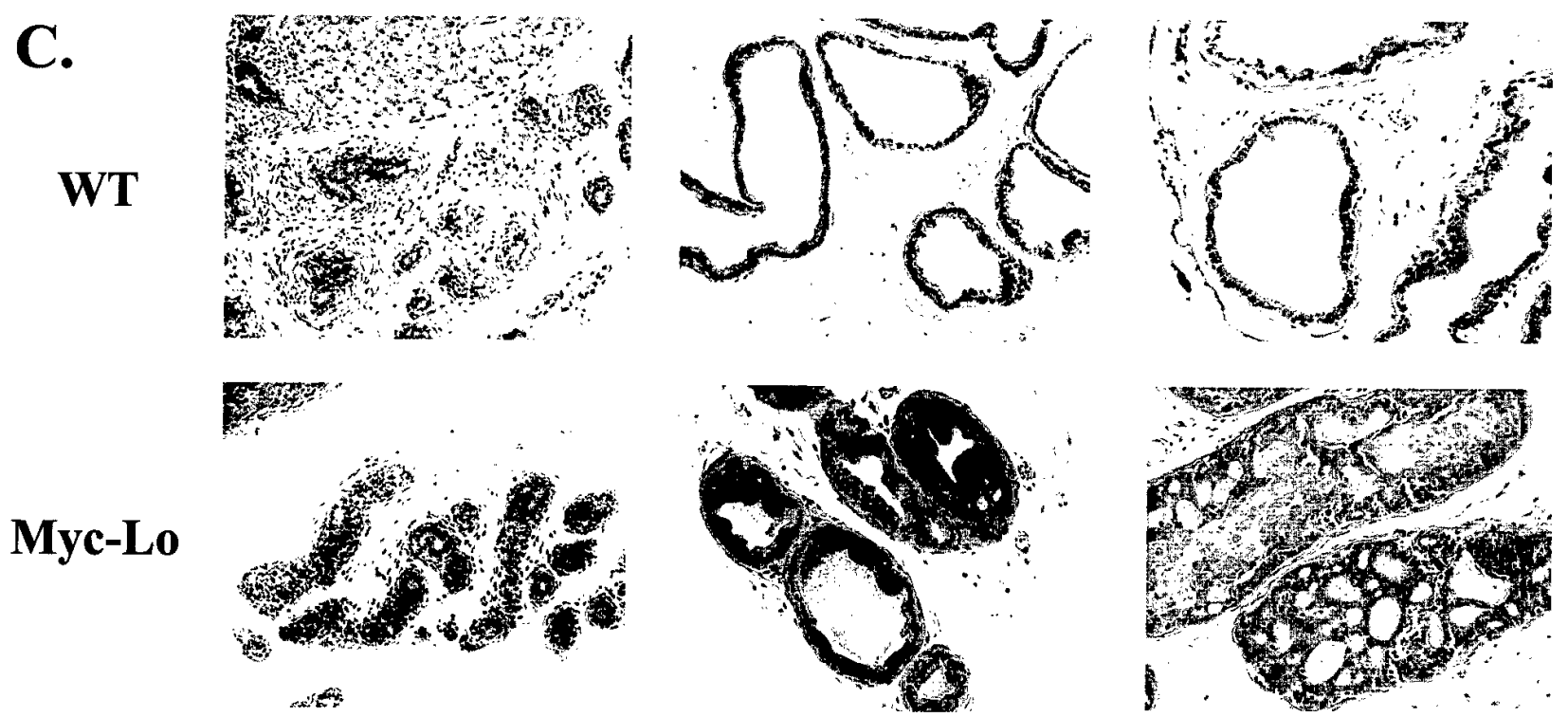

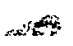

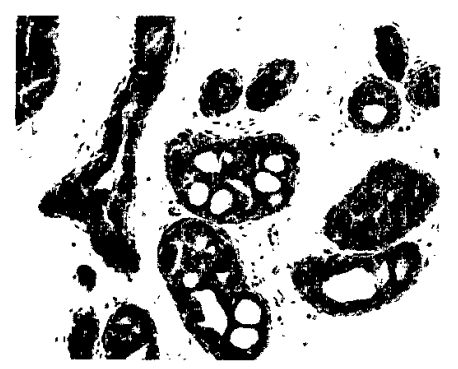

2 Week

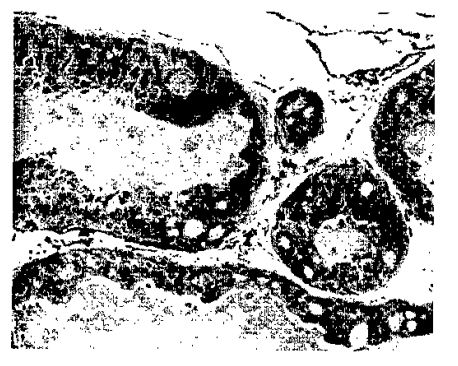

4 Week

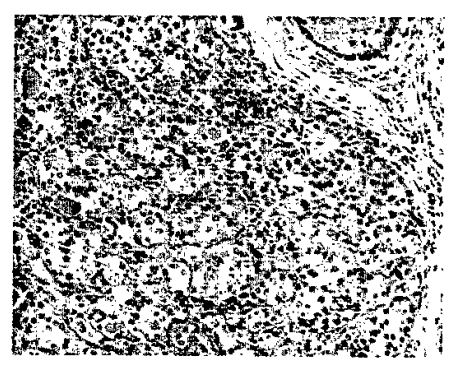

6 Months 


\section{Figure 2}

A.

Myc-Lo
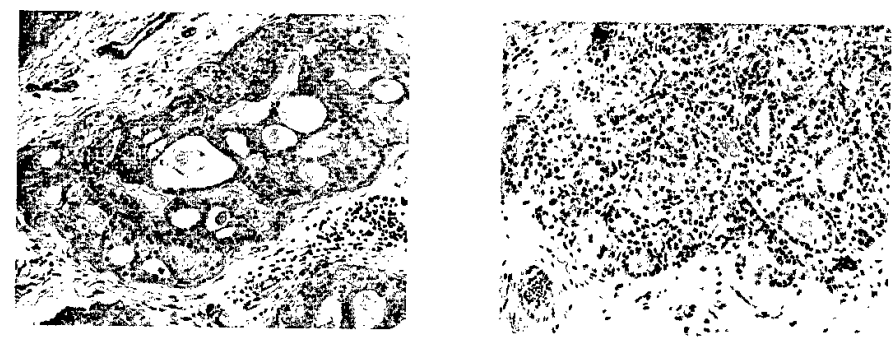

Myc-Hi

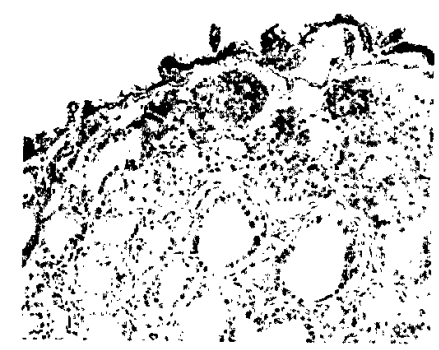

6 Months

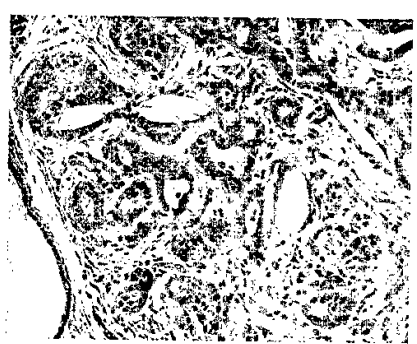

12 Months

B.
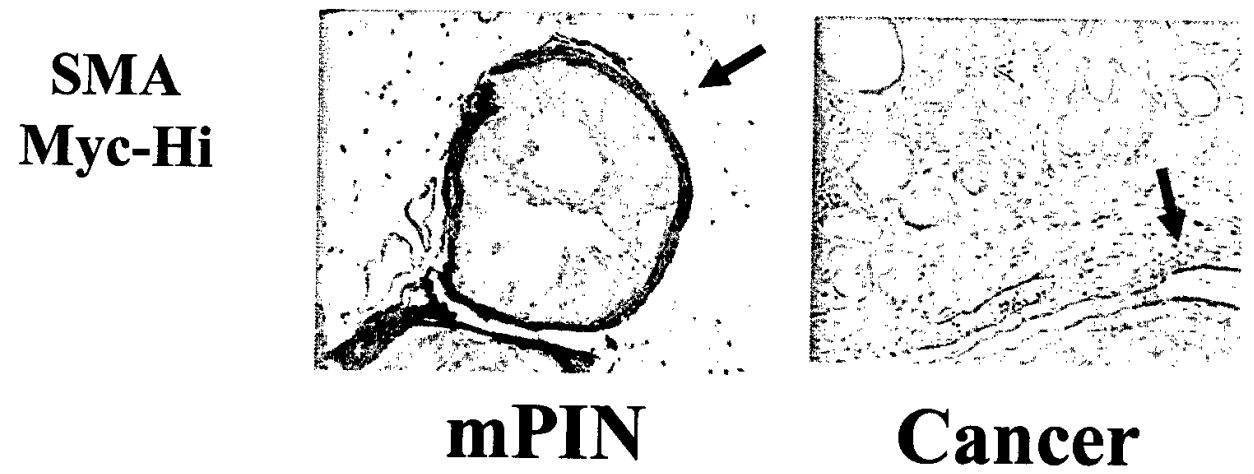

C.

Synaptophysin

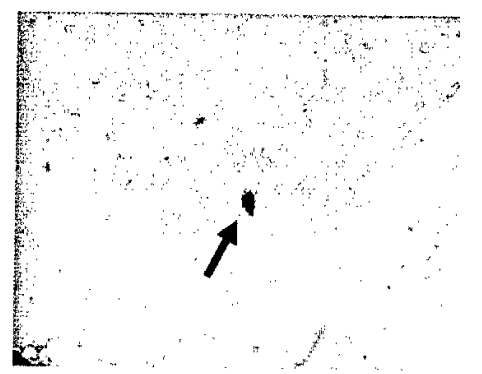

Benign

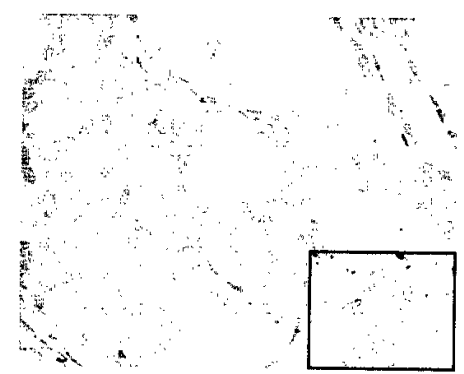

Cancer 


\section{Figure 3}
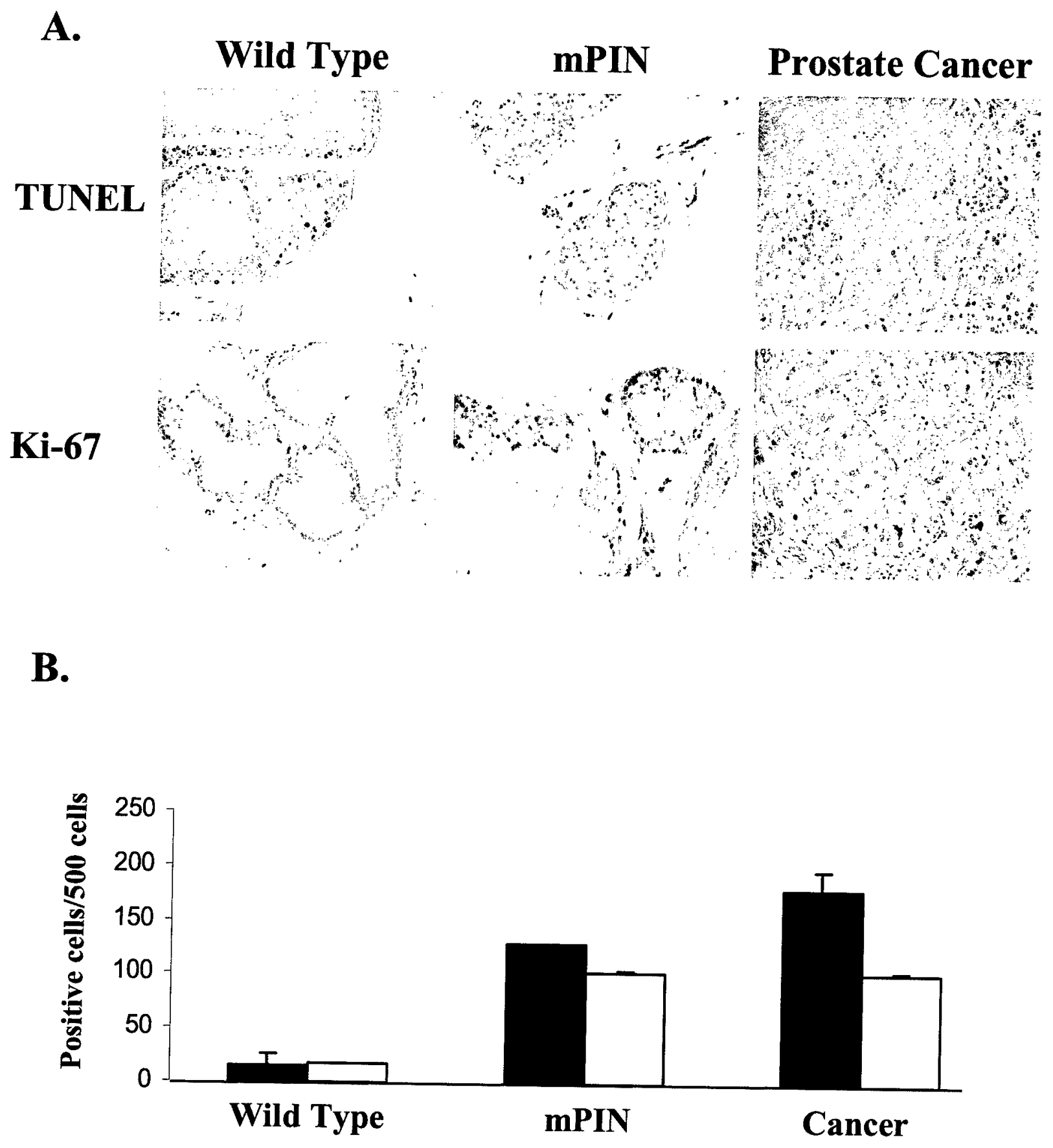

Proliferation Index $\square$ Apoptotic Index 


\section{Figure 4}
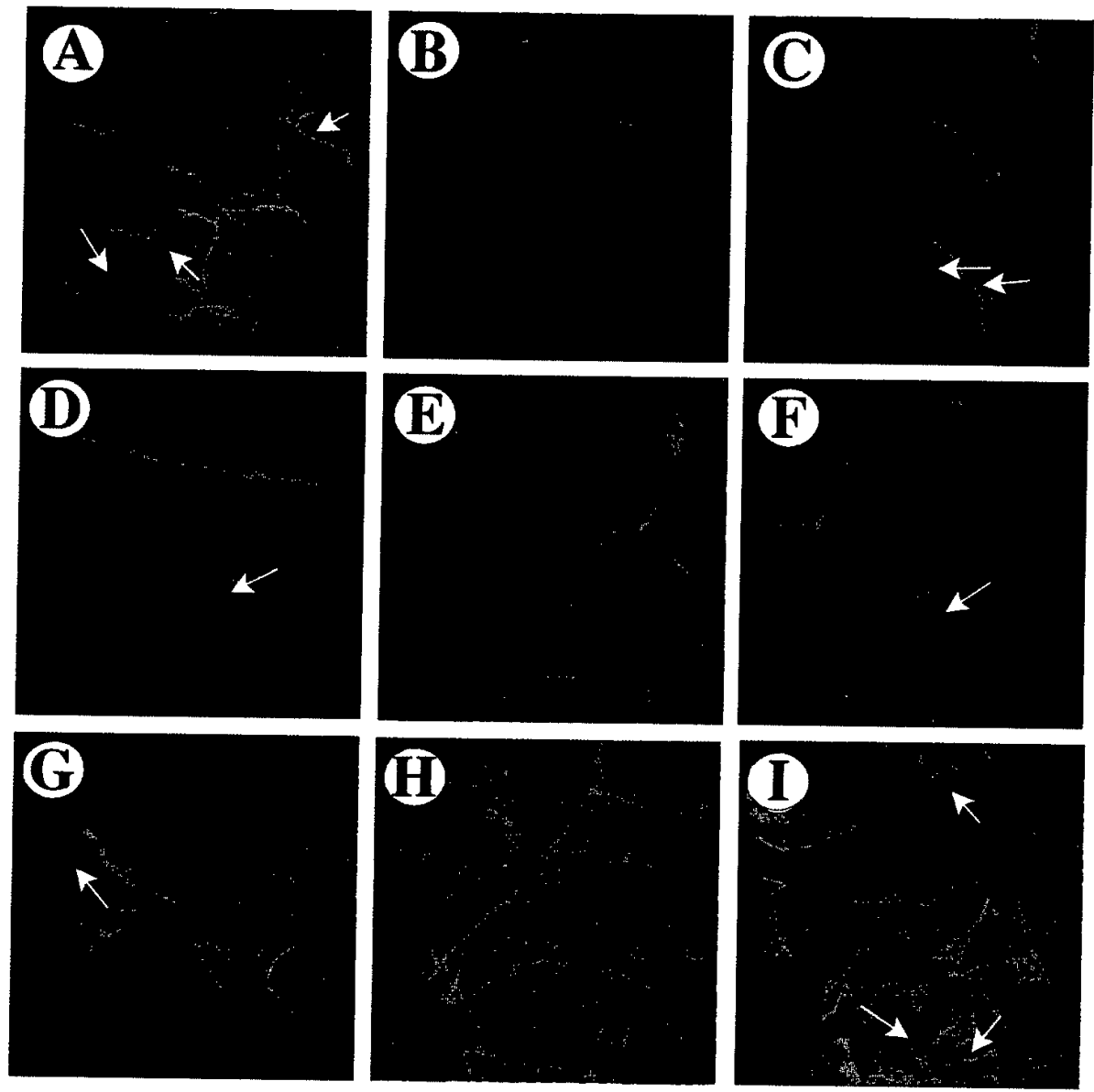

Vascular density $\left(\mathrm{mm}^{2}\right)$

\begin{tabular}{|l|l|l|}
\hline & 2 months & 1 year \\
\hline Wild-type animals & $23( \pm 3)$ & $21( \pm 6)$ \\
\hline Transgenic animals & $34( \pm 5)$ & $45( \pm 9)$ \\
\hline
\end{tabular}




\section{Figure 5}

A.

Wt

IIIIIIIIIIIIIIIIII

\section{Cancer}

*8 month castration

MPIN 6 Months
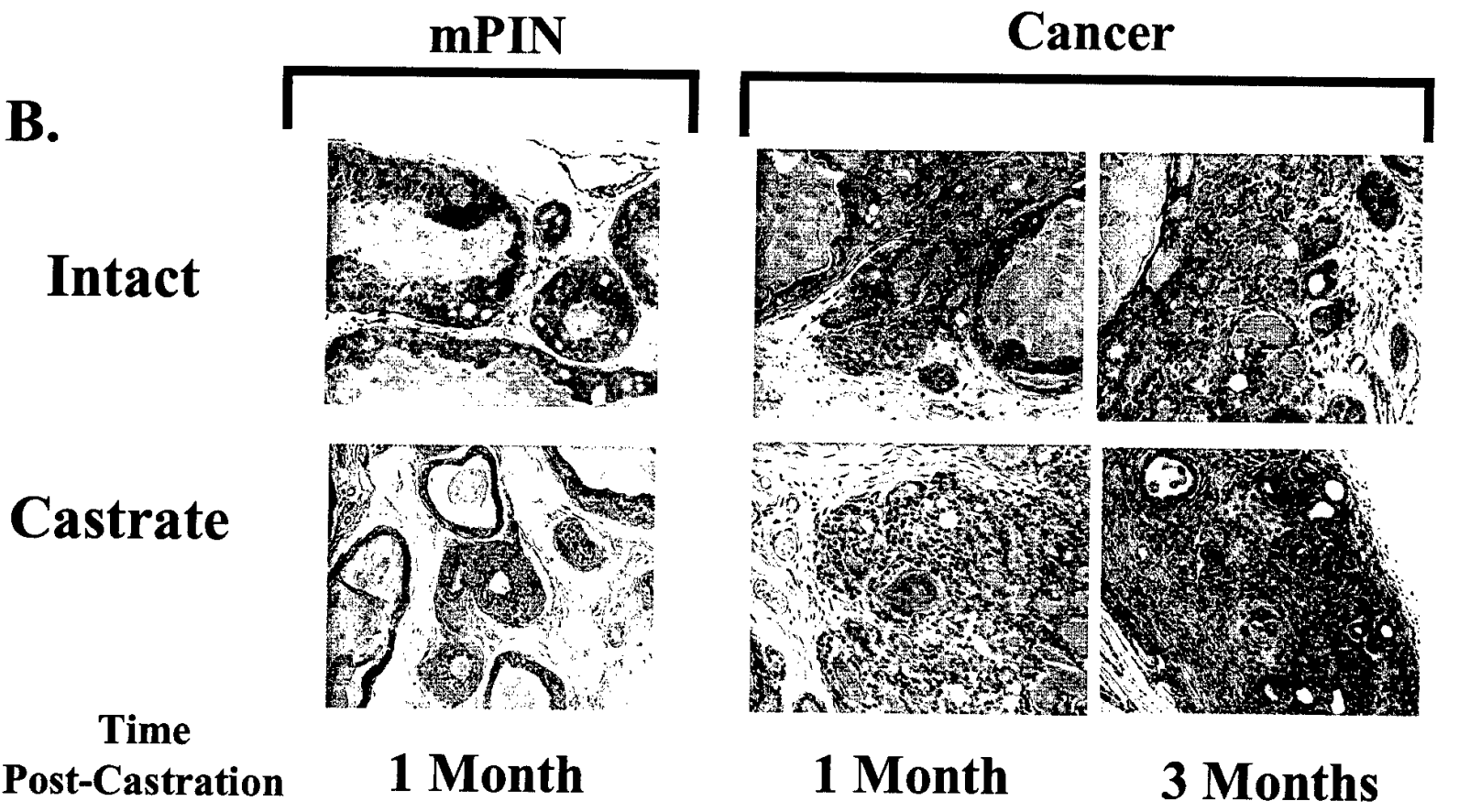

Time

Post-Castration

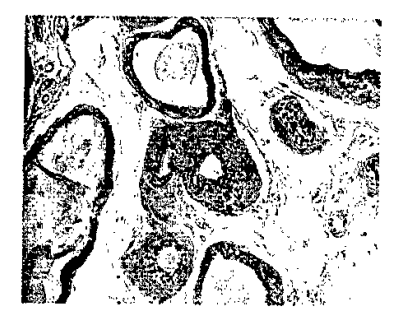

1 Month

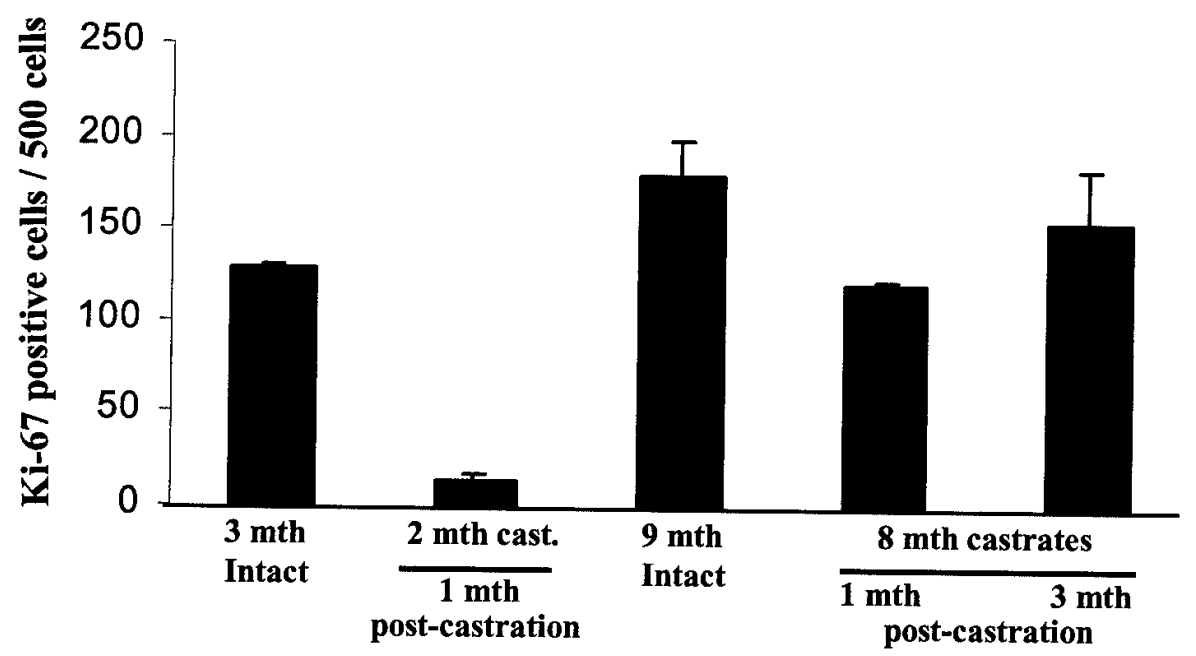




\section{Figure 6}

A.

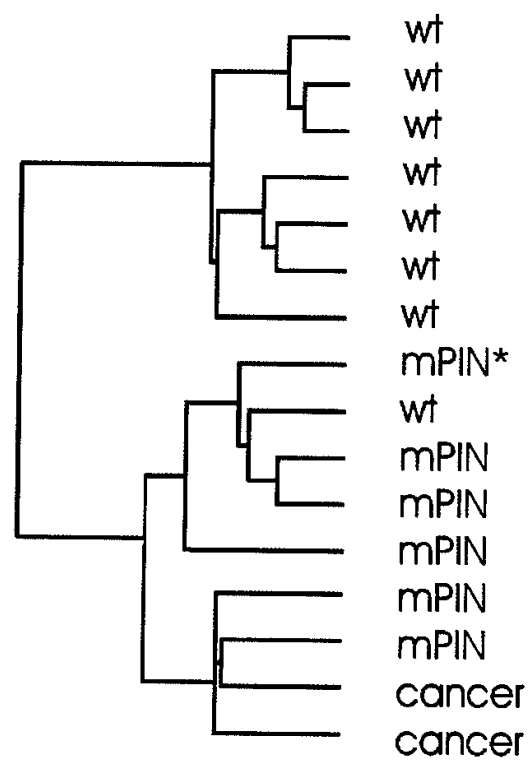

C.

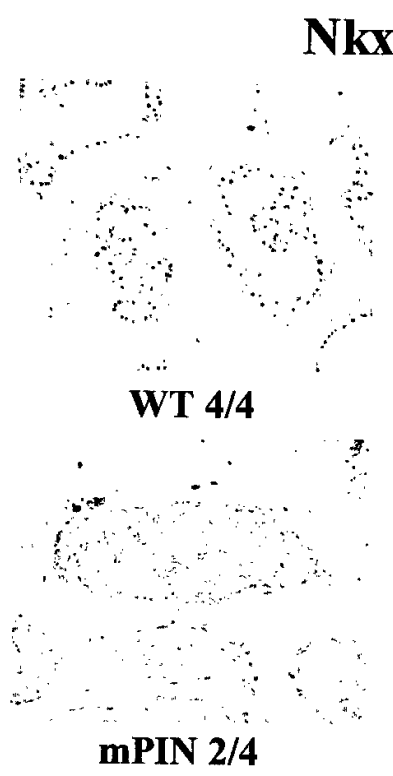

Cancer 6/6
B.

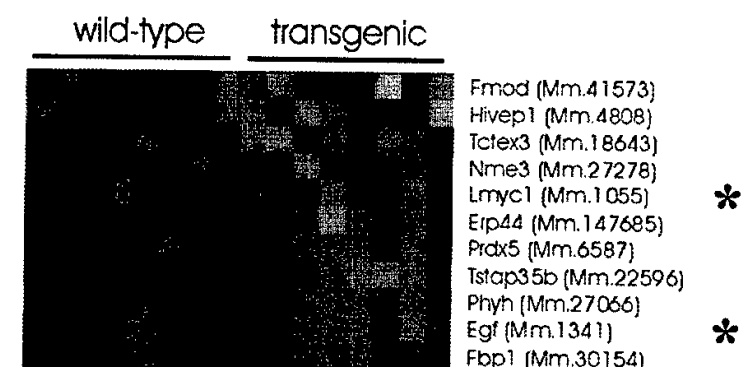

$*$

$*$

Fopl (Mm.30154)

Car2 (Mm.1186)

Manl a(Mm 117294

Vnnl (Mm.27 154)

Satbl (Mm.438)

Prom (Mm.6250)

Nkx3-1 (Mm.3520)

,

Tmpiss2 (Mm.25743) *

Fnliprpl (Mm. 10753)

Dgcro (Mm.27155)

Mopbplo (Mm.41680)

FKbo2 (Mm.4234)

Cidn4 (Mm.7339)

lde (Mm28365)

inpo5b (Mm.25777)

Ddost (Mm.7236)

Vps28 (Mm.30028)

Aldh2 (Mm.2621)

Jcaml (Mm. 20903)

Prto (Mm.28797)

G2an (Mm.3196)

Slc7a5 (Mm. 27943)

Gata3 (Mm.606)

Bglap-Is? (Mm.213026)

Rpn2 (Nm.22130)

Pahal (Mm 34775)

Tes (Mm 88645)

Vi2 (Mm.455)

Hadhsc (Mm.2491)

Thra (Mm.26587)

Pxmp3 (Mm. 16453)

Fth $(\mathrm{Mm}$. 776$)$

Hist2 (Mm.219659)

Mer (Mm.4582)

Roigl (Mm.42093)

Rnu22 (Mm.28239)

Hsdi7bl 2 (Mm.22505)

syngrl (Mm.1021 7)

Dpp7 (Mm.21440)

Rpl37a (Mm.21529)

Eng (Mm 4851)

Fiml (Mm.2322)

Slc25a17 (Mm.195498)

Sparc (Mm.35439)

tyoa (Mm8180)

SWAM2 (Mm 6433 )

Spr2a (Mm.6853)

Lysd (Mm.878)

UCK2 (Mm.25309)

Lyoc (Mm.1583)

$*$

D.
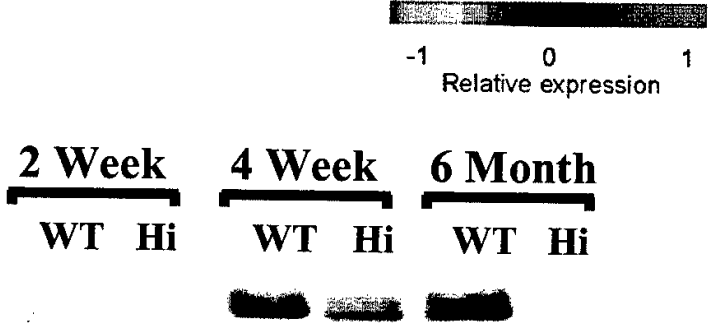

$-1$

Relative expression

$\alpha$ Nkx3.1 


\section{Figure 7}

A.

Genes differentially expressed between wildtype and transgenic Myc Prostate
Human Orthologues in:

A) Prostate cancer dataset 1

B) Prostate cancer dataset 2

C) Breast cancer dataset

Weighted gene voting

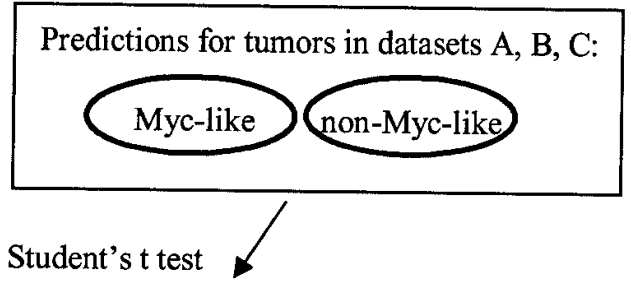

Genes differentially expressed between Myc-like and non-Myc-like human cancers: ranked lists for datasets: A B C

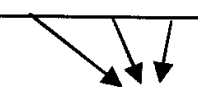

Overlap: genes consistently differentially expressed between Myc-like and non-Myc-like human cancers

B.

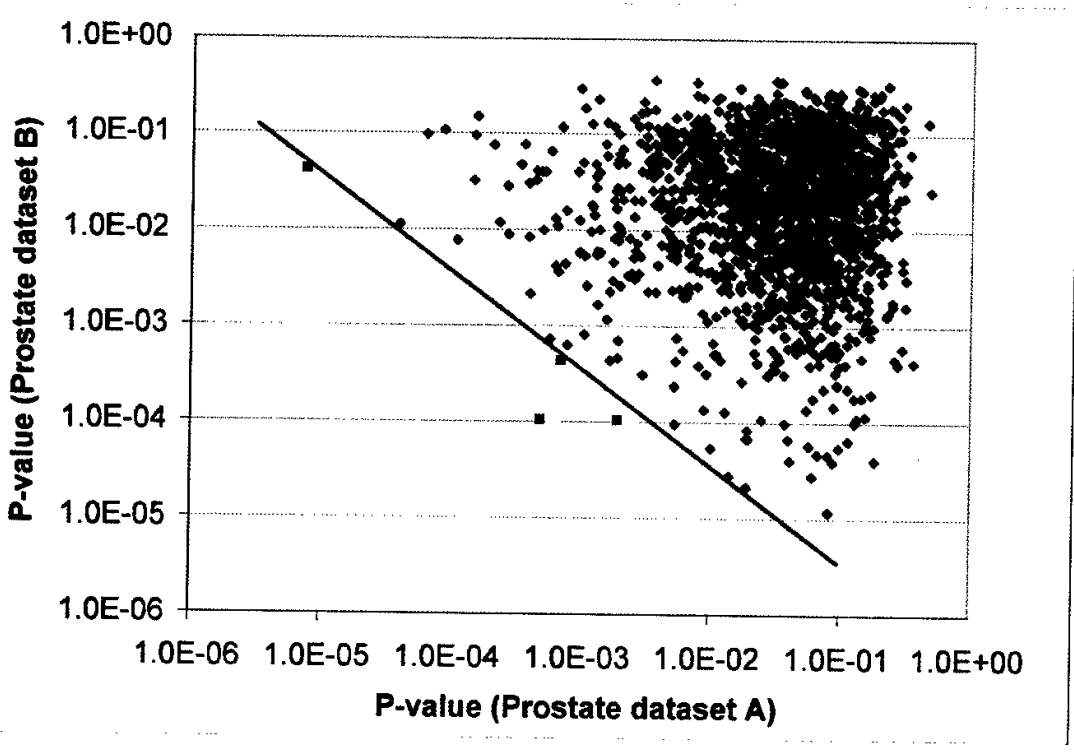




\section{Table 1A}

Strain Age \# Mice Phenotype Comments

Myc-Hi $\leq 3$ months $16 \quad 16 / 16$ mPIN mPIN in 4/4 mice at

$\geq 6$ months $\quad 20 \quad 19 / 20$ invasive cancer 2 weeks

1/20 mPIN

Myc-Lo $\leq 10$ months $10 \quad 8 / 10 \mathrm{mPIN} \quad 2$ mice at 2 weeks

$\geq 10$ months $\quad 10 \quad 10 / 10$ invasive cancer

\section{Table 1B}

mPIN mPIN/cancer transition Invasive cancer

Myc-Hi 2 weeks

Myc-Lo

4 weeks

6-12 months

3-6 months

$>6$ months

$>12$ months 


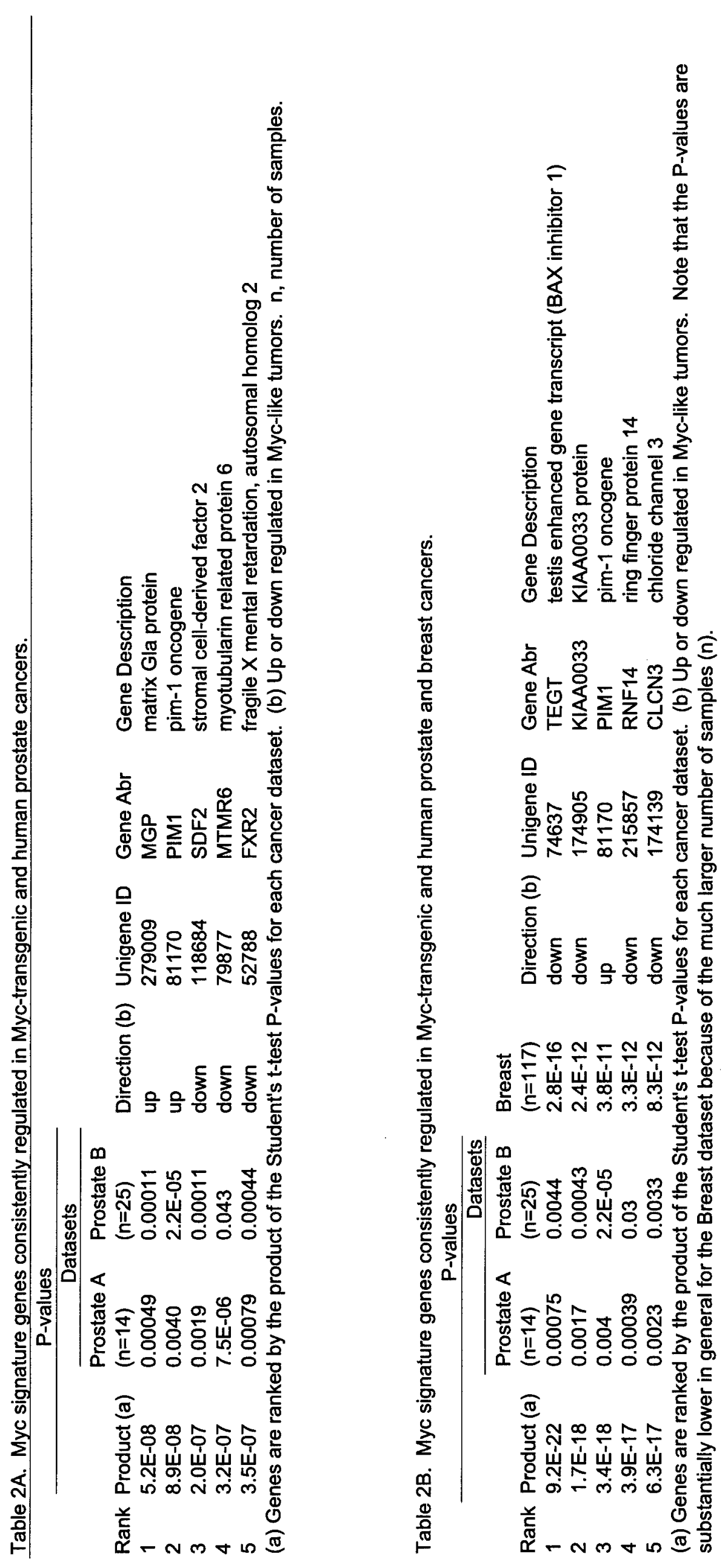

